\title{
Work Plan for the Site- wide SSHAC Level 3 Probabilistic Seismic Hazard Analysis at INL
}

Project 33050

May 2019

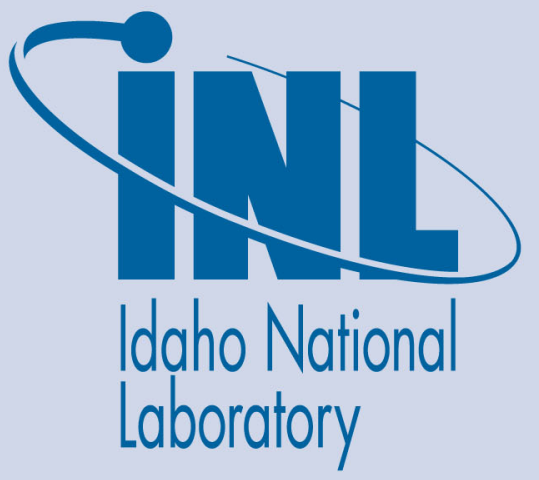

The INL is a U.S. Department of Energy National Laboratory operated by Battelle Energy Alliance 


\section{DISCLAIMER}

This information was prepared as an account of work sponsored by an agency of the U.S. Government. Neither the U.S. Government nor any agency thereof, nor any of their employees, makes any warranty, expressed or implied, or assumes any legal liability or responsibility for the accuracy, completeness, or usefulness, of any information, apparatus, product, or process disclosed, or represents that its use would not infringe privately owned rights. References herein to any specific commercial product, process, or service by trade name, trade mark, manufacturer, or otherwise, does not necessarily constitute or imply its endorsement, recommendation, or favoring by the U.S. Government or any agency thereof. The views and opinions of authors expressed herein do not necessarily state or reflect those of the U.S. Government or any agency thereof. 
INL/EXT-18-52101

Revision 1

\section{Work Plan for the Site-wide SSHAC Level 3 Probabilistic Seismic Hazard Analysis at INL}

May 2019

Idaho National Laboratory Idaho Falls, Idaho 83415

http://www.inl.gov

Prepared for the

U.S. Department of Energy

Office of Nuclear Energy, Science, and Technology

Under DOE Idaho Operations Office

Contract DE-AC07-05ID14517 


\section{Idaho National Laboratory}

\section{Work Plan for the Site-wide SSHAC Level 3 Probabilistic Seismic Hazard Analysis at INL}

INL/EXT-18-52101

Revision 1

May 2019

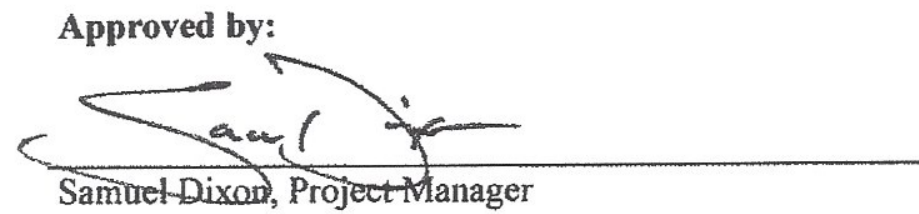

$\frac{05 / 08 / 2019}{\text { Date }}$
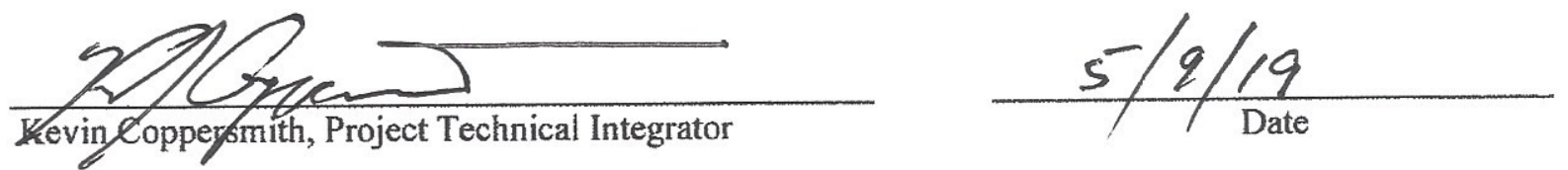


\section{EXECUTIVE SUMMARY}

This work plan provides the overall framework, key activities, key tasks, and schedule for the execution of a probabilistic seismic hazard analysis at Idaho National Laboratory (INL). The probabilistic seismic hazard analysis will follow processes and procedures appropriate for the Senior Seismic Hazard Analysis Committee (SSHAC) Level 3 study provided in U. S. Nuclear Regulatory Commission guidance, NUREG-2213. The SSHAC Level 3 probabilistic seismic hazard analysis (PSHA) is being conducted as an INL site-wide effort. The work plan was developed and revised by participants who will perform the SSHAC Level 3 PSHA. The work plan also includes the quality-assurance requirements commensurate with American Society of Mechanical Engineers Nuclear Quality Assurance NQA 1 2008/2009 and 2011 Addendum for design of nuclear facilities under the U.S. Department of Energy and U. S. Nuclear Regulatory Commission. The work plan may be subject to revisions after its initial issuance to SSHAC participants to accommodate changes in schedule, technical approaches, or programmatic needs of stakeholders.

The SSHAC Level 3 PSHA is designed to produce the mean-centered definition of seismic hazard with the appropriate treatment of uncertainties, supported by associated technical justifications. The SSHAC Level 3 study will properly implement and completely document the activities of evaluation, integration, and documentation. The evaluation process will consider data, models, and methods proposed by the larger technical community that are relevant to the PSHA at INL. The integration process will build seismic-source and ground-motion characterization models that represent the center, body, and range of technically defensible interpretations, taking into consideration the outcomes of the evaluation process. Key tasks and activities - such as a project kickoff meeting, three workshops, four formal working meetings, and a briefing meeting with the Participatory Peer Review Panel-will occur for the sevenmember technical integration teams to construct seismic-source and groundmotion-characterization models. Both preliminary and final hazard-input documents will be developed to perform sensitivity analyses and the final PSHA, respectively. The entire study will be thoroughly documented in draft and final reports. The Participatory Peer Review Panel will review the SSHAC Level 3 study from start to finish, including the draft and final INL Site-wide SSHAC Level 3 reports, so they can provide a closure letter documenting the study's adherence to SSHAC processes and technical adequacy of the final products. 
REVISION LOG

\begin{tabular}{|c|c|c|c|}
\hline Rev. & Date & Affected Sections & Revision Description \\
\hline 0 & & All & Original issue. \\
\hline 1 & May 7, 2019 & $\begin{array}{l}\text { Section } 2 \text {, Section } \\
4.2 \text {, Section } 4.3 .1, \\
\text { Appendix B, and } \\
\text { other pages }\end{array}$ & $\begin{array}{l}\text { Section 2: Revised and clarified technical products } \\
\text { from INL Site-wide SSHAC Level } 3 \text { PSHA, analyses } \\
\text { included in the PSHA, and analyses excluded from } \\
\text { PSHA. Clarified technical products per each } \\
\text { stakeholder for each site and facility included in the } \\
\text { PSHA. } \\
\text { Section 4.2: Updated text for quality assurance } \\
\text { requirements. } \\
\text { Section 4.3.1: Added SSC and GMC model } \\
\text { development under integration. } \\
\text { Appendix B: Removed Table B-1 and added } \\
\text { Attachment A that lists PPRP review criteria. } \\
\text { Other pages: Revised for various editorial comments. }\end{array}$ \\
\hline
\end{tabular}




\section{ACKNOWLEDGEMENTS}

The following individuals contributed to development of the plan: Kevin Coppersmith (project technical integrator), Julian Bommer (ground motion characterization technical integration lead), Suzette Payne (INL technical lead), Jordan Hill (quality engineer) and Samuel Dixon (project manager). The plan was provided to members of the Participatory Peer Review Panel prior to the kickoff meeting. The U. S. Department of Energy (DOE), Office of Nuclear Energy, Science, and Technology funded this work under DOE Idaho Field Office Contract DE-AC07-05ID14517. 


\section{CONTENTS}

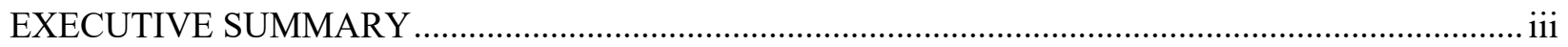

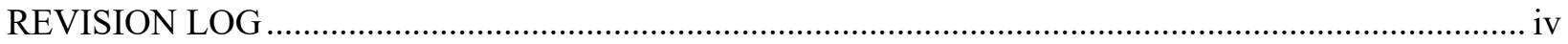

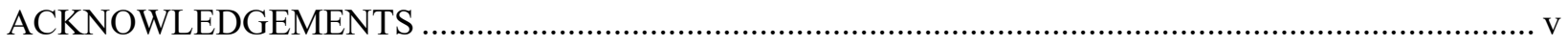

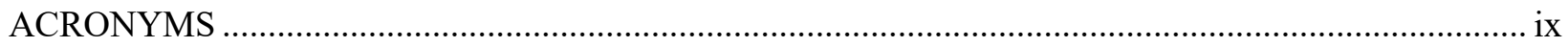

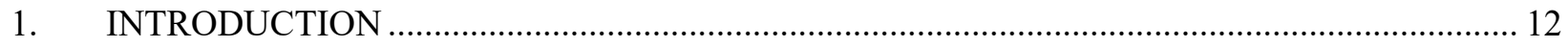

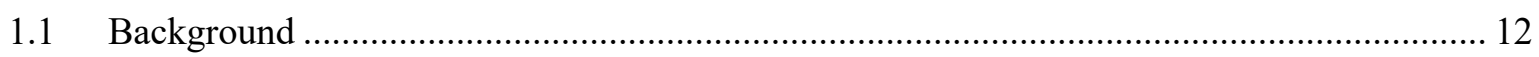

1.2 Regulatory Context and Selection of SSHAC Level 3 .................................................. 12

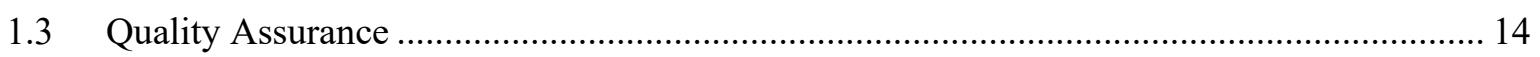

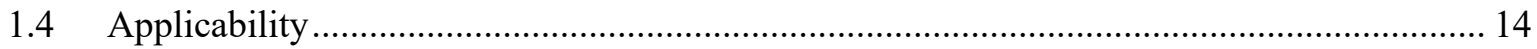

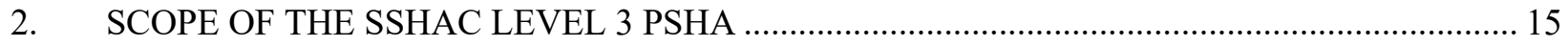

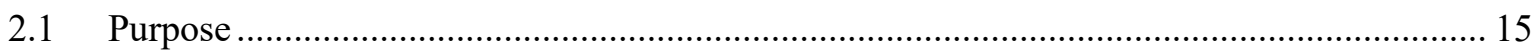

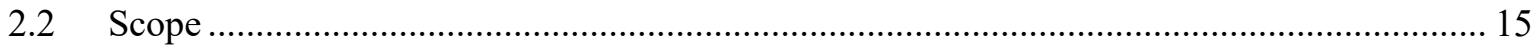

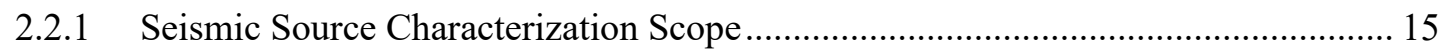

2.2.2 Ground Motion Characterization Scope................................................................. 15

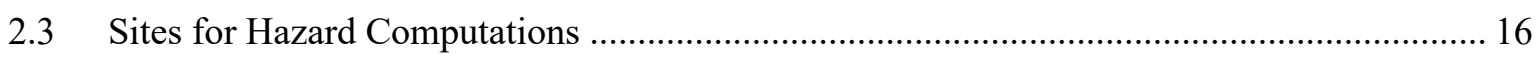

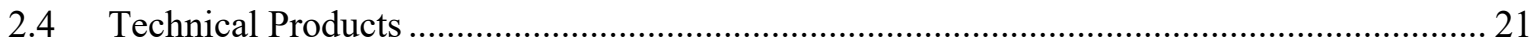

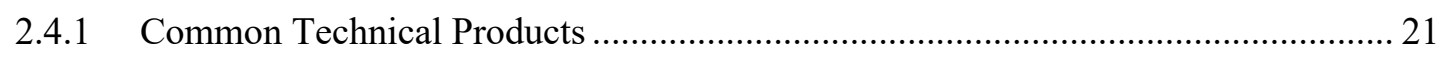

2.4.2 Specific Technical Products ........................................................................... 21

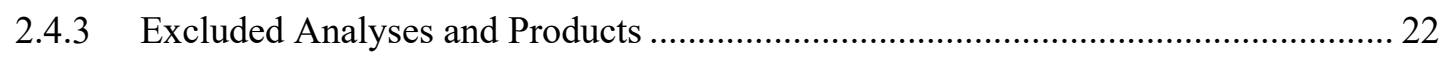

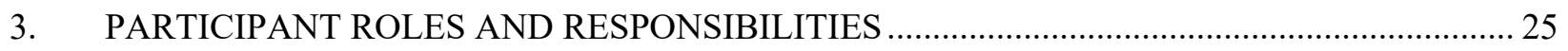

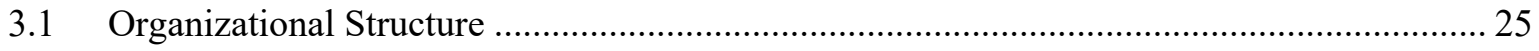

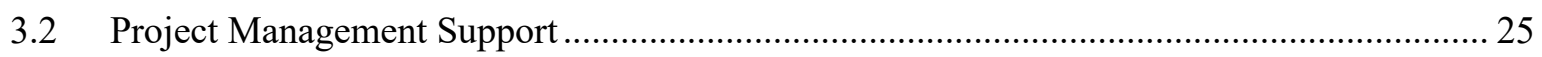

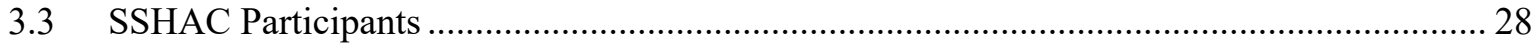

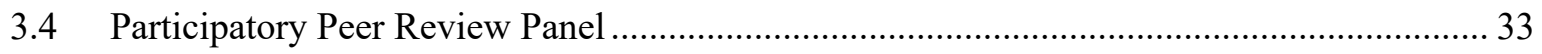

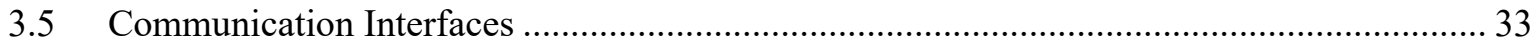

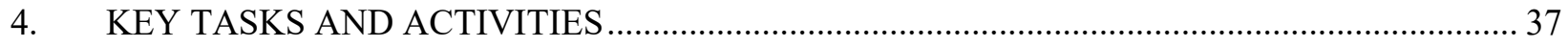

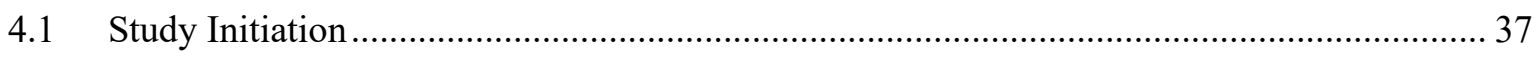

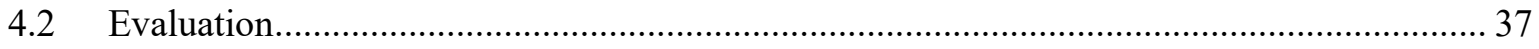

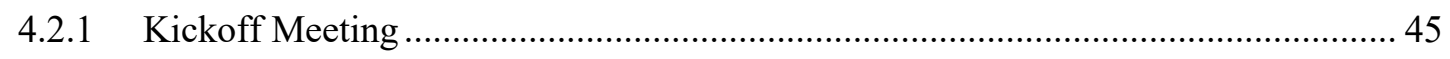

4.2.2 Database Development and Management ............................................................. 46

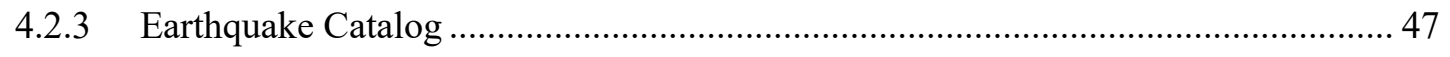

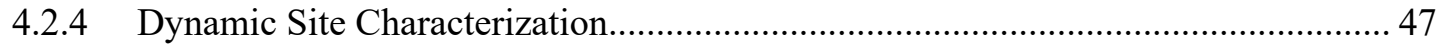

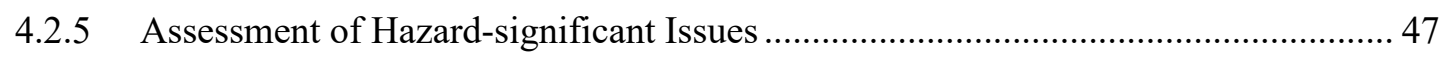

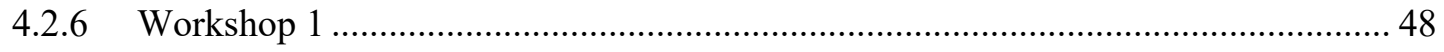

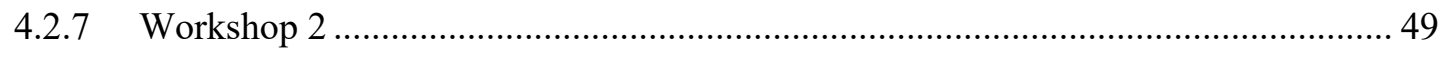




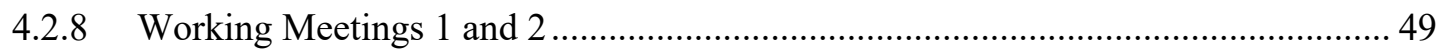

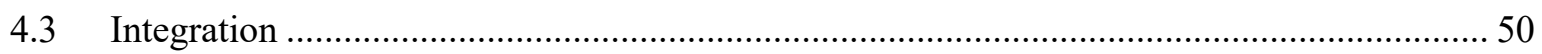

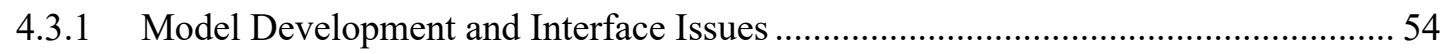

4.3.2 Development of Preliminary Models and HID ............................................................ 55

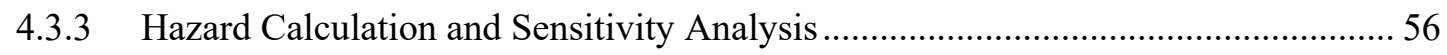

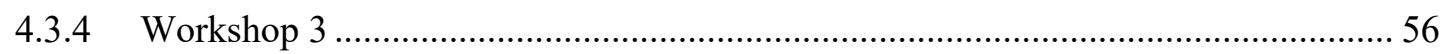

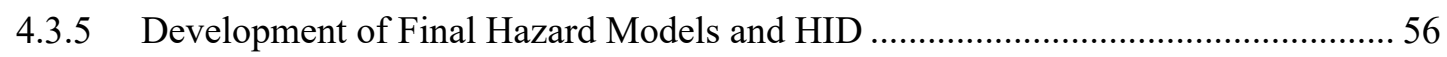

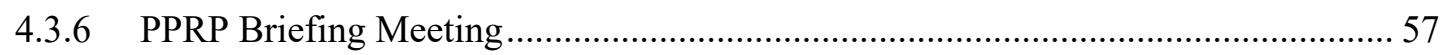

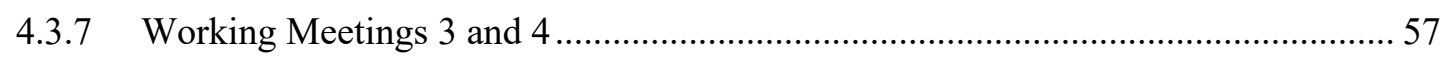

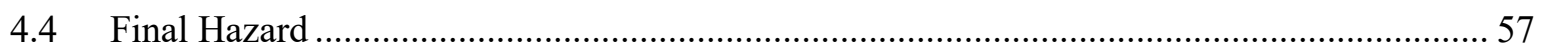

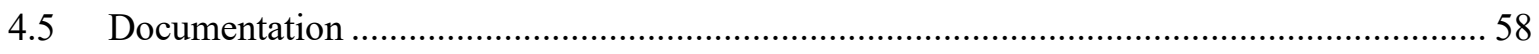

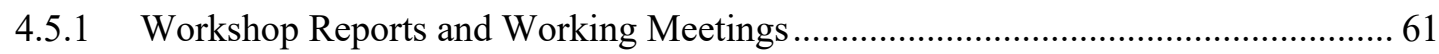

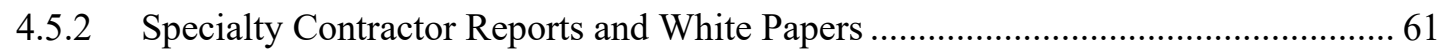

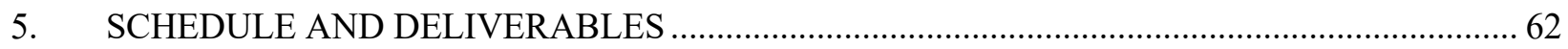

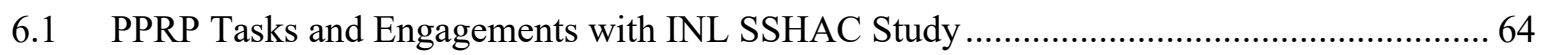

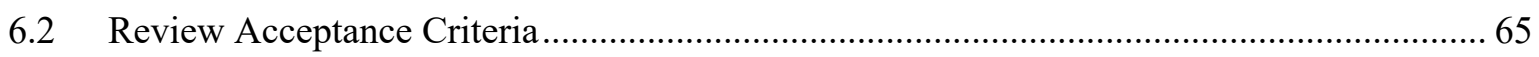

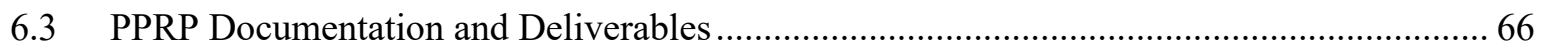

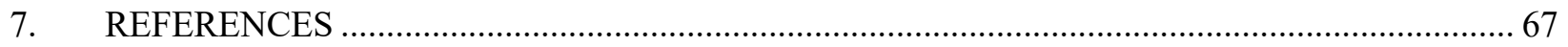

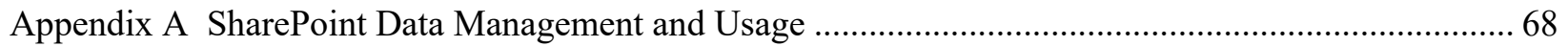

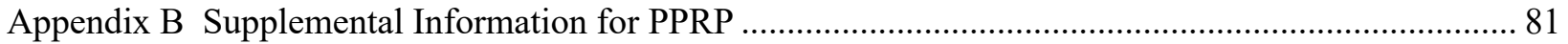




\section{FIGURES}

Figure 1. Graphic shows the DOE and NRC guidance documents governing the INL Site-wide SSHAC Level 3 PSHA.

Figure 2. Map showing INL sites: ATR, CFPP (Site 3), INTEC, MFC, NRF; Central Facilities Area (CFA), Radioactive Waste Management Complex (RWMC), and Test Area North (TAN).

Figure 3. Flowchart illustrating the steps of a SSHAC Level 3 PSHA study, with time running from top to bottom. The solid horizontal arrows emerging from the PPRP bar indicate engagements of the full panel whereas the dashed arrows indicate the engagements by one or more representatives of the panel (NRC 2018).

Figure 4. Organization of participants for the INL Site-wide SSHAC Level 3 study. ............................25

Figure 5. Diagram illustrating key interface issues in a site-specific PSHA (NRC 2017). 55

\section{TABLES}

Table 1. Technical products and site conditions for INL sites and stakeholders.................................... 18

Table 2. Roles and responsibilities of the project manager and management support team...................... 26

Table 3. Roles and responsibilities of SSHAC participants and the PPRP............................................ 29

Table 4. SSHAC participant communication interface responsibilities.................................................... 34

Table 5. Tasks to be performed by SSHAC Level 3 participants under the evaluation process................. 39

Table 6. Tasks to be performed by SSHAC Level 3 participants under the integration process................50

Table 7. Tasks to be performed by SSHAC Level 3 participants under the documentation process. ........ 59

Table 8. Schedule of tasks for INL Site-wide SSHAC Level 3 PSHA....................................................... 62 


\section{ACRONYMS}

AFE

ANS

ANSI

ASCE

ASME

ATR

BEA

CBR

CFA

CFPP

CFR

COLA

DEM

DOE

DRS

ESRP

FI

FIRS

FMF

FMP

GIS

GMC

GMM

GMPE

GMRS

HID

INL

INTEC

ISFSI annual frequency of exceedance

American Nuclear Society

American National Standards Institute

American Society of Civil Engineers

American Society of Mechanical Engineers

Advanced Test Reactor

Battelle Energy Alliance

center, body, and range

Central Facilities Area

Carbon Free Power Project

Code of Federal Regulations

combined license application

digital elevation map

Department of Energy

design response spectrum

Eastern Snake River Plain

Fluor Idaho

foundation input-response spectrum

Fuel Manufacturing Facility

Fluor Marine Propulsion

Geographic Information System (database)

ground-motion characterization

ground-motion model

ground-motion-prediction equation

ground-motion response spectrum

hazard-input document

Idaho National Laboratory

Idaho Nuclear Technology and Engineering Center

Independent Spent Fuel Storage Installation 


\begin{tabular}{|c|c|}
\hline LiDAR & light detection and ranging \\
\hline $\mathbf{M}$ & moment magnitude \\
\hline MFC & Materials and Fuels Complex \\
\hline MRD & modulus reduction and damping \\
\hline NQA & Nuclear Quality Assurance \\
\hline NRC & Nuclear Regulatory Commission \\
\hline NRF & Naval Reactors Facility \\
\hline PGA & peak ground acceleration \\
\hline PPRP & Participatory Peer Review Panel \\
\hline PSHA & probabilistic seismic hazard analysis \\
\hline PTI & project technical integrator \\
\hline QA & quality assurance \\
\hline QE & quality engineer \\
\hline QAPP & Quality Assurance Project Plan \\
\hline RG & Regulatory Guide \\
\hline RWMC & Radioactive Waste Management Complex \\
\hline SDC & Seismic Design Category \\
\hline SEI & Structural Engineers Institute \\
\hline SFHP & Spent Fuel Handling Recapitalization Project \\
\hline SOW & statement of work \\
\hline $\mathrm{SSC}$ & seismic-source characterization \\
\hline SSI & soil structure interaction \\
\hline SSHAC & Senior Seismic Hazard Analysis Committee \\
\hline SWUS & Southwest United States \\
\hline TAN & Test Area North \\
\hline TDI & technically defensible interpretation \\
\hline $\mathrm{TI}$ & technical integration \\
\hline TMI & Three Mile Island \\
\hline UAMPS & Utah Associated Municipal Power Systems \\
\hline UHRS & uniform hazard-response spectrum \\
\hline
\end{tabular}


$\mathrm{V} / \mathrm{H} \quad$ vertical/horizontal (ratio)

$\mathrm{V}_{\mathrm{S}} \quad$ shear-wave velocity

VTR Versatile Test Reactor

ZPPR Zero Power Physics Reactor 


\section{Work Plan for the Site-wide SSHAC Level 3 Probabilistic Seismic Hazard Analysis at INL \\ 1. INTRODUCTION}

This work plan provides a single point of reference that identifies the overall framework, key activities, key tasks, schedule, and quality assurance (QA) requirements for the execution of the Senior Seismic Hazard Analysis Committee (SSHAC) Level 3 study at Idaho National Laboratory (INL). The work plan is the implementation plan for "INL SSHAC L3 Project," which is being conducted by Battelle Energy Alliance (BEA) on behalf of the sponsor, U.S. Department of Energy (DOE).

The INL Site-wide SSHAC Level 3 study will replace the existing probabilistic seismic hazard analysis (PSHA) that supports the seismic safety bases of ongoing INL operations. The study will also provide the necessary seismic bases for design and licensing of a new small modular reactor and design of other future nuclear facilities at INL.

\subsection{Background}

INL last completed a PSHA in 1996 that, with updated computations in 2000, currently supports the seismic safety basis of existing INL nuclear facilities classified as Seismic Design Category (SDC)-3 and above. The initial 1996 PSHA was not conducted under the SSHAC framework since it predates the development of U.S. Nuclear Regulatory Commission's (NRC's) SSHAC guidance, and thus it cannot be used to support the design of new nuclear facilities. INL recently completed a SSHAC Level 1 study at three INL sites (Advanced Test Reactor [ATR], Materials and Fuels Complex [MFC], and Naval Reactors Facility [NRF]), which identified key seismic hazard issues and provides a starting point for the INL Sitewide SSHAC Level 3 study.

\subsection{Regulatory Context and Selection of SSHAC Level 3}

The regulatory context for the INL Site-wide SSHAC Level 3 study includes both DOE and NRC guidance. The SSHAC Level 3 PSHA at INL is being conducted in accordance with DOE Order 420.1C, "Facility Safety" (DOE 2012a), for new and existing nuclear facilities. The Order is implemented through Standard DOE-STD-1020, "Natural Phenomena Hazard Analysis and Design Criteria for Department of Energy Facilities," (DOE 2012b; 2016) which governs approaches for developing seismic design criteria that are graded and consistent with the risk significance of the facility. DOE's Standard refers to and endorses the approaches provided in American National Standards Institute/American Nuclear Society (ANSI/ANS) ANSI/ANS-2.29-2008 (ANSI 2008) for conducting a PSHA for purposes of seismic design of facilities having various SDC levels (as per American Society of Civil Engineers [ASCE])/Structural Engineers Institute [SEI], ASCE/SEI 43-05). The methodology in ANSI/ANS-2.29-2008 refers to the SSHAC approach provided in NRC's regulatory guidance for conducting PSHAs, such as NUREG-6372 (NRC 1997) and NUREG-2117 (NRC 2012).

The SSHAC Level 3 PSHA at INL is also being conducted to fulfill 10 Code of Federal Regulations (CFR) Part 52, "Licenses, Certifications, and Approvals for Nuclear Power Plants," in support of 10 CFR 52 Subpart C, "Combined Licensing Application," and Regulatory Guide (RG) 1.206 (NRC 2007a) for the Carbon Free Power Project (CFPP) site for a new small modular reactor. The graphic in Figure 1 shows that DOE's and NRC's guidance documents each endorse the approaches provided in NRC RG 1.208, "A Performance Based Approach to Define the Site-specific Earthquake Ground Motion" (NRC 2007b), for defining site-specific earthquake ground motions. NUREG-2213 (NRC 2018) states that the SSHAC process as an acceptable framework to implement the recommendations in RG 1.208 with regard to performing a PSHA. The SSHAC process for the INL PSHA was chosen because it provides a formalized and documented process for compilation of available data and information, 
DOE

U.S. Department of

Energy

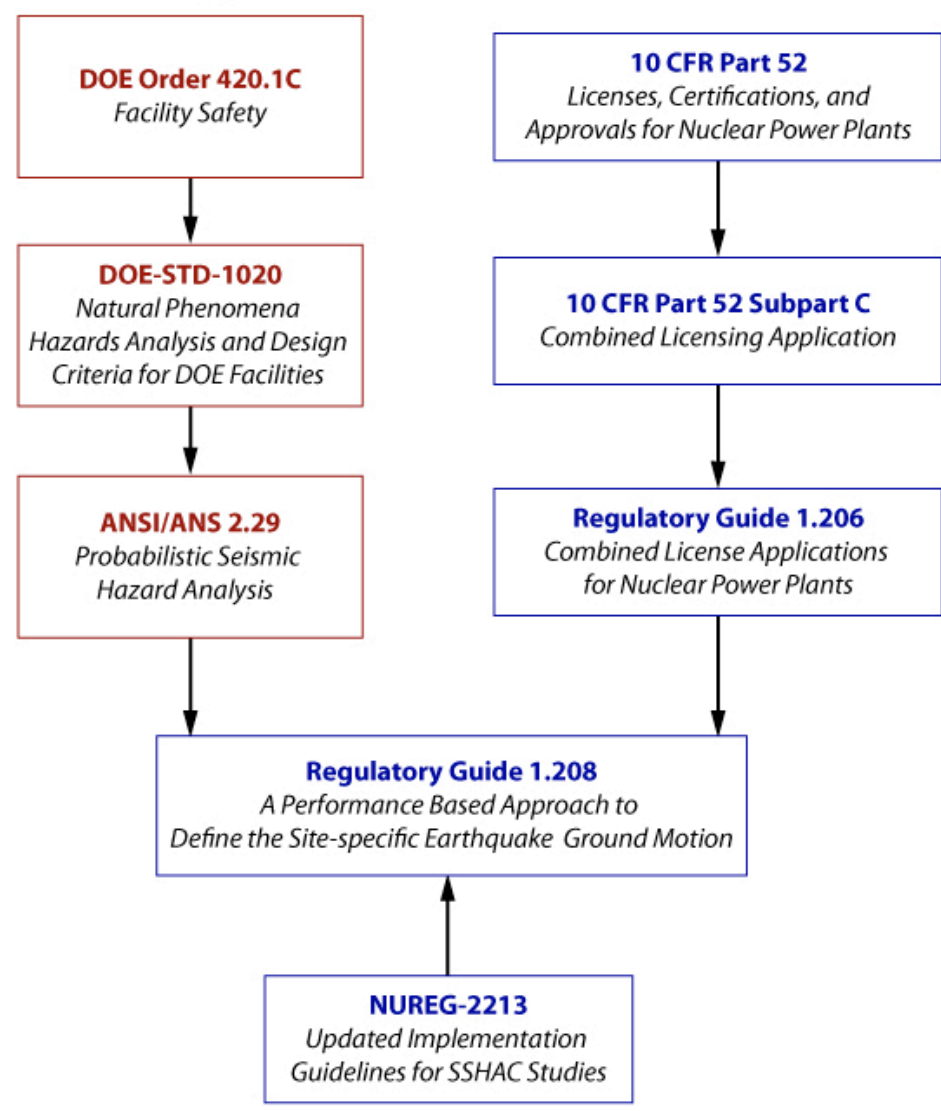

Figure 1. Graphic shows the DOE and NRC guidance documents governing the INL Site-wide SSHAC Level 3 PSHA.

consideration and evaluation of data, models, and methods, and integration of alternative hypotheses into a composite or "community distribution" that represents the center, body, and range of TDIs.

A SSHAC Level 3 study was chosen to perform the PSHA based on the regulatory assurance necessary to support existing and planned new nuclear facilities at INL and to address subsurface geologic complexities underlying INL. The products of the PSHA will be used to update the seismic safety bases of existing nuclear facilities at INL classified as SDC-3 and higher, for seismic design of new INL test reactor classified as SDC-4 or SDC-5, and for acquiring an NRC license of a site on INL for construction and operations of a new small modular reactor. Additionally, there is a high degree of technical complexity and a level of uncertainty in the hazard inputs for ground-motion models. Quaternary volcanism in the Eastern Snake River Plain (ESRP) has produced a complex and highly unpredictable subsurface stratigraphy that has alternating layers of basalt rocks and sediments. This stratigraphy leads to highly variable shear-wave velocities and velocity reversals within the upper few hundred meters of the surface, which can have significant effects on earthquake ground motions.

The work and methodology identified in this work plan will be performed to achieve the goal of regulatory acceptance of the results for both DOE and NRC. To enhance the probability of acceptance, methodologies with considerable precedence and recognition by the NRC in NUREG-2213 (NRC 2018) and NUREG-2117 (NRC, 2012) are being used. The work plan is consistent with RG 1.208 (NRC 2007b) and ASCE/SEI 43-05 (ASCE 2005), which stipulate the manner in which a PSHA should be carried out 
and define acceptable approaches to specifying design-basis ground motions for the design of nuclear facilities. These documents are widely regarded as representing international best practice and the most stringent procedures for conducting analyses of the seismic loading to be considered in the design of nuclear facilities.

\subsection{Quality Assurance}

Quality assurance requirements for the INL SSHAC L3 Project are consistent with BEA's QA program, which is commensurate with American Society of Mechanical Engineers (ASME) Nuclear Quality Assurance (NQA) NQA-1 2008/2009 Addendum. The Project is also being conducted to fulfill 10 CFR Part 52, Licenses, Certifications, and Approvals for Nuclear Power Plants via 10 CFR 50, Domestic Licensing of Production and Utilization Facilities, Appendix B, "Quality Assurance Criteria for Nuclear Power Plants and Fuel Reprocessing Plants."

QA requirements and work processes are identified in the quality assurance project plan, PLN-5753, and shall be implemented by all SSHAC participants. The requirement to implement this work plan and the QAPP are formally promulgated through each participant's statement of work (SOW). Each participant's SOW requires that work be performed as instructed in this work plan and per the QAPP. Each participant is required to undergo indoctrination of the work processes prior to beginning their work. The work will include, but is not limited to:

- Literature searches

- Data compilations

- Analysis of data

- Evaluation of data and information
- Development of inputs to calculations

- Performing calculations

- Documentation of work performed

- Peer reviews.

- Development of models

\subsection{Applicability}

This work plan is applicable to all INL SSHAC L3 Project participants, whose roles within the project are defined in Section 3. The work plan was finalized prior to commencement of the project and is valid for its duration, unless modifications are made. The scope of the work defined in this work plan has been promulgated into the applicable SOWs for each project participant.

Modifications to this original work plan may be made to accommodate potential changes in schedule (e.g., CFPP data collection), technical approach, or programmatic needs of stakeholders. Any changes to this document during the course of the project will be issued as a revision of the original work plan and then disseminated to all participants. 


\section{SCOPE OF THE SSHAC LEVEL 3 PSHA \\ 2.1 Purpose}

The INL Site-wide SSHAC Level 3 study is being conducted to provide the seismic-source characterization (SSC) model, ground-motion characterization (GMC) model, and PSHA framework to compute the site-specific hazard for ten designated site conditions at five facility areas at INL. Seismic hazard products will also be generated to allow future INL projects to incorporate new subsurface data and produce site-specific hazard at their site of interest. The specific purpose of the PSHA is to provide quantitative assessments of the ground-shaking hazard and its uncertainty to support the seismic-safety bases of existing nuclear facilities and design of future new nuclear facilities.

\subsection{Scope}

The scope of the INL Site-wide SSHAC Level 3 PSHA involves performing the PSHA for sitespecific conditions within the framework of a SSHAC Level 3 study consistent with NRC NUREG-2213 guidance (NRC, 2018). The PSHA will focus on characterization of the seismic hazard in terms of quantitatively defined ground motions and their uncertainties at INL sites of interest to several stakeholders (Section 2.3). Technical products will be produced for each of the INL sites or facilities as requested by their respective stakeholder for subsequent structural analyses that are not included in the SSHAC Level 3 study (Section 2.4).

In terms of hazards that can be generated by earthquakes, this study is focused exclusively on the ground shaking generated by the passage of seismic waves, including the influence of near-surface geomaterials that may amplify or otherwise modify the motions. This study will also produce the framework of SSC and GMC models that can be used in future site-specific PSHAs for new and uncharacterized sites at INL. The final quantitative assessments of those hazards for future sites fall outside the scope of this SSHAC Level 3 study. Surface faulting hazards and secondary hazards associated with seismic shaking, such as liquefaction, landsliding, or subsidence, are specifically not part of this study.

The INL Site-wide SSHAC Level 3 study includes compilations and evaluations of data to characterize and then construct the SSC and GMC models for the PSHA. The SSHAC framework provides the necessary processes and procedures for teams of experts at three workshops and four formal working meetings to create the SSC and GMC models, exercise those models in the PSHA, and perform final hazard calculations (Section 2.5).

\subsubsection{Seismic Source Characterization Scope}

New and existing data compilations in the surrounding region of INL regarding earthquake characterization will establish the SSC model. The SSC model provides estimates of the locations, rates, and sizes of future earthquakes that can produce ground shaking at any nuclear facility site on INL. The INL is located in the volcanic region of the ESRP and is surrounded by seismically active Basin and Range regions. Potential seismic sources for INL include regional and local zones of seismicity, faults, and earthquakes associated with volcanic processes. Characterization of seismic sources will involve compiling and evaluating data to assess the seismotectonic setting, source geometries, rupture processes, activity rates of sources, earthquake magnitudes, and associated uncertainties. The SSC model will represent the expected locations, sizes, and frequencies of future earthquakes for INL, and provide the context for the GMC model to properly interface with the SSC model in the PSHA. The minimum magnitude for the PSHA calculations will be moment magnitude (M) 5.0 (see Bommer and Crowley 2017 for a discussion of the minimum magnitude issue).

\subsubsection{Ground Motion Characterization Scope}

Characterization of earthquake ground motions and how they attenuate as they travel from an earthquake source to a facility site at INL will establish the GMC model. Available existing and new 
subsurface data incorporated into ground motion models (GMMs) will produce site-specific ground motions at the appropriate location of design-input motions for each site condition of interest (Section 2.3). The GMC will involve use of ground motion prediction equations (GMPEs), adjustments of those GMPEs to INL site conditions at a reference rock horizon, and site response analysis to determine the relative amplification factors from reference rock horizon to each of the target locations. The INL is underlain by basalt rocks interbedded with sedimentary layers of varying thickness and spatial extents. The thickness of the interbedded basalt sequence also varies $(0.5$ to $1.1 \mathrm{~km})$ and overlies rhyolite. Due to the highly variable nature of the subsurface beneath INL, the reference rock horizon may be defined for a generic rock profile as an alternative to identifying buried rock horizons at multiple locations across the site. The reference-rock horizon will be defined at a depth that can then be treated as the top of an elastic half-space in site-response analyses for the overlying layers. The site response will be combined with rock hazard that appropriately treats components of uncertainty.

\subsection{Sites for Hazard Computations}

PSHA computations will be performed for site-specific rock and soil sites at existing facilities and sites where there are existing data and new site-specific data will be collected. The sites have been designated by "stakeholders" who will use the hazard products, which is a term that is being used to collectively refer to owners (e.g., Fluor Marine Propulsion, FMP) and entities that manage facilities on behalf of an owner (e.g., BEA for DOE). At INL, one or more nuclear facilities are located at facility areas, and thus the facility area is termed a site in the INL Site-wide SSHAC Level 3 study. Requests from stakeholders include technical products for existing, planned new, and future new nuclear facilities at their respective site of interest. Table 1 lists the INL site names, facility status, stakeholder, site conditions, status of data, and specific technical products requested from the stakeholder (Section 2.4).

From Table 1, stakeholders have identified the ATR, MFC, NRF, Idaho Nuclear Technology and Engineering Center (INTEC), and CFPP sites for technical products from final hazard computations (see Figure 2). The ATR, MFC, and NRF sites were characterized using existing data as part of the SSHAC Level 1 PSHA (INL 2016). These three sites in the south-central part of INL span the range of subsurface geology, including sites with thin surficial soils $(<20 \mathrm{~m})$ above basalt rock that includes sedimentary interbeds (ATR and NRF) and basalt without interbeds (MFC). The INTEC site near ATR has thin soils overlying basalt with fewer sedimentary interbeds. The CFPP site (referred to as site 3 ) is located along the western boundary of INL and likely has different geology (Figure 2). The site may be underlain by basalt with thin interbeds over a thick sequence of sediments with some basalt layers which overlies rhyolite. New subsurface data will be collected at the MFC, NRF, ATR, the CFPP site, and possibly at INTEC (Table 1). With regard to soil site conditions, the thickness of soil above basalt rock varies greatly over short distances and beneath the footprint of most facilities due to the highly irregular surface of basalt lava flows. Where site-specific soil ground motions are requested, site conditions in Table 1 list the soil thicknesses above basalt rock associated with the facility. Where rock surface ground motions are requested, Table 1 lists a general description of the basalt sequence and ignores the soil above.

Due to the number of requests from stakeholders and schedule considerations, two hazard analysts will compute the hazard for the five INL sites and thirteen site conditions listed in Table 1. To provide flexibility and support the CFPP schedule for data collection and the combined license application (COLA), one hazard analyst will be dedicated to computing hazard at the CFPP site. Table 1 lists the assigned sites below each hazard analyst. 


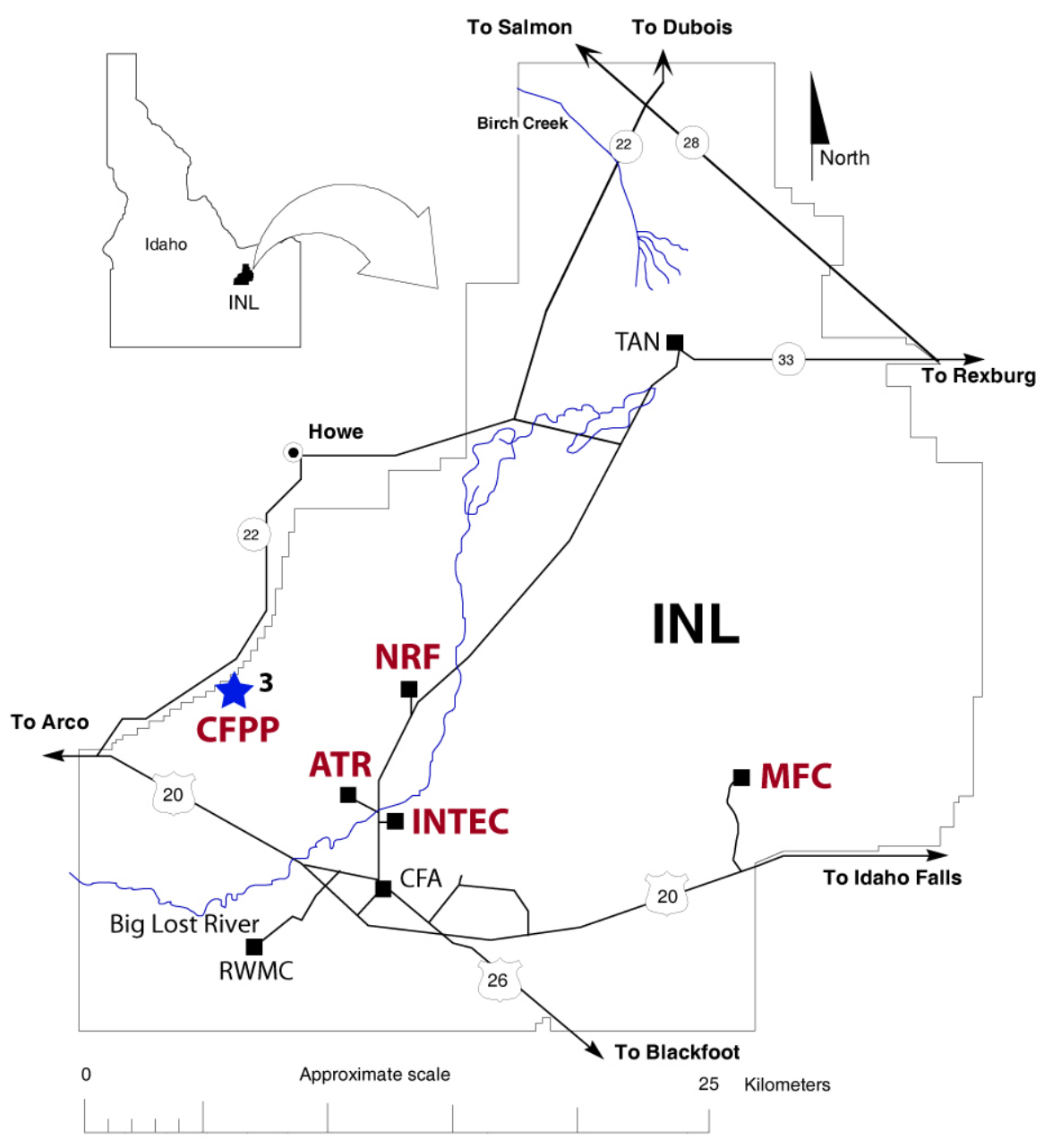

Figure 2. Map showing INL sites: ATR, CFPP (Site 3), INTEC, MFC, NRF; Central Facilities Area (CFA), Radioactive Waste Management Complex (RWMC), and Test Area North (TAN). 
Table 1. Technical products and site conditions for INL sites and stakeholders.

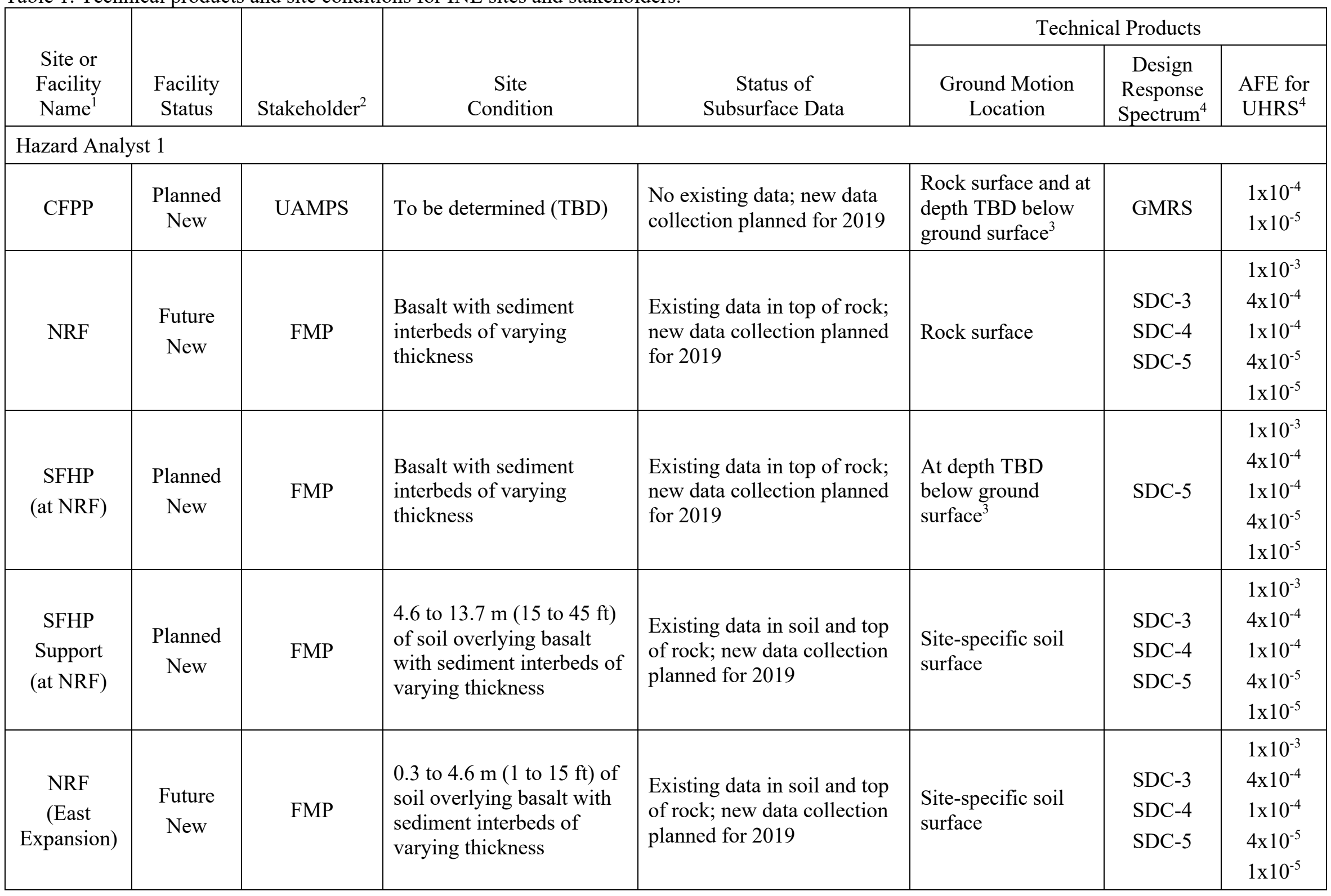




\begin{tabular}{|c|c|c|c|c|c|c|c|}
\hline \multirow[b]{2}{*}{$\begin{array}{c}\text { Site or } \\
\text { Facility } \\
\text { Name }^{1}\end{array}$} & \multirow[b]{2}{*}{$\begin{array}{l}\text { Facility } \\
\text { Status }\end{array}$} & \multirow[b]{2}{*}{ Stakeholder $^{2}$} & \multirow[b]{2}{*}{$\begin{array}{c}\text { Site } \\
\text { Condition } \\
\end{array}$} & \multirow[b]{2}{*}{$\begin{array}{c}\text { Status of } \\
\text { Subsurface Data } \\
\end{array}$} & \multicolumn{3}{|c|}{ Technical Products } \\
\hline & & & & & $\begin{array}{l}\text { Ground Motion } \\
\text { Location }\end{array}$ & $\begin{array}{c}\text { Design } \\
\text { Response } \\
\text { Spectrum }^{4} \\
\end{array}$ & $\begin{array}{l}\text { AFE for } \\
\text { UHRS }^{4}\end{array}$ \\
\hline INTEC & $\begin{array}{l}\text { Future } \\
\text { New }\end{array}$ & FI or BEA & $\begin{array}{l}\text { Basalt with sediment } \\
\text { interbeds of varying } \\
\text { thickness }\end{array}$ & $\begin{array}{l}\text { Existing data in top of rock; } \\
\text { possible new data collection }\end{array}$ & Rock surface & $\begin{array}{l}\text { SDC-3 } \\
\text { SDC-4 } \\
\text { SDC-5 }\end{array}$ & $\begin{array}{l}4 \times 10^{-4} \\
1 \times 10^{-4} \\
4 \times 10^{-5} \\
1 \times 10^{-5}\end{array}$ \\
\hline $\begin{array}{c}\text { TMI-2 } \\
\text { ISFSI } \\
\text { (at INTEC) }\end{array}$ & Existing & DOE & $\begin{array}{l}7.6 \text { to } 20.1 \mathrm{~m} \text { ( } 25 \text { to } 66 \mathrm{ft}) \\
\text { of soil overlying basalt } \\
\text { with few and thin } \\
\text { sediment interbeds }\end{array}$ & $\begin{array}{l}\text { Existing data in soil and top } \\
\text { of rock; possible new data } \\
\text { collection }\end{array}$ & $\begin{array}{l}\text { Site-specific soil } \\
\text { surface }\end{array}$ & UHRS & $\begin{array}{l}5 \times 10^{-4} \\
4 \times 10^{-4} \\
1 \times 10^{-4} \\
4 \times 10^{-5}\end{array}$ \\
\hline \multicolumn{8}{|c|}{ Hazard Analyst 2} \\
\hline ATR & Existing & BEA & $\begin{array}{l}\text { Basalt with sediment } \\
\text { interbeds of varying } \\
\text { thickness }\end{array}$ & $\begin{array}{l}\text { Existing data in soil and top } \\
\text { of rock; new data collection } \\
\text { planned for June } 2019\end{array}$ & $\begin{array}{l}\text { At depth TBD } \\
\text { below ground } \\
\text { surface }^{3}\end{array}$ & SDC-4 & $\begin{array}{l}4 \times 10^{-4} \\
4 \times 10^{-5}\end{array}$ \\
\hline ATR & $\begin{array}{l}\text { Future } \\
\text { New }\end{array}$ & BEA & $\begin{array}{l}\text { Basalt with sediment } \\
\text { interbeds of varying } \\
\text { thickness }\end{array}$ & $\begin{array}{l}\text { Existing data in soil and top } \\
\text { of rock; new data collection } \\
\text { planned for June } 2019\end{array}$ & Rock surface & $\begin{array}{l}\text { SDC-3 } \\
\text { SDC-4 } \\
\text { SDC-5 }\end{array}$ & $\begin{array}{l}4 \times 10^{-4} \\
1 \times 10^{-4} \\
4 \times 10^{-5} \\
1 \times 10^{-5} \\
\end{array}$ \\
\hline $\begin{array}{c}\text { ATR } \\
\text { Support }\end{array}$ & Existing & BEA & $\begin{array}{l}6.1 \text { to } 18.3 \mathrm{~m}(20 \text { to } 60 \mathrm{ft}) \\
\text { of soil overlying basalt } \\
\text { with sediment interbeds of } \\
\text { varying thickness }\end{array}$ & $\begin{array}{l}\text { Existing data in soil and top } \\
\text { of rock; new data collection } \\
\text { planned for June } 2019\end{array}$ & $\begin{array}{l}\text { Site-specific soil } \\
\text { surface }\end{array}$ & SDC-4 & $\begin{array}{l}4 \times 10^{-4} \\
4 \times 10^{-5}\end{array}$ \\
\hline MFC & $\begin{array}{l}\text { Future } \\
\text { New }\end{array}$ & BEA & $\begin{array}{l}\text { Basalt with few and thin } \\
\text { sediment interbeds }\end{array}$ & $\begin{array}{l}\text { Existing data from surface to } \\
350 \mathrm{~m} \text { depth in rock; new } \\
\text { data collection to begin in } \\
\text { May } 2019\end{array}$ & Rock surface & $\begin{array}{l}\text { SDC-3 } \\
\text { SDC-4 } \\
\text { SDC-5 }\end{array}$ & $\begin{array}{l}4 \times 10^{-4} \\
1 \times 10^{-4} \\
4 \times 10^{-5} \\
1 \times 10^{-5}\end{array}$ \\
\hline
\end{tabular}




\begin{tabular}{|c|c|c|c|c|c|c|c|}
\hline \multirow[b]{2}{*}{$\begin{array}{l}\text { Site or } \\
\text { Facility } \\
\text { Name }^{1}\end{array}$} & \multirow[b]{2}{*}{$\begin{array}{c}\text { Facility } \\
\text { Status }\end{array}$} & \multirow[b]{2}{*}{ Stakeholder ${ }^{2}$} & \multirow[b]{2}{*}{$\begin{array}{c}\text { Site } \\
\text { Condition }\end{array}$} & \multirow[b]{2}{*}{$\begin{array}{c}\text { Status of } \\
\text { Subsurface Data }\end{array}$} & \multicolumn{3}{|c|}{ Technical Products } \\
\hline & & & & & $\begin{array}{l}\text { Ground Motion } \\
\text { Location }\end{array}$ & $\begin{array}{l}\text { Design } \\
\text { Response } \\
\text { Spectrum }^{4} \\
\end{array}$ & $\begin{array}{l}\text { AFE for } \\
\text { UHRS }^{4} \\
\end{array}$ \\
\hline $\begin{array}{c}\text { VTR } \\
\text { (at MFC) }\end{array}$ & $\begin{array}{l}\text { Future } \\
\text { New }\end{array}$ & BEA & $\begin{array}{l}\text { Basalt with few and thin } \\
\text { sediment interbeds }\end{array}$ & $\begin{array}{l}\text { Existing data from surface to } \\
350 \mathrm{~m} \text { depth in rock; new } \\
\text { data collection to begin in } \\
\text { May } 2019\end{array}$ & $\begin{array}{l}\text { At depth of } 30 \mathrm{~m} \\
\text { below ground } \\
\text { surface }^{3}\end{array}$ & $\begin{array}{l}\text { SDC-4 } \\
\text { (or SDC- } \\
5 \text { ) }\end{array}$ & $\begin{array}{l}4 \times 10^{-4} \\
4 \times 10^{-5} \\
\left(1 \times 10^{-4}\right. \\
\left.1 \times 10^{-5}\right)\end{array}$ \\
\hline $\begin{array}{c}\text { FMF } \\
\text { (at MFC) }\end{array}$ & Existing & BEA & $\begin{array}{l}1.5 \text { to } 4.3 \mathrm{~m} \text { ( } 5 \text { to } 14 \mathrm{ft}) \text { of } \\
\text { soil overlying basalt with } \\
\text { few and thin sediment } \\
\text { interbeds }\end{array}$ & $\begin{array}{l}\text { Existing data in soil, and } \\
\text { from surface to } 350 \text { m depth } \\
\text { in rock; new data collection } \\
\text { to begin in May } 2019\end{array}$ & $\begin{array}{l}\text { Site-specific soil } \\
\text { surface }\end{array}$ & SDC-3 & $\begin{array}{l}4 \times 10^{-4} \\
4 \times 10^{-5}\end{array}$ \\
\hline $\begin{array}{c}\text { ZPPR } \\
\text { (at MFC) }\end{array}$ & Existing & BEA & $\begin{array}{l}0.6 \text { to } 14.0 \mathrm{~m}(2 \text { to } 46 \mathrm{ft}) \\
\text { of soil overlying basalt } \\
\text { with few and thin } \\
\text { sediment interbeds }\end{array}$ & $\begin{array}{l}\text { Existing data in soil, and } \\
\text { from surface to } 350 \mathrm{~m} \text { depth } \\
\text { in rock; new data collection } \\
\text { to begin in May } 2019\end{array}$ & $\begin{array}{l}\text { Site-specific soil } \\
\text { surface }\end{array}$ & SDC-3 & $\begin{array}{l}4 \times 10^{-4} \\
4 \times 10^{-5}\end{array}$ \\
\hline
\end{tabular}

1. Site and facility abbreviations: ATR - Advanced Test Reactor; CFPP - Carbon Free Power Project; FMF - Fuels and Manufacturing Facility; ISFSI - Independent Spent Fuel Storage Installation; MFC - Materials and Fuels Complex; Naval Reactors Facility (NRF); SFHP - Spent Fuel Handling Recapitalization Project; TMI Three Mile Island; VTR - Versatile Test Reactor; ZPPR - Zero Power Physics Reactor.

2. Stakeholder abbreviations: BEA - Battelle Energy Alliance; DOE - U.S. Department of Idaho; FI - Fluor Idaho; FMP - Fluor Marine Propulsion; UAMPS - Utah Association of Municipal Power Systems.

3. Depth below ground surface may change or will be provided by the project as design of the proposed new facility evolves.

4. Seismic design abbreviations: AFE - annual frequency of exceedance; GMRS - ground motion response spectrum; SDC - seismic design category; UHRS uniform horizontal response spectrum. 


\subsection{Technical Products}

The INL Site-wide SSHAC Level 3 PSHA will produce technical products as requested by stakeholders for their site of interest. Several of the technical products will be produced for all stakeholders and are discussed in Section 2.4.1. Technical products that are specific to each stakeholder are listed in Table 1 and discussed in Section 2.4.2. Section 2.4.3 identifies analyses that will not be performed and technical products that will not be generated as part of the INL Site-wide SSHAC Level 3 PSHA.

The INL Site-wide SSHAC Level 3 PSHA is being conducted with the recognition that new stakeholders with new nuclear facilities will need hazard levels at sites on INL that were not included in the current PSHA. The final report of the INL Site-wide SSHAC Level 3 study will provide future stakeholders with the basis to perform follow-on SSHAC studies and determine new data collection. However, detailed planning of such follow-on studies is the responsibility of the future stakeholder and beyond the scope of the current study.

\subsubsection{Common Technical Products}

Several technical products will be produced from the final PSHA for all sites and facilities listed in Table 1. These products include the following.

- The hazard will be expressed in the form of geometric mean horizontal spectral accelerations with 5\% of critical damping defined for peak ground acceleration (PGA) and a minimum of 20 spectral frequencies from $0.1 \mathrm{~Hz}$ (10 seconds) to $100 \mathrm{~Hz}$ ( 0.01 seconds). Selection of spectral frequencies will be determined by the GMC Technical Integration (TI) Team.

- For each oscillator frequency, mean hazard curves and fractiles (5th, 15 th, 50 th, $85^{\text {th }}$, and 95 th percentiles) will be generated for AFEs from $10^{-2}$ to $10^{-8}$.

- Disaggregations to identify relative contributions from different bins of magnitude, distance, and epsilon (ground-motion exceedance in terms of numbers of standard deviations) will be performed at frequency $(f)$-AFE combinations as specified for the AFEs in Table 1 . The frequencies will be $0.5,1$, and $10 \mathrm{~Hz}$.

- Mean hazard curves at the reference rock horizon will be generated for use by the stakeholder to develop response spectra defining the ground motion for soil structure interaction (SSI) analyses.

- Vertical/horizontal $(\mathrm{V} / \mathrm{H})$ ratios will be defined to perform transformation of the horizontal ground motion spectra into vertical components.

\subsubsection{Specific Technical Products}

Specific technical products listed in Table 1 will be generated from the final PSHA as requested by each stakeholder. Horizontal design response spectra (DRS) for MFC, ATR, NRF, and INTEC will be produced consistent with guidance in ASCE 43-05 (ASCE, 2005) as per Standard DOE-STD-1020 (DOE 2012b; 2016). Horizontal uniform hazard-response spectra (UHRS) will be produced from the final PSHA for the AFEs needed to compute the DRS for SDC-3, SDC-4, or SDC-5 as defined in Table 1. Also listed in Table 1 is the location of the ground motion and site condition for the DRS, which is specified by the stakeholder to be at rock surface, site-specific soil surface (or performance based surface response spectra), or a depth (base rock level) below ground surface. V/H ratios generated as part of the SSHAC Level 3 study will be used to compute the corresponding vertical DRS for the SDC levels listed in Table 1 .

Technical products for the CFPP site include those listed in Table 1 and other stakeholder-requested products to be provided in the final study report. The CFPP site will follow guidance in NRC RG 1.208 (NRC, 2007b) to produce ground-motion response spectra (GMRS). The GMRS will be produced at a 
depth below ground surface which is to be below the deepest foundation depth and determined following new data collection. Horizontal UHRS will be produced from the final PSHA for the AFEs listed in Table 1 which are needed to compute the GMRS as per RG 1.208. V/H ratios generated as part of the SSHAC Level 3 study will then be used to compute the corresponding vertical GMRS.

Utah Association of Municipal Power Systems (UAMPS) who is the stakeholder for the CFPP site requested products from the preliminary PSHA. Mean hazard curves will be generated at the reference rock horizon level for a limited number of oscillator frequencies (to be determined). Any additional analyses (e.g., site response analyses or SSI) using the hazard curves from the preliminary PSHA will be the responsibility of the stakeholder.

Additional products requested for CFPP and by other INL projects will come from the INL Site-wide SSHAC Level 3 study report. The final study report will include the following descriptions and details of the methodologies used for simulations of site profiles and site amplification. UAMPS has requested that Approach 3 (NUREG/CR-6728, NRC 2001) be used for site amplification to be compatible with the method that they plan to use to develop the foundation input-response spectrum (FIRS). Stakeholders for other INL projects listed in Table 1, such as MFC (e.g., Versatile Test Reactor), NRF, and ATR, also plan to develop a FIRS and will use the same approach for site amplification. The following information will be included in the final study report for the CFPP site and other INL sites.

- Description of the methodology used for simulation of site profiles:

- Methodology used for simulation of the site profile

- Correlation parameters for inter-layer correlation of properties

- Range of variation considered for each soil layer property and thickness

- Nonlinear soil curves and its variation and simulation

- Statistical model used for simulation of each parameter and associated statistical parameters

- Methodology used to handle epistemic uncertainty and associated weights.

- Details of the methodology for site amplification:

- Methods used (Random Vibration theory or time history analysis)

- Number of seismic hazard convolution analysis and methodology for de-aggregation of the seismic input for site amplification analysis

- Methodology for handling nonlinear soil properties including damping derived from the range of kappa at the site

- Methodology to obtain effective shear strain from maximum shear strain in each layer

- Methodology used to develop seismic hazard curves at the GMRS (how the amplified hazard motion for all simulated profiles are processed; how the mean and variation of amplified hazard are obtained, number of frequencies used to get amplified hazard curves and any interpolation applied to cover all other frequencies)

- High and low frequency amplified hazard curve results at the GMRS horizon

- Methodology to consider epistemic uncertainty in the amplified hazard responses

- Methodology used to obtain GMRS from uniform hazard spectra (calculation of scale factors)

- Methodology used to develop vertical spectra from horizontal spectra.

\subsubsection{Excluded Analyses and Products}

Other analyses and associated products are the responsibilities of the stakeholders and will not be performed as part of the INL Site-wide SSHAC Level 3 study. These include development or recommendations of acceleration time-histories for use in dynamic analyses, SSI, FIRS for facility control points, strain compatible property profiles, hazard products (beyond fractiles) for seismic probabilistic 
risk assessments (SPRAs), and other products (e.g., recommendations for strong motion duration or amplification factors derived from response spectra). The funding and schedule for such efforts are to be included in the stakeholder's projects that use the PSHA products from the INL Site-wide SSHAC Level 3 study.

\subsection{SSHAC Level 3 Framework}

The INL Site-wide SSHAC Level 3 PSHA study is organized to follow and complete the work-flow processes of a SSHAC Level 3 study (Figure 3). The study is designed to produce mean-centered estimates of earthquake ground motions and the associated uncertainties from the PSHA that are supported by defensible technical justifications.

Under the SSHAC Level 3 process, roles for all participants are clearly defined and include the required attributes which also form criteria for selecting individuals for each role (Section 3 ). The technical ownership of the SSC and GMC models lies with the TI teams, which are charged with constructing logic trees for SSC and GMC models that form the PSHA computational framework. Model development will be achieved through a specified sequence of key tasks and activities (Section 4). Through these activities the TI teams will undertake the three phases of the INL SSHAC Level 3 studynamely, Evaluation, Integration and Documentation as per NUREG-2213 (NRC 2018).

- Evaluation considers available data, models, and methods in an objective and impartial manner as to their relevance for characterization of the hazard at the site. This includes new data to be collected in 2019 at the CFPP, MFC, and NRF (and possibly ATR and INTEC) sites, for the Beaverhead Fault Reconnaissance study, and for new light detection and ranging (LiDAR) covering INL and the closest fault segments. The process also includes identifying the quality and limits of existing data, gaps in existing data, and the resolution and uncertainties in available data.

- Integration uses the outcomes of the evaluation process to develop models that reflect both the best estimate of each element of the hazard input and the associated uncertainty within the current state of knowledge. This distribution is referred to as the center, body, and range (CBR) of technically defensible interpretations (TDIs). The process involves construction of hazard-input models for SSC and GMC that address both aleatory variability and epistemic uncertainties.

- Documentation provides a complete and transparent record of the evaluation and integration processes. Specifically, the documentation must identify data, models, and methods considered in the evaluation and justify, in sufficient detail, the technical interpretations that support the hazard-input models. In addition, the documentation must be sufficiently detailed to allow the hazard analyses to be reproduced by an external reviewer.

The INL SSHAC Level 3 study plans to hold three workshops and four formal working meetings to accomplish tasks supporting SSHAC evaluation and integration phases (Section 4). The workshops will include attendance by all SSHAC study participants and others who are invited to present information by fulfilling the roles of resource and proponent experts. The format of each workshop includes clearly defined objectives and a well-planned agenda of presentations by selected participants.

The INL SSHAC Level 3 study includes the Participatory Peer Review Panel (PPRP), which provides independent oversight and performs both process and technical reviews of the study throughout its duration (Section 6). The PPRP is charged with reviewing the TI Team evaluation of available data, models, and methods and assessing that it was carried out objectively and that adequate technical justifications for the outcomes of the evaluation are provided. The PPRP is also charged with reviewing the integrated logic trees and assessing their technical basis to capture the CBR of TDI. The PPRP must review the PSHA documentation for completeness and clarity. The process review by the PPRP is focused on adherence to the SSHAC Level 3 process. The PPRP documents its oversight, reviews the study through written comments at key milestones, and documents its determination of study acceptance in a formal closure letter. 


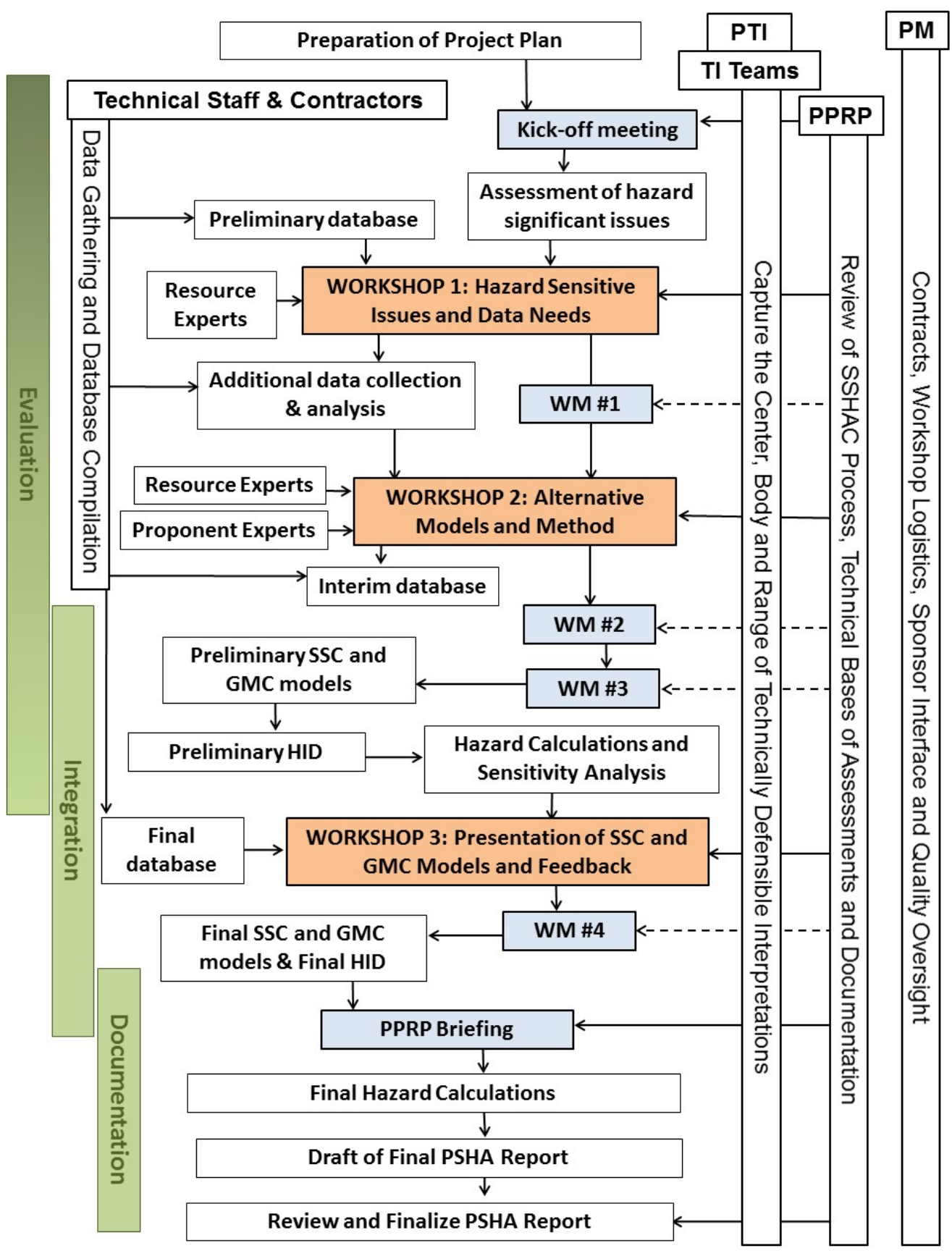

Figure 3. Flowchart illustrating the steps of a SSHAC Level 3 PSHA study, with time running from top to bottom. The solid horizontal arrows emerging from the PPRP bar indicate engagements of the full panel whereas the dashed arrows indicate the engagements by one or more representatives of the panel (NRC 2018). 


\section{PARTICIPANT ROLES AND RESPONSIBILITIES}

Roles and responsibilities of participants in the INL SSHAC Level 3 study define their contributions and describe how each participant fits into the overall study. The descriptions of roles and responsibilities are consistent with those defined in the SSHAC implementation guidance NUREG-2213 (NRC 2018). Each person is expected to perform an assigned role and execute assigned responsibilities (as specified in the following sections) to complete the tasks in Section 4.

\subsection{Organizational Structure}

The organizational structure for participants in the INL Site-wide SSHAC Level 3 study is shown in Figure 4. The owner and sponsor is DOE. It commissioned the INL SSHAC L3 Project and will own the products. DOE will invite regulators, who will observe the process through their attendance at the kickoff meeting and workshops. The project manager (PM) role will be fulfilled by a BEA employee who operates the INL on behalf of DOE and has responsibility to complete the study under the INL SSHAC L3 Project. The PM will be supported by the Management Support Team, utilizing BEA's and INL's administrative resources and processes. The PPRP will be external to INL and will provide independent oversight of the SSHAC study communicating only through the PM. The PM will rely on the project technical integrator (PTI) to implement SSHAC processes and manage the TI teams, hazard analysts, and database manager. The TI teams will invite participation of the technical community through the use of resource and proponent experts. Specialty contractors will assist the TI teams as requested.

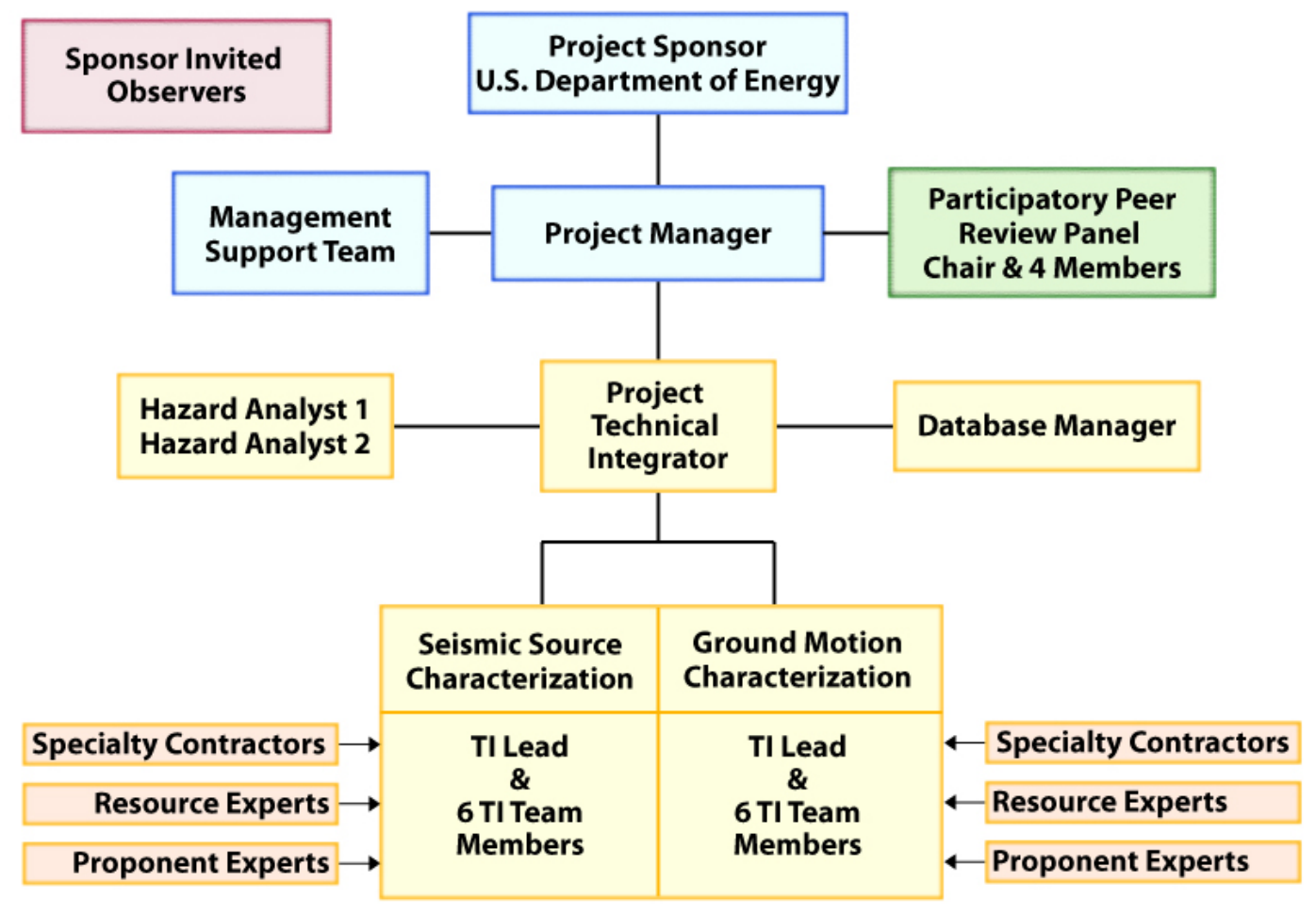

Figure 4. Organization of participants for the INL Site-wide SSHAC Level 3 study.

\subsection{Project Management Support}

The project management support team includes the PM and other BEA staff needed to facilitate and complete key tasks and activities of the INL Site-wide SSHAC Level 3 study (Section 4). The PM has the overall role of managing the INL SSHAC L3 Project. Table 2 lists the responsibilities for the PM, 
including adherence to project schedule and budget, procuring the SSHAC participants, compliance with the QA requirements, and providing regular updates and status of study progress to DOE. To accomplish project management tasks, the PM will be supported by the following participants who will be expected to serve in the following roles and complete responsibilities listed in Table 2.

- An INL technical lead to assist with developing technical documents to initiate the project and other support as needed

- An administrative professional will schedule workshops and meetings and coordinate with participants regarding logistics

- The procurement specialist will procure and administer subcontracts of SSHAC participants

- A quality engineer $(\mathrm{QE})$ will establish QA requirements and ensure their implementation

- A systems engineer will assist the QE with establishing QA requirements and implementation

- A Geographic Information System (GIS) database expert will provide GIS resources to participants and manage the project database

- A SharePoint data expert will administer SSHAC Level 3 Project SharePoint web portal which will house the project database

- A technical editor will perform technical editing functions and administer documents for the project

- A graphics designer will provide graphic support to the technical editor to produce publication quality documents.

Table 2. Roles and responsibilities of the project manager and management support team.

\begin{tabular}{|l|l|}
\hline \multicolumn{1}{|c|}{ Title and Primary Role } & \multicolumn{1}{c|}{ Responsibilities } \\
\hline & $\begin{array}{l}\text { Adheres to schedule, budget, scope, and compliance with QA } \\
\text { Selects PTI and TI leads } \\
\text { Prepares SOW and place all subcontracts } \\
\text { Manages work of BEA support staff } \\
\text { Project Manager }\end{array}$ \\
$\begin{array}{l}\text { Manage the project for INL } \\
\text { Site-wide SSHAC Level 3 } \\
\text { PSHA }\end{array}$ & $\begin{array}{l}\text { Attends workshops and formal working meetings } \\
\text { Facilitates exchange of data and information via the project database } \\
\text { Works with DOE to select the PPRP }\end{array}$ \\
& $\begin{array}{l}\text { Receives feedback from PPRP and provide it to the PTI } \\
\text { Provides final acceptance of the PPRP Checklist } \\
\text { Provides status of study to sponsor } \\
\text { Delivers final product to sponsor }\end{array}$ \\
\hline \multirow{5}{*}{ INL Technical Lead } & $\begin{array}{l}\text { Assists PM and QE with developing technical documents to initiate the } \\
\text { project } \\
\text { Guides development of the SharePoint framework and populates it with } \\
\text { INL SSHAC Level 1 data, information, and references } \\
\text { Compiles data and information from various INL projects for the project } \\
\text { database }\end{array}$ \\
\hline
\end{tabular}




\begin{tabular}{|c|c|}
\hline Title and Primary Role & Responsibilities \\
\hline $\begin{array}{l}\text { Administrative Professional } \\
\text { Coordinate meetings and } \\
\text { schedules }\end{array}$ & $\begin{array}{l}\text { Schedules and arranges meeting venues } \\
\text { Supports preparations of formal working meetings and three workshops } \\
\text { Acts as point of contact for SSHAC participants and experts to resolve } \\
\text { issues regarding travel, logistics, and meeting requirements }\end{array}$ \\
\hline $\begin{array}{l}\text { Procurement Specialist } \\
\text { Procure all subcontracts }\end{array}$ & $\begin{array}{l}\text { Procures more than } 50 \text { subcontracts for SSHAC participants and experts } \\
\text { Manages all subcontracts contractually }\end{array}$ \\
\hline $\begin{array}{l}\text { Quality Engineer } \\
\text { Provide QA requirements } \\
\text { and ensure implementation }\end{array}$ & $\begin{array}{l}\text { Develops and oversee implementation of QA requirements } \\
\text { Ensures QA requirements consistent with DOE and NRC guidance for } \\
\text { nuclear facilities } \\
\text { Performs surveillances throughout the project } \\
\text { Arranges for or performs QA audits of hazard analysts to qualify them as } \\
\text { vendors for the project }\end{array}$ \\
\hline $\begin{array}{l}\text { Systems Engineer } \\
\text { Provides QA implementation } \\
\text { support to QE }\end{array}$ & $\begin{array}{l}\text { Assists the QE with developing the QA plan } \\
\text { Assists the QE with ensuring the QA requirements are consistent with } \\
\text { DOE and NRC guidance }\end{array}$ \\
\hline $\begin{array}{l}\text { GIS Database Expert } \\
\text { Provide GIS resources for } \\
\text { project database }\end{array}$ & $\begin{array}{l}\text { Determines the GIS map projection and data for the project } \\
\text { Supports data transformations and development of GIS data as requested } \\
\text { Maintains the GIS database for the project } \\
\text { Makes GIS data available on the SharePoint site } \\
\text { Develops GIS-related figures for draft and final reports }\end{array}$ \\
\hline $\begin{array}{l}\text { Network Engineer } \\
\text { Administer the project } \\
\text { SharePoint web portal }\end{array}$ & $\begin{array}{l}\text { Administers all aspects of the web-based portal for file exchange } \\
\text { Manages the levels of permissions for all who can access SSHAC data } \\
\text { and information } \\
\text { Creates necessary frameworks for receiving data and information from } \\
\text { SSHAC participants } \\
\text { Sets up the web-based resource for the final PSHA report accessible to } \\
\text { the public }\end{array}$ \\
\hline $\begin{array}{l}\text { Technical Editor } \\
\text { Perform technical editing } \\
\text { and administer } \\
\text { documentation }\end{array}$ & $\begin{array}{l}\text { Creates document formats and templates for planning documents, } \\
\text { presentations, workshop reports, and INL Site-wide SSHAC Level } 3 \\
\text { report } \\
\text { Performs technical editing and document development } \\
\text { Manages reviews and releases through Laboratory Review System } \\
\text { process } \\
\text { Produces the final INL Site-wide SSHAC Level } 3 \text { report as documents for } \\
\text { online or web-site access }\end{array}$ \\
\hline $\begin{array}{l}\text { Graphic Designer } \\
\text { Provide graphic support to } \\
\text { the Technical Editor }\end{array}$ & $\begin{array}{l}\text { Develops a banner that appears on documents, slides, and other materials } \\
\text { for the SSHAC project } \\
\text { Produces graphics for the draft and final INL Site-wide SSHAC Level } 3 \\
\text { reports }\end{array}$ \\
\hline
\end{tabular}




\subsection{SSHAC Participants}

The PTI, TI teams, hazard analysts, and database manager have responsibilities to perform the technical tasks (Section 4) under the work-flow process in Figure 3 to complete the evaluation, integration, and documentation processes of the SSHAC study. The PTI has overall responsibility for managing and coordinating all SSHAC participants. The TI teams are divided into the SSC and GMC teams each with a TI lead. TI leads have added responsibilities for inviting resource and proponent experts to the workshops and leading development of the SSC and GMC models among others. TI leads and team members work with specialty contractors who assist them with data collection or analyses as needed. Table 3 lists the responsibilities for each SSHAC participant and the following lists their respective primary roles.

- The PTI has the primary role that is complementary to that of the PM and includes being the technical lead and spokesperson for the technical products of the INL SSHAC Level 3 study

- The hazard analyst has the primary role of performing all PSHA computations using the SSC and GMC model inputs, including the exploratory sensitivity analyses, preliminary hazard calculations and sensitivity analyses, and final hazard computations under the QA requirements (Section 4.4)

- The database manager has the primary role of compiling, maintaining, and disseminating data, methods, and models that are to be evaluated by the TI teams

- The TI lead has the primary role of leading the TI team to develop the SSC or GMC model and to ensure that it captures the CBR of TDI

- TI team members have the primary role of performing the evaluation (Section 4.2) and integration (Section 4.3) processes to develop SSC or GMC models, and documentation (Section 4.5) process to develop the INL Site-wide SSHAC Level 3 report

- The specialty contractor has the primary role of assisting TI team members with data collection or analyses as requested

- A resource expert has the primary role of presenting data (including limitations, assumptions, caveats, resolution, and uncertainties) in an impartial manner without advocating a model

- A proponent expert has the primary role of advocating a specific model, method, or parameter that is deemed to be relevant and credible for the hazard analysis. 
Table 3. Roles and responsibilities of SSHAC participants and the PPRP.

\begin{tabular}{|c|c|}
\hline Title and Primary Role & Responsibilities \\
\hline $\begin{array}{l}\text { Project Technical Integrator } \\
\text { Provide overall technical } \\
\text { coordination of INL Site-wide } \\
\text { SSHAC Level } 3 \text { PSHA }\end{array}$ & $\begin{array}{l}\text { Coordinates all technical activities and production of the final PSHA } \\
\text { report } \\
\text { Presents technical products to the sponsor and to the regulator } \\
\text { Attends briefings with the sponsor as requested } \\
\text { Ensures project deliverables satisfy the requirements of the sponsor and } \\
\text { the regulatory body that will assess the hazard study } \\
\text { Assists with selection of suitable candidates for TI leads, TI team } \\
\text { members, and hazard analyst } \\
\text { Coordinates the work of the database manager and hazard analyst } \\
\text { Liaises closely with TI leads to identify and resolve model-interface } \\
\text { issues } \\
\text { Ensures adequate time is made available for the preparation, execution, } \\
\text { checking, and reporting of the hazard calculations } \\
\text { Also has authority to perform the role of either SSC or GMC TI lead }\end{array}$ \\
\hline $\begin{array}{l}\text { Hazard Analysts } \\
\text { Perform all PSHA } \\
\text { computations using the SSC } \\
\text { and GMC model inputs }\end{array}$ & $\begin{array}{l}\text { Perform hazard calculations for the INL sites as assigned (Table 1) } \\
\text { Inform the PTI and PM of the time periods needed for computations } \\
\text { Inform TI teams of any limitations or input requirements specific to the } \\
\text { hazard-calculation code being used } \\
\text { Query the TI teams to understand the way that SSC and GMC models } \\
\text { are specified for the PSHA in the Hazard Input Documents (HIDs) } \\
\text { Perform all PSHA calculations requested by TI teams } \\
\text { Perform sensitivity analyses for Workshop } 1 \\
\text { Perform PSHA calculations using preliminary SSC and GMC models for } \\
\text { presentation at Workshop } 3 \\
\text { Perform final PSHA calculations that are documented in the final project } \\
\text { report } \\
\text { Resolve any issues that may arise pertaining to hazard calculations } \\
\text { Perform all QA requirements to support the final hazard calculations }\end{array}$ \\
\hline $\begin{array}{l}\text { Database Manager } \\
\text { Compile, maintain, and } \\
\text { distribute all project data and } \\
\text { information }\end{array}$ & $\begin{array}{l}\text { Compiles and maintains all relevant data, models, and methods to be } \\
\text { evaluated by the TI teams } \\
\text { Arranges for scanning from paper to electronic media as needed } \\
\text { Adds all project documents to the database } \\
\text { Provides SSHAC participants access to database for uploading and } \\
\text { retrieving data } \\
\text { Informs SSHAC participants of new data added to the database } \\
\text { Maintains a secure web-based portal for file exchange and access to } \\
\text { project data and information } \\
\text { Organizes and catalogs information } \\
\text { Provides secure backups }\end{array}$ \\
\hline
\end{tabular}




\begin{tabular}{|c|c|}
\hline Title and Primary Role & Responsibilities \\
\hline $\begin{array}{l}\text { Technical Integration Lead } \\
\text { Lead the TI team to develop } \\
\text { the SSC or GMC model that } \\
\text { captures the CBR of the TDI }\end{array}$ & $\begin{array}{l}\text { Ensures timely delivery of an SSC or GMC model that captures the CBR } \\
\text { of the TDI } \\
\text { Ensures the TI team, collectively and individually, assumes full } \\
\text { intellectual ownership of the final model } \\
\text { Ensures all members of the TI team are made aware of the potential for } \\
\text { cognitive and motivational bias and are informed when biases may be } \\
\text { influencing their assessments } \\
\text { Instructs any members of the TI team who are not fully conversant with } \\
\text { the concepts of aleatory variability and epistemic uncertainty and their } \\
\text { application to PSHA } \\
\text { Supports PTI in presenting technical products to the sponsor and to the } \\
\text { regulator } \\
\text { Works with their TI teams to identify suitable resource and proponent } \\
\text { experts and provide clear instructions of the scope for their participation } \\
\text { at the appropriate workshop } \\
\text { Facilitates workshop sessions to ensure that all participants clearly } \\
\text { understand the workshop objectives, their individual roles, required } \\
\text { output from the workshops, and implications of the issues under } \\
\text { discussion for the seismic hazard analysis } \\
\text { Convenes and facilitates formal working meetings (Section 4) with the } \\
\text { TI team during the course of the study } \\
\text { Ensures all TI team members have full access to the available data and } \\
\text { information needed to construct their models } \\
\text { Ensures documentation of the SSC or GMC model is complete and } \\
\text { comprehensive } \\
\text { Ensures SSC or GMC evaluations, uploaded to SharePoint, are } \\
\text { technically checked (see Appendix A for upload forms and their usage) } \\
\text { Remains vigilant of TI team members' productivity and objectivity; } \\
\text { takes appropriate actions if any are delinquent } \\
\text { Works with the PTI to maintain communication with the other TI lead } \\
\text { regarding interface issues of importance }\end{array}$ \\
\hline
\end{tabular}




\begin{tabular}{|c|c|}
\hline Title and Primary Role & Responsibilities \\
\hline $\begin{array}{l}\text { TI Team Members } \\
\text { Perform Evaluation and } \\
\text { Integration processes to } \\
\text { develop SSC or GMC models }\end{array}$ & $\begin{array}{l}\text { As evaluator experts, objectively identify existing data, models, and } \\
\text { methods and objectively evaluate these in terms of their general quality, } \\
\text { reliability, and their specific applicability to the assessments being made } \\
\text { Develop the SSC and GMC databases using the upload forms as } \\
\text { discussed in Appendix A to document the evaluations } \\
\text { Evaluate data and diverse models, challenge their technical bases and } \\
\text { underlying assumptions, and, where possible, test the models against } \\
\text { observations } \\
\text { As part of their evaluation responsibility, interact with resource and } \\
\text { proponent experts at workshops } \\
\text { As an integrator expert, construct SSC and GMC models } \\
\text { Present clear technical justifications and rationales for choices, both in } \\
\text { terms of selected models and the weights assigned to them } \\
\text { Provide documented justification for excluding any particular model that } \\
\text { exists within the technical community } \\
\text { Interact openly and constructively with the other members of the TI } \\
\text { team } \\
\text { Assume intellectual ownership for the final SSC and GMC models, } \\
\text { individually and collectively } \\
\text { Review specialty contractor analysis or data collection prior to upload to } \\
\text { the SharePoint website } \\
\text { Contribute documentation to the draft and final INL Site-wide SSHAC } \\
\text { Level } 3 \text { reports (Section } 4.5 \text { ) } \\
\text { Declare intent to the other TI team members when temporarily assuming } \\
\text { the role of a resource or proponent expert }\end{array}$ \\
\hline $\begin{array}{l}\text { Specialty Contractor } \\
\text { Assist TI team members with } \\
\text { data collection or analyses }\end{array}$ & $\begin{array}{l}\text { Compiles or conducts data collection to inform TI teams during the } \\
\text { evaluation process } \\
\text { Performs analyses of data as requested by the TI team } \\
\text { Delivers clear and complete documentation of the work performed, } \\
\text { including provision of any numerical data or results in appropriate } \\
\text { format } \\
\text { If invited, presents results at a workshop in the role of a resource expert }\end{array}$ \\
\hline $\begin{array}{l}\text { Resource Expert } \\
\text { Present data in an impartial } \\
\text { manner to the TI team }\end{array}$ & $\begin{array}{l}\text { Is invited to present data, methods, or models in an impartial manner at } \\
\text { Workshop } 1 \text { or } 2 \text { or in formal working meetings of the TI team } \\
\text { Presents expert understanding of a particular data set, including how the } \\
\text { data were obtained with full disclosure of uncertainties, caveats, } \\
\text { assumptions, and limitations } \\
\text { Responds candidly and impartially to TI team questions } \\
\text { Assumes full responsibility for the material presented and avoid } \\
\text { ownership of the hazard models }\end{array}$ \\
\hline
\end{tabular}




\begin{tabular}{|c|c|}
\hline Title and Primary Role & Responsibilities \\
\hline $\begin{array}{l}\text { Proponent Expert } \\
\text { Advocate for a model to the TI } \\
\text { team }\end{array}$ & $\begin{array}{l}\text { At Workshop 2, advocates for a specific model, method, or parameter } \\
\text { that is deemed to be relevant and credible for the hazard analysis } \\
\text { Promotes adoption of a model as input to the hazard calculations based } \\
\text { on justifying the assertion, demonstrating the technical basis, and } \\
\text { defending the model } \\
\text { Presents the expert's own model, other researchers' published models } \\
\text { (which may be widely known or controversial), or new models not yet } \\
\text { published } \\
\text { Presents the benefits and limitations of the model, including all } \\
\text { underlying assumptions } \\
\text { Assumes full responsibility for the material presented } \\
\text { Avoids participating in any way with the TI team to weight alternative } \\
\text { hypotheses }\end{array}$ \\
\hline $\begin{array}{l}\text { Participatory Peer Review } \\
\text { Panel Chair } \\
\text { Lead PPRP members and } \\
\text { perform technical and process } \\
\text { reviews }\end{array}$ & $\begin{array}{l}\text { Establishes review acceptance criteria } \\
\text { Coordinates the work of the PPRP members } \\
\text { Ensures the PPRP remains independent and impartial during assessments } \\
\text { of the adherence to SSHAC principles and the technical evaluation and } \\
\text { integration processes } \\
\text { Participates as a PPRP member } \\
\text { Ensures that any technical or process deficiencies are identified at the } \\
\text { earliest possible stage so that they can be corrected } \\
\text { PPRP members review and comment on preliminary lists of Resource } \\
\text { and Proponent Experts } \\
\text { Provides feedback through perspectives and advice regarding the manner } \\
\text { in which ongoing activities can be improved or carried out more } \\
\text { effectively } \\
\text { Reviews the draft INL Site-wide SSHAC Level } 3 \text { report and provides } \\
\text { documentation of comments to the PM } \\
\text { Issues the PPRP closure letter documenting determinations of adherence } \\
\text { to the SSHAC process and acceptability of the products } \\
\text { Completes reviews and documentation of reviews as specified on the } \\
\text { Participatory Peer Review Checklist (Section 6) }\end{array}$ \\
\hline
\end{tabular}




\begin{tabular}{|l|l|}
\hline \multicolumn{1}{|c|}{ Title and Primary Role } & \multicolumn{1}{c|}{ Responsibilities } \\
\hline \multirow{5}{*}{$\begin{array}{l}\text { Establish review acceptance criteria } \\
\text { Advise how activities can be improved or carried out more effectively } \\
\text { Provide clear and timely feedback to ensure corrections of technical or } \\
\text { process deficiencies } \\
\text { Perform technical and process } \\
\text { reviews }\end{array}$} & $\begin{array}{l}\text { Enshlight any data, models, or proponents that have not been considered } \\
\text { Ensull range of data, models, and methods have been duly } \\
\text { Ensure models developed in the PSHA capture the CBR of TDI } \\
\text { Ensure all technical decisions are adequately justified and documented } \\
\text { Ensure the project conforms to a SSHAC Level 3 study } \\
\text { Review the draft INL Site-wide SSHAC Level 3 report and provide } \\
\text { documentation of comments } \\
\text { Review the final INL Site-wide SSHAC Level 3 report and responses to } \\
\text { comments by the TI team on the draft report } \\
\text { Contribute to the PPRP closure letter documenting determinations of } \\
\text { adherence to the SSHAC process and acceptability of the products } \\
\text { Complete reviews as specified on the Participatory Peer Review } \\
\text { Checklist (Section 6) }\end{array}$ \\
\hline
\end{tabular}

\subsection{Participatory Peer Review Panel}

The PPRP has key roles and responsibilities that are an indispensable element of a SSHAC Level 3 study. Collectively, the PPRP's primary role is oversight of the technical and process tasks to ensure acceptance of the final PSHA products (Table 3). The PPRP is charged with ensuring that the full range of data, models, and methods has been duly considered in the assessment; that the SSC and GMC models developed capture CBR of TDI; and that all technical decisions are adequately justified and documented. The PPRP is also charged with performing the process review, which means ensuring that the INL Sitewide SSHAC Level 3 study conforms to the requirements of the SSHAC process for a Level 3 study. Collectively, these two oversight roles assure that evaluation and integration are performed appropriately. The PPRP documents their determinations of technical and process reviews in the PPRP closure letter, which is issued after reviewing the draft report and receiving the final report with PPRP comments adequately addressed. Table 3 lists the primary roles and responsibilities for the PPRP chair and members. Since the PPRP is responsible for assuring that the INL Site-wide SSHAC Level 3 study conforms to the requirements of a SSHAC Level 3 process, there is a particular onus on the PPRP Chair to ensure that all members of the Panel are conversant with the SSHAC guidelines and that all PPRP feedback is consistent with the PPRP's technical and process review. Section 6 discusses review criteria, tasks, documentation, and deliverables by which the PPRP will engage with the INL SSHAC Level 3 study.

\subsection{Communication Interfaces}

The organizational structure of the SSHAC participants shown in Figure 4 is supported by communication interface responsibilities identified in Table 4. Each SSHAC participant has responsibilities for communicating with other participants. To ensure that the SSHAC work-flow process shown in Figure 3 is implemented, the following highlight some of the key interface responsibilities:

- $\quad$ PM and PTI communicate with each other and with DOE on a regular basis 
- PPRP chair communicates with the PM to provide timely feedback to the PTI and TI teams

- QE communicates QA requirements and deficiencies to the PM and PTI

- $\quad$ PTI directs work of the hazard analysts, database manager, and TI teams

- Database manager alerts TI teams to new data in the database

- Hazard analysts communicate model issues with TI teams and time constraints to the PTI for computing hazard results

- TI leads dialog with resource and proponent experts on their roles and responsibilities for attending workshops.

Table 4. SSHAC participant communication interface responsibilities.

\begin{tabular}{|c|c|}
\hline Participant & Project Interface Responsibilities \\
\hline $\begin{array}{l}\text { Project Sponsor } \\
\text { (DOE) }\end{array}$ & $\begin{array}{l}\text { Concurs with appointments for PPRP chair, PPRP members, PM, PTI } \\
\text { Invites regulator observers to attend the kickoff meeting and workshops }\end{array}$ \\
\hline Regulator Observers & $\begin{array}{l}\text { Observe workshops and meetings to which invited } \\
\text { Communicate only with sponsor or DOE }\end{array}$ \\
\hline Project Manager & $\begin{array}{l}\text { Provides regular status to the PM and support PM interactions with DOE } \\
\text { Serves as point of contact for communications between PPRP and PTI } \\
\text { Communicates project work directly with the PTI and support PTI } \\
\text { interactions with the TI Leads } \\
\text { Directs work of Management Support Team members and database } \\
\text { manager } \\
\text { Transmits final report and associated electronic files to DOE }\end{array}$ \\
\hline $\begin{array}{l}\text { Administrative } \\
\text { Professional }\end{array}$ & $\begin{array}{l}\text { Communicates meeting venue, logistics, and schedules to PTI and TI leads, } \\
\text { and other SSHAC participants } \\
\text { Communicates with resource and proponent experts to address travel } \\
\text { related issues }\end{array}$ \\
\hline Quality Engineer & $\begin{array}{l}\text { Communicates and engages in assessments with PM and PTI regarding QA } \\
\text { requirements } \\
\text { Informs the PM and PTI of deficiencies and corrective actions }\end{array}$ \\
\hline $\begin{array}{l}\text { Procurement } \\
\text { Specialist }\end{array}$ & $\begin{array}{l}\text { Keeps the PM informed of any contractual issues and resolutions } \\
\text { Communicates with SSHAC participants, resource experts, proponent } \\
\text { experts and specialty contractors regarding subcontracts }\end{array}$ \\
\hline Network Engineer & $\begin{array}{l}\text { Dialogs with the database manager, PTI, and PM regarding administration } \\
\text { issues and resolutions of the SharePoint web portal } \\
\text { Disseminates the project database through the SharePoint web portal }\end{array}$ \\
\hline GIS Specialist & $\begin{array}{l}\text { Transmits GIS products to the project database, PTI, TI teams, and } \\
\text { technical editor }\end{array}$ \\
\hline
\end{tabular}




\begin{tabular}{|c|c|}
\hline Participant & Project Interface Responsibilities \\
\hline Technical Editor & $\begin{array}{l}\text { Transmits templates and formatting conventions for reports to PTI and TI } \\
\text { Leads } \\
\text { Disseminates draft and final documents to the PTI and PM } \\
\text { Instructs the graphic designer and GIS specialist on needs for images for } \\
\text { draft and final reports }\end{array}$ \\
\hline PPRP Chair & $\begin{array}{l}\text { Communicates feedback and recommendations directly to the PM for the } \\
\text { PTI and TI teams } \\
\text { Organizes work of the PPRP members and reconciles divergent views } \\
\text { among members of the Panel so that a consensus view can be conveyed } \\
\text { Transmits official closure letter of concurrence to the PM }\end{array}$ \\
\hline PPRP Members & $\begin{array}{l}\text { Communicates feedback and recommendations to the PM through the } \\
\text { PPRP chair } \\
\text { Individual members observe formal working meetings }\end{array}$ \\
\hline $\begin{array}{l}\text { Project Technical } \\
\text { Integrator }\end{array}$ & $\begin{array}{l}\text { Directs work of the hazard analyst } \\
\text { Communicates project work directly with PM, TI leads, QE, and database } \\
\text { manager } \\
\text { Provides regular status of the study to DOE and PM }\end{array}$ \\
\hline Hazard Analyst & $\begin{array}{l}\text { Communicates directly with PTI, TI leads and TI team members } \\
\text { Communicates with QE through notifications to the PTI and PM to correct } \\
\text { deficiencies or resolve QA issues }\end{array}$ \\
\hline Database Manager & $\begin{array}{l}\text { Provides electronic communications to distribute, store, access, and } \\
\text { organize data, information, and all project files } \\
\text { Alerts TI team members of new data in the database } \\
\text { Communicates with the GIS specialists on the needs for GIS products } \\
\text { Communicates with the network engineer on the needs for SharePoint } \\
\text { framework to house and disseminate data for the SSHAC participants }\end{array}$ \\
\hline $\begin{array}{l}\text { Technical Integration } \\
\text { Team Lead }\end{array}$ & $\begin{array}{l}\text { Communicates directly with their respective SSC or GMC TI teams and } \\
\text { with the other TI lead } \\
\text { Communicates with and directs objectives of resource and proponent } \\
\text { experts } \\
\text { Communicates directly with the database manager and specialty contractors }\end{array}$ \\
\hline $\begin{array}{l}\text { Technical Integration } \\
\text { Team Member }\end{array}$ & $\begin{array}{l}\text { Communicates directly with appropriate SSC or GMC TI leads and other TI } \\
\text { team members } \\
\text { Interacts with resource and proponent experts } \\
\text { Communicates with database manager and specialty contractors }\end{array}$ \\
\hline Specialty Contractor & $\begin{array}{l}\text { Communicates with TI Leads and TI team members } \\
\text { Engages with Management Support Team and database manager }\end{array}$ \\
\hline
\end{tabular}




\begin{tabular}{|c|l|}
\hline \multicolumn{1}{|c|}{ Participant } & \multicolumn{1}{c|}{ Project Interface Responsibilities } \\
\hline Resource Expert & $\begin{array}{l}\text { Dialogs with TI leads } \\
\text { Interacts with TI team members } \\
\text { Engages with procurement specialist, administrative professional, and } \\
\text { database manager }\end{array}$ \\
\hline Proponent Expert & $\begin{array}{l}\text { Dialogs with TI leads } \\
\text { Interacts with TI team members } \\
\text { Engages with procurement specialist, administrative professional, and } \\
\text { database manager }\end{array}$ \\
\hline
\end{tabular}




\section{KEY TASKS AND ACTIVITIES}

The key tasks and activities are categorized in this section under subheadings of Evaluation, Integration, Final Hazard, and Documentation. Each category discusses the tasks to be performed and identifies the performers of those tasks. The tasks are categorized in this manner to perform work per nonnuclear and nuclear QA requirements. Work performed for evaluation, integration and documentation will fall under QA requirements for non-nuclear applications and will adhere to the QA guidance in NUREG-2213 (NRC 2018). Since the results of the final PSHA computations will be used in design or safety assessments or both for nuclear facilities, a greater level of rigor is applied with regard to software, model development and PSHA calculations to meet NQA-1 safety software requirements (Section 1.3).

\subsection{Study Initiation}

The INL Site-wide SSHAC Level 3 study will be initiated by BEA under the INL SSHAC L3 Project. Prior planning and scoping were completed for initiation of the project involving development of the draft work plan, QA plan, SharePoint site framework, budget, and preliminary schedule. Initiation of the study includes the following tasks and will be performed by participants listed in the parentheses:

- Complete and issue the QA plan (QE and technical editor)

- Complete and issue SSHAC Level 3 work plan (PM, PTI, TI leads, QE, and technical editor)

- Review the SSHAC work plan for classification and external release (technical editor)

- Procure SSHAC participants and PPRP (PM, procurement specialists, and QE)

- Set up SharePoint web portal and add INL SSHAC Level 1 study files (network engineer)

- Provide all project participants with the INL Site-wide SSHAC Level 3 work plan (PM and PTI).

\subsection{Evaluation}

The SSHAC participants will complete Tasks 1 to 11 (from Table 5) to achieve the objective of the SSHAC evaluation process and to complete steps of the SSHAC work flow shown in Figure 3. Specifically, available data, models, and methods are to be compiled and evaluated in an objective and impartial manner to determine their relevance for characterizing the seismic hazard at each INL site and for each site condition. The available body of knowledge will be supplemented by new data collection, collected outside of the SSHAC Level 3 Project and based on previous studies and licensing needs:

- Seismic velocities in up to eight boreholes at MFC (2), CFPP (2), NRF (2), and ATR (1), and possibly at INTEC (1)

- Geomorphic investigations on the southernmost fault segment of the Beaverhead fault to determine its most recent offset and whether future paleoseismic studies are necessary (i.e., fault trenching)

- Airborne LiDAR to produce $1 \mathrm{~m}$ digital elevation map (DEM) of INL, volcanic features outside and along the southern INL border, and southern two fault segments of the Lost River, Lemhi, and Beaverhead faults closest to INL

- New (yet to be identified) data collection for CFPP COLA.

Tasks for the evaluation process include database development (see Appendix A), compiling the earthquake catalog, gathering dynamic site characterization, assessing hazard-significant issues, performing the kickoff and two working meetings, and conducting Workshops 1 and 2 . The 11 tasks listed in Table 5 are presented first, followed by sections that discuss aspects of several tasks.

Work performed by the SSC and GMC TI teams will involve compilations and evaluations of data, calculations, and computer programs that will be used to inform development of SSC and GMC models which may or may not be used in the final PSHA. For those evaluations, calculations, and use of 
computer programs that support final SSC and GMC models and are therefore used in the final PSHA, additional documentation shall be provided. Sufficient documentation is needed for reviewers to understand the analysis in context, as well as provide for a complete QA record. The reviews and documentation to support SSC and GMC final models shall involve the following:

- Performers

- Develop and document the technical justifications for inputs, approaches, methods, and computations with enough detail that the SSHAC Level 3 PSHA could be reproduced by a peer and can stand alone. This documentation shall be included in the draft and final reports as discussed in Section 4.5.

- Clearly identify assumptions when used in a technical justification of an SSC or GMC model. This documentation shall be included in the draft and final reports as discussed in Section 4.5.

- Provide a brief summary of the basis (or reference thereto) to use the supporting application of the computer program to the specific problem.

- Identify the calculations and any computer programs used, including:

- Name or a short description of calculations

- Computer program name and version, or short description of program code

- Purpose for using the code and how the code works.

- Provide inputs and outputs used in the code.

- Identify or discuss the method used to demonstrate that the calculations are correct for the application. Possible methods can include one or more of the following that apply:

- Logs of intermediate outputs from programs as they are running

- Plots of outputs and use of professional judgement

- Statistical modeling of data using built in modules such as linear regression or robust regression to develop correlations between various types of data

- Calculations using Microsoft (MS) Excel, MatLab, R, and other commercially available or open-source software using common inputs to produce program test case outputs for programming languages (i.e., FORTRAN codes)

- Checking of MatLab, MS Excel, or spreadsheet type software can be accomplished by periodic random hand calculation checks, as long as they are included as part of the documentation.

- Indicate that the outputs are correct per the chosen method.

- Provide the results of the code and where results of the code are used in final SSC or GMC models.

- Technical Checker

- A participant of the SSHAC Level 3 Study who did not perform the work will perform the checking of calculations used in the evaluation of data methods and models. Checking of technical correctness applies to any calculations used to develop input to the final PSHA; calculations of parameters, models, and uncertainties; the SSC and GMC Hazard Input Document (HID); and technical justifications of models, parameters, methods, and approaches. Technical checker will use and evaluate any of the following that apply:

- Validity of assumptions, if stated

- Technical approach or method used

- References used 
- Performing alternative calculations

- Consistency with the technical guidance in the SSHAC Level 3 study (i.e., NUREG-2213)

- Results produced as consistent with alternative methods used elsewhere

- Comments or errors noted by the checker are addressed by the performer.

- Document the checking process (ex. hand calculations), name of the checker, and the date checking was performed.

- Documentation of checking shall be documented in SSC and GMC evaluations, reports of analyses included as appendices to the draft and final reports, or in presentations for peer reviews by the PPRP during workshops or PPRP Briefing.

- Peer Review

- The performer presents SSC and GMC models with their respective technical justifications for inputs, approaches, methods, and computations with enough detail for review by the PPRP. PPRP reviews shall be performed during Workshop 3 (Section 4.3.4), at the PPRP Briefing (Section 4.3.5), or in review of the draft report (Section 4.5).

NOTE: The final hazard calculations will be done under a qualified supplier's NQA-1 program.

Table 5. Tasks to be performed by SSHAC Level 3 participants under the evaluation process.

\begin{tabular}{|c|c|c|}
\hline Task & Description of Task & Performers ${ }^{1}$ \\
\hline 1 & $\begin{array}{l}\text { New Data Collection Activities } \\
\text { - Prepare and issue subcontract to perform the Beaverhead fault- } \\
\text { reconnaissance study } \\
\text { - Incorporate new data separately collected and scheduled by other } \\
\text { INL projects (e.g., CFPP) into SSC or GMC databases as they } \\
\text { become available }\end{array}$ & $\begin{array}{l}\text { PM } \\
\text { Subcontractor } \\
\text { Procurement Specialist }\end{array}$ \\
\hline $2 \mathrm{~A}$ & $\begin{array}{l}\text { Prepare for Kickoff Meeting } \\
\text { - Schedule and arrange location, lodging, and travel logistics } \\
\text { - Work with TI teams, PPRP, and others to arrange travel } \\
\text { - Complete and transmit Kickoff meeting agenda } \\
\text { - Prepare presentations by the PTI and TI leads } \\
\text { - Prepare QA and SharePoint presentations }\end{array}$ & $\begin{array}{l}\text { PTI } \\
\text { SSC TI lead } \\
\text { GMC TI lead } \\
\text { PPRP chair } \\
\text { Database Manager } \\
\text { PM } \\
\text { QE } \\
\text { Administrative professional }\end{array}$ \\
\hline $2 \mathrm{~B}$ & $\begin{array}{l}\text { Conduct 2-day kickoff meeting (Section 4.2.1) } \\
\text { - Formal start of the INL Site-wide SSHAC Level } 3 \text { PSHA } \\
\text { - Perform QA and SharePoint indoctrination of SSHAC participants } \\
\text { - Disseminate expectations, procedures, and project work to } \\
\text { performers } \\
\text { - Plan and schedule project work } \\
\text { - Determine communication methods } \\
\text { - PPRP establishes review acceptance criteria } \\
\text { - PPRP comments on work plan review to PM } \\
\text { - Document kickoff meeting } \\
\text { - Provide meeting products to participants through SharePoint }\end{array}$ & $\begin{array}{l}\text { PTI } \\
\text { SSC TI team } \\
\text { GMC TI team } \\
\text { PPRP } \\
\text { Hazard analysts } \\
\text { Database manager } \\
\text { GIS specialist } \\
\text { PM } \\
\text { QE } \\
\text { Sponsor }\end{array}$ \\
\hline
\end{tabular}




\begin{tabular}{|c|c|c|}
\hline Task & Description of Task & Performers ${ }^{1}$ \\
\hline $3 \mathrm{~A}$ & $\begin{array}{l}\text { Develop and Disseminate the SSC Database } \\
\text { - Define the region for earthquake sources (e.g., radius of } \sim 300 \mathrm{~km} \\
\text { from INL) and any contributing distant sources (e.g., Cascadia } \\
\text { Subduction Zone) } \\
\text { - Compile relevant geological, geophysical, and seismological data } \\
\text { from existing INL databases (e.g., SSHAC Level 1 PSHA), the } \\
\text { professional literature, resources within academia, any available } \\
\text { commercial data sets, and data generated by new data collection } \\
\text { activities } \\
\text { - Compile relevant models and methods for characterizing } \\
\text { earthquake sources relevant to the SSC model } \\
\text { - Where applicable, enter data into a GIS with a common projection } \\
\text { to enable visualizations of the interactions and relations between } \\
\text { the different data sets, and include detailed metadata } \\
\text { - Compile a comprehensive bibliography of literature with electronic } \\
\text { copies and appropriate citations } \\
\text { - Compile new SSC data collected for CFPP performed by } \\
\text { UAMPS's subcontractors } \\
\text { - Provide SharePoint web-based repository support for data and } \\
\text { information until preliminary SSC models developed } \\
\text { - Objectively evaluate data, models, and methods for developing } \\
\text { SSC models and document the evaluations in SSC database } \\
\text { (Appendix A) }\end{array}$ & $\begin{array}{l}\text { PTI } \\
\text { SSC TI team } \\
\text { Specialty contractor } \\
\text { Resource expert } \\
\text { Proponent expert } \\
\text { Database manager } \\
\text { GIS specialist } \\
\text { Network engineer }\end{array}$ \\
\hline
\end{tabular}




\begin{tabular}{|c|c|c|}
\hline Task & Description of Task & Performers ${ }^{1}$ \\
\hline $3 \mathrm{~B}$ & $\begin{array}{l}\text { Develop and Disseminate the GMC Database } \\
\text { - For INL sites, compile subsurface geological, geophysical, } \\
\text { seismological, and geotechnical data from existing INL databases } \\
\text { (e.g., SSHAC Level } 1 \text { PSHA), the professional literature, resources } \\
\text { within academia and other government agencies (e.g., U.S. } \\
\text { Geological Survey), other relevant subsurface sites (e.g., Hanford), } \\
\text { and data generated by new data collection activities } \\
\text { - For the CFPP site, compile subsurface geological, geophysical, } \\
\text { seismological, and geotechnical data from new site characterization } \\
\text { - Compile relevant earthquake recorded ground motions and } \\
\text { intensity of ground shaking } \\
\text { - Compile applicable models (e.g., GMPEs) and appropriate methods } \\
\text { for adjusting ground-motion predictions to reference-rock } \\
\text { conditions, partitioning and quantification of ground-motion } \\
\text { variability, and performance of site-response analyses } \\
\text { - Where applicable, enter data into a GIS with a common projection } \\
\text { to enable visualizations of the interactions and relations between } \\
\text { the different data sets, and include detailed metadata } \\
\text { - Compile a comprehensive bibliography of literature, with } \\
\text { electronic copies and appropriate citations } \\
\text { - Provide SharePoint web-based repository support for data and } \\
\text { information until preliminary GMC models developed } \\
\text { - Objectively evaluate data, models, and methods for developing } \\
\text { GMC models and document the evaluations in the GMC database } \\
\text { (Appendix A) }\end{array}$ & $\begin{array}{l}\text { PTI } \\
\text { GMC TI team } \\
\text { Specialty contractor } \\
\text { Resource expert } \\
\text { Proponent expert } \\
\text { Database manager } \\
\text { GIS specialist } \\
\text { Network engineer }\end{array}$ \\
\hline 4 & $\begin{array}{l}\text { Develop Earthquake Catalog } \\
\text { - Write a task plan with schedule and steps to compile earthquake } \\
\text { data and complete analyses of the homogenized earthquake catalog } \\
\text { - Develop the catalog of earthquakes extending to earliest } \\
\text { documented events and to present; separate all seismic activity of } \\
\text { anthropogenic origin, such as mine blasts } \\
\text { - Include origin time, epicentral location, focal depth and magnitude } \\
\text { estimates, and estimates of the associated uncertainties in the } \\
\text { determination of these parameters } \\
\text { - Resolve elevation datum issues among catalogs for determining } \\
\text { focal depths (specified datum versus sea level) } \\
\text { - Include focal mechanisms and moment tensor centroid solutions, } \\
\text { where possible } \\
\text { - Produce a comprehensive and homogenized moment magnitude } \\
\text { (M) earthquake catalog } \\
\text { - Perform de-clustering or remove all foreshocks and aftershocks } \\
\text { - Perform analyses to assess periods of completeness for different M } \\
\text { - Provide earthquake data to database and disseminate to SSC TI } \\
\text { team }\end{array}$ & $\begin{array}{l}\text { SSC TI team member } \\
\text { Specialty contractor } \\
\text { Database manager }\end{array}$ \\
\hline
\end{tabular}




\begin{tabular}{|c|c|c|}
\hline Task & Description of Task & Performers ${ }^{1}$ \\
\hline 5 & $\begin{array}{l}\text { Dynamic Site Characterization } \\
\text { - Compile existing data and any new subsurface data for INL sites } \\
\text { (including subsurface Vs profile data, rock and soil properties, and } \\
\text { stratigraphic layering) } \\
\text { - Compile data to define the reference-rock profile to depth } \\
\text { - Evaluate data to develop the model for the dynamic amplification } \\
\text { effects at each site (including probabilistic frequency-dependent } \\
\text { non-linear amplification factors relative to the reference-rock } \\
\text { horizon profile) } \\
\text { - Analyze regional earthquake recordings to estimate ground-motion } \\
\text { model parameters (e.g., stress parameter, } \Delta \sigma \text {; kappa, } \kappa_{0} \text {; and } \\
\text { regional attenuation, Q) } \\
\text { - Compile and evaluate data to select an approach for site-response } \\
\text { calculations } \\
\text { - Develop suites of randomized shear-wave velocity ( } \mathrm{V}_{\mathrm{S}} \text { ) profiles } \\
\text { including mass density, modulus reduction and damping (MRD) } \\
\text { curves, and layer-to-layer correlation model for input site-response } \\
\text { analyses } \\
\text { - Provide all data and information to the database and disseminate to } \\
\text { the GMC TI team }\end{array}$ & $\begin{array}{l}\text { GMC TI team } \\
\text { Specialty contractor } \\
\text { Database manager }\end{array}$ \\
\hline 6 & $\begin{array}{l}\text { Assessment of Hazard-Significant Issues } \\
\text { - Evaluate the hazard-sensitivity analyses performed for the INL } \\
\text { SSHAC Level } 1 \text { PSHA } \\
\text { - Assess key drivers of the hazard based on the influence of both best } \\
\text { estimate models for each element of the SSC and GMC models and } \\
\text { associated uncertainty } \\
\text { - Identify those elements of the SSC and GMC models warranting } \\
\text { the greatest attention from the TI teams in terms of constraint and } \\
\text { uncertainty reduction through data collection and refinements in } \\
\text { modeling } \\
\text { - Identify SSC and GMC elements by evaluating other PSHA studies } \\
\text { for sites in similar tectonic settings and other recently completed } \\
\text { SSHAC Level } 3 \text { studies } \\
\text { - Perform hazard-sensitivity calculations using exploratory SSC and } \\
\text { GMC models defined by the TI teams to identify key elements of } \\
\text { the SSC and GMC models } \\
\text { - Identify SSC and GMC hazard-sensitivity analyses to be presented } \\
\text { at Workshop } 1\end{array}$ & $\begin{array}{l}\text { PTI } \\
\text { SSC TI team } \\
\text { GMC TI team } \\
\text { Hazard analysts }\end{array}$ \\
\hline
\end{tabular}




\begin{tabular}{|c|c|c|}
\hline Task & Description of Task & Performers ${ }^{1}$ \\
\hline $7 \mathrm{~A}$ & $\begin{array}{l}\text { Prepare for Workshop } 1 \\
\text { - Plan and arrange logistics of the workshop } \\
\text { - Request that the sponsor invite regulatory observers } \\
\text { - Request that CFPP present their proposed data-collection plans to } \\
\text { support the NRC COLA } \\
\text { - Identify and contact resource experts with existing data and } \\
\text { including those associated with new data collection } \\
\text { - Procure up to } 15 \text { resource experts for Workshop } 1 \\
\text { - Provide a presentation template to each resource expert with } \\
\text { instructions on content and their role as a participant } \\
\text { - Prepare draft and final agendas for each day of the workshop, SSC } \\
\text { issues ( } 2 \text { days), GMC issues ( } 2 \text { days), and SSC-GMC model } \\
\text { interfaces (1 day) } \\
\text { - PPRP review draft agenda and proposed resource expert list and } \\
\text { provide feedback } \\
\text { - Prepare presentations regarding an overview of the project, roles } \\
\text { and responsibilities of all participants attending the workshop, and } \\
\text { technical presentations (Section 4.2.6) }\end{array}$ & $\begin{array}{l}\text { PPRP } \\
\text { PTI } \\
\text { SSC TI lead } \\
\text { GMC TI lead } \\
\text { Resource experts } \\
\text { PM } \\
\text { Administrative professional } \\
\text { Procurement specialist } \\
\text { Technical editor } \\
\text { Sponsor }\end{array}$ \\
\hline $7 \mathrm{~B}$ & $\begin{array}{l}\text { Conduct Workshop } 1 \text { (5 days): Hazard-significant Issues and Data } \\
\text { Needs (Section 4.2.6) } \\
\text { - Identify SSC and GMC issues of highest significance to the PSHA } \\
\text { - Identify data and information that will be required to address those } \\
\text { issues } \\
\text { - Resource experts present data impartially without advocating } \\
\text { models } \\
\text { - Document the workshop in a report (including agendas, participant } \\
\text { list, copies of all presentations with reference lists, daily summaries } \\
\text { capturing issues and actions, PPRP consensus report of activities, } \\
\text { and TI team response to PPRP report) } \\
\text { - Add all Workshop } 1 \text { documentation to the project database } \\
\text { - CFPP presents their proposed data collection plans with schedule } \\
\text { - PPRP comments on Workshop } 1 \\
\text { - TI team responds to PPRP comments }\end{array}$ & $\begin{array}{l}\text { PPRP } \\
\text { PTI } \\
\text { SSC TI team } \\
\text { GMC TI team } \\
\text { Hazard analysts } \\
\text { Specialty contractors } \\
\text { Resource experts } \\
\text { Database manager } \\
\text { Sponsor } \\
\text { Observers } \\
\text { PM } \\
\text { Administrative professional } \\
\text { QE }\end{array}$ \\
\hline 8 & $\begin{array}{l}\text { Revise SSHAC Level } 3 \text { work plan for CFPP, if needed } \\
\text { - Revise the work plan tasks and schedule to include the CFPP data } \\
\text { collection schedule } \\
\text { - Complete and issue Revision } 1 \text { of the SSHAC Level } 3 \text { work plan } \\
\text { - Disseminate Revision } 1 \text { of SSHAC Level } 3 \text { work plan to all } \\
\text { participants } \\
\text { - Require all participants read Revision } 1 \text { as part of QA requirements }\end{array}$ & $\begin{array}{l}\text { PM } \\
\text { Technical Editor }\end{array}$ \\
\hline
\end{tabular}




\begin{tabular}{|c|c|c|}
\hline Task & Description of Task & Performers $^{1}$ \\
\hline $9 \mathrm{~A}$ & $\begin{array}{l}\text { Prepare for Working Meeting } 1 \\
\text { - Plan and arrange logistics of the meeting } \\
\text { - Prepare agenda } \\
\text { - Prepare work products to discuss at the meeting } \\
\text { - Invite PPRP participation } \\
\text { - PPRP chair selects two PPRP members to attend for SSC and GMC }\end{array}$ & $\begin{array}{l}\text { PPRP } \\
\text { PTI } \\
\text { SSC TI lead } \\
\text { GMC TI lead } \\
\text { PM } \\
\text { Administrative professional }\end{array}$ \\
\hline $9 \mathrm{~B}$ & $\begin{array}{l}\text { Conduct three-day Working Meeting } 1 \text { plus a one-day field trip } \\
\text { - Conduct one-day field trip to INL and geologic features significant } \\
\text { to SSC and GMC } \\
\text { - Discussions of work in progress and status of schedule } \\
\text { - Exchanges of views on evaluation process and actions from } \\
\text { Workshop } 1 \\
\text { - Discussions on elements of the project database with regard to } \\
\text { presentations of resource experts at Workshop } 1 \\
\text { - Discussions for how to resolve issues and technical challenges } \\
\text { - Identifying resource and proponent experts for Workshop } 2 \\
\text { - PPRP members observe and report back to PPRP chair }\end{array}$ & $\begin{array}{l}\text { PTI } \\
\text { SSC TI team } \\
\text { GMC TI team } \\
\text { PPRP members } \\
\text { Specialty contractor } \\
\text { (Earthquake Catalog) } \\
\text { PM }\end{array}$ \\
\hline $10 \mathrm{~A}$ & $\begin{array}{l}\text { Prepare for Workshop } 2 \\
\text { - Plan and arrange logistics of the workshop } \\
\text { - Request that the sponsor invite regulator observers } \\
\text { - If necessary, identify and contact resource experts not already } \\
\text { considered in Workshop } 1 \text { with existing data and including those } \\
\text { associated with new data collection (e.g., CFPP) } \\
\text { - Identify and contact proponent experts to represent alternative } \\
\text { models and methods } \\
\text { - Subcontract resource and proponent experts (up to 15) } \\
\text { - Provide a presentation template to each resource and proponent } \\
\text { expert with instructions on content and their role as a participant } \\
\text { - Prepare draft and final agendas for each day of the workshop for } \\
\text { SSC alternatives ( } 3 \text { days) and GMC alternatives ( } 3 \text { days) } \\
\text { - PPRP review draft agenda and proposed resource and proponent } \\
\text { expert lists and provide feedback } \\
\text { - Prepare presentations regarding an overview of the project, roles } \\
\text { and responsibilities of all participants attending the workshop, and } \\
\text { technical presentations (Section 4.2.7) }\end{array}$ & $\begin{array}{l}\text { PPRP } \\
\text { PTI } \\
\text { SSC TI Lead } \\
\text { GMC TI Lead } \\
\text { Proponent Experts } \\
\text { PM } \\
\text { Administrative Professional } \\
\text { Procurement Specialist } \\
\text { Tech Editor } \\
\text { Sponsor }\end{array}$ \\
\hline
\end{tabular}




\begin{tabular}{|c|c|c|}
\hline Task & Description of Task & Performers ${ }^{1}$ \\
\hline $10 \mathrm{~B}$ & $\begin{array}{l}\text { Conduct Workshop } 2 \text { ( } 6 \text { days): Alternative Models and Interpretations } \\
\text { (Section 4.2.7) } \\
\text { - Debate alternative viewpoints regarding models and methods } \\
\text { - Juxtapose proponent experts with alternative interpretations in } \\
\text { order to identify their technical bases } \\
\text { - Determine bases for SSC and GMC models covering alternatives } \\
\text { - Resource experts present data impartially without advocating } \\
\text { models and defend their interpretations } \\
\text { - Proponent experts present interpretations, models, and methods } \\
\text { - TI team members and specialty contractors may present as resource } \\
\text { or proponent experts } \\
\text { - Document the workshop in a report (including agendas, participant } \\
\text { list, copies of all presentations with reference lists, daily summaries } \\
\text { capturing issues and actions, PPRP consensus report of activities, } \\
\text { and TI team response to PPRP report) } \\
\text { - Add all Workshop } 2 \text { documentation to the project database } \\
\text { - PPRP comments on Workshop } 2 \\
\text { - TI team responds to PPRP comments }\end{array}$ & $\begin{array}{l}\text { PPRP } \\
\text { PTI } \\
\text { SSC TI team } \\
\text { GMC TI team } \\
\text { Hazard analysts } \\
\text { Specialty contractors } \\
\text { Proponent experts } \\
\text { Database manager } \\
\text { Sponsor } \\
\text { Observers } \\
\text { PM } \\
\text { Administrative professional } \\
\text { QE }\end{array}$ \\
\hline $11 \mathrm{~A}$ & $\begin{array}{l}\text { Prepare for Working Meeting } 2 \\
\text { - Plan and arrange logistics of the meeting } \\
\text { - Prepare agenda } \\
\text { - Prepare work products to discuss at the meeting } \\
\text { - Invite PPRP participation } \\
\text { - PPRP chair selects two PPRP members to attend for SSC and GMC } \\
\text { - Invite resource and proponent experts, if needed }\end{array}$ & $\begin{array}{l}\text { PPRP chair } \\
\text { PTI } \\
\text { SSC TI lead } \\
\text { GMC TI lead } \\
\text { PM } \\
\text { Administrative professional }\end{array}$ \\
\hline $11 \mathrm{~B}$ & $\begin{array}{l}\text { Conduct Three-day Working Meeting } 2 \\
\text { - Discussions of work in progress and any impacts to schedule } \\
\text { - Exchanges of views on evaluation process and actions from } \\
\text { Workshop } 2 \\
\text { - Discussions of alternative models and methods based on } \\
\text { presentations from Proponent Experts at Workshop } 2 \\
\text { - Discussions of ways to resolve issues and technical challenges } \\
\text { - Presentations by resource or proponent experts if needed after } \\
\text { - Workshop } 2 \\
\text { - Directing specialty contractors (if needed) to develop amplification } \\
\text { functions for site response }\end{array}$ & $\begin{array}{l}\text { PTI } \\
\text { SSC TI team } \\
\text { GMC TI team } \\
2 \text { PPRP members } \\
\text { Specialty contractor } \\
\text { (Earthquake Catalog) } \\
\text { PM }\end{array}$ \\
\hline
\end{tabular}

\subsubsection{Kickoff Meeting}

The kickoff meeting will be the formal start to the INL Site-wide SSHAC Level 3 PSHA study (Tasks 2A and 2B in Table 5). Two primary objectives will be achieved at this meeting: 1) dissemination of expectations, procedures, and project work to performers and 2) scheduling project work. The kickoff meeting will occur over two days. Participants at the workshop include the sponsor, PM, PTI, TI teams, hazard analysts, PPRP, and PM support (Table 5). The meeting presentations will be centered on: 
- Overview of sponsor expectations including deliverables and schedule

- Summaries of previous seismic hazard studies for INL

- Introduction to PSHA, epistemic uncertainty and logic trees

- Overview of the SSHAC process and project roles

- Overview of SSHAC Level 3 work plan followed by presentations on the SSC and GMC detailed tasks

- An overview of SSC-GMC-hazard-engineering interfaces

- Indoctrination for INL SharePoint use and QA requirements, including

○ Use of "SSC Evaluation" form to develop SSC database

- Use of "GMC Evaluation" form to develop GMC database

○ Use of "Add Checklist Item" form to track PPRP activities

- Breakout sessions to accomplish:

- Organization of TI team work, interactions, communications, and schedule

- Definition of hazard-sensitivity calculations to be performed ahead of Workshop 1

- Identification of resource experts to be invited to Workshop 1

- Organization of PPRP work; development of review acceptance criteria.

\subsubsection{Database Development and Management}

The first objective is to develop a comprehensive, uniform regional database including existing and new data for use in the SSC and GMC assessments. The database development task in Table 5 is divided between data for SSC (Task 3A) and for GMC (Task 3B), each directed and coordinated by the respective TI lead and supported by the database manager, GIS specialist, and network engineer. The second objective is to make available to the TI teams a database with available data and models that could potentially be relevant to the seismic characterization of the INL region and ten sites (Table 1).

Data for the SSHAC Level 3 PSHA will be gathered from existing databases at INL, professional literature, resources within academia (such as theses and research reports), and any commercial data sets that can be obtained, for example, from exploration activities. The complete database will comprise all of the information compiled from these sources, supplemented by new data collection activities at INL (Section 4.2).

The database will include a variety of geologic, seismologic, geophysical, and geotechnical information all in electronic format housed on an INL SharePoint site with a web-based portal (see Appendix A). It will include reports and papers, maps, geophysical data sets, in situ measurements, field notes and photographs, borehole logs, ground-motion recordings, and the earthquake catalog, among many other types of information. All of these sources of information will be structured in a manner to facilitate easy searches and allow access to specific files. The database will also house the documents produced by the TI teams during evaluation, and integration, and by the PPRP, preliminary and final HIDs, workshop reports, PPRP briefing, working meeting notes, and the draft and final INL Site-wide SSHAC Level 3 report. The database will also be structured with permissions allowing various participants to view, upload, and download data and documents, depending on their roles and responsibilities as a SSHAC participant (Section A-2, Appendix A). The database will also provide a means to exchange data and information with the CFPP.

The database will make available the SSC and GMC models, data, references, and other information compiled under the INL SSAHC Level 1 PSHA (INL 2016). The SSHAC Level 1 study produced an SSC data summary table which indexes all references and information that were included in or excluded from 
study along with the supporting justifications. Also, Appendix E of the SSHAC Level 1 study discusses models that were evaluated and excluded from consideration and the basis for that assessment.

\subsubsection{Earthquake Catalog}

The goal of Task 4 (Table 5) is to develop a uniform and up-to-date catalog of historical and instrumental earthquakes for the INL region that can be used for SSC. Consistent with modern groundmotion models, the catalog will provide moment magnitude for all events. The starting point for this work will be the 1850-2014 seismicity catalog developed for the SSHAC Level 1 PSHA (INL 2016). After the comprehensive and homogenized earthquake catalog is compiled, declustering will be performed on the catalog to remove dependent events such as foreshocks and aftershocks. The final step in preparing the earthquake catalog to be used in the derivation of recurrence relationships is the assessment of the time periods for which the catalog is considered complete at different magnitude levels. Task 4 in Table 5 lists the steps planned for developing the updated earthquake catalog.

\subsubsection{Dynamic Site Characterization}

The focus of Task 5 (Table 5) is to compile and evaluate data to develop the model for the dynamic amplification effects at the site. This will ultimately include probabilistic frequency-dependent non-linear amplification factors relative to the reference-rock horizon, and the dynamic characterization of the reference-rock horizon itself. The task also includes compilation and evaluation of data to perform siteresponse calculations.

Under the evaluation process, site-specific existing and new data will be compiled for development of the GMC model. These data are anticipated to include geologic profiles, Vs, local recordings (if available), and dynamic soil and rock properties such as modulus reduction and damping (MRD) curves or G/Gmax. The data will assist the GMC TI team in establishing the site conditions for customizing a GMM at each INL site. This task will make extensive use of the data obtained from the new data collection at MFC, NRF, and CFPP sites, as well as existing data at the other INL sites.

The $\mathrm{V}_{\mathrm{S}}$ profiles obtained from the measurements conducted will inform the definition of the reference-rock horizon and provide the $\mathrm{V}_{\mathrm{S}}$ profiles for target horizons for site-response modeling. The site-response profiles will include randomizations of the $\mathrm{V}_{\mathrm{S}}$ profile, informed by the lateral variations and any differences in the results obtained from different measurements, applied together with a suitable layer-to-layer correlation model. The profiles also require mass density, low-strain damping and MRD curves for modeling the non-linear response under higher levels of strain due to stronger input motions. The calculation of the amplification factors will account for variability in the MRD curves as well as in the $\mathrm{V}_{\mathrm{S}}$ profiles.

Analysis of the recordings obtained from regional earthquake monitoring, supplemented by additional information, will provide estimates of the high-frequency site attenuation parameter kappa, $\kappa_{0}$. The estimate of this parameter is required together with the deep $V_{S}$ profile for the reference-rock horizon to calibrate ground-motion predictions to this target elevation. The characterization of the deep reference and target profiles will also account for uncertainty in both the deep $\mathrm{V}_{\mathrm{S}}$ profile and the value of $\kappa_{0}$.

\subsubsection{Assessment of Hazard-significant Issues}

Under Task 6 (Table 5), the TI teams will focus on identifying key hazard-significant issues in terms of which elements of the SSC and GMC models are likely to exert the greatest influence on the hazard estimates at all sites and at individual sites. This assessment considers the influence to the site hazard regarding best-estimate models for both each element and the associated uncertainty. The objective is to identify those elements of the model warranting the greatest attention from the TI teams in terms of constraint and uncertainty reduction through data collection and refinements in the modeling.

The seismic hazard produced at MFC, ATR, and NRF and sensitivity analyses completed for SSHAC Level 1 PSHA provide an initial starting point for the TI teams to assess hazard-significant issues. The 
SSC model in the SSHAC Level 1 study included 11 source zones, 16 fault sources (13 regional and three local), a combined volcanic source zone, and an updated seismicity catalog (1850-2014). Additionally, the Cascadia interface source was included to evaluate contributions out to structural periods of 10 seconds. For GMC, the ground-motion model (GMM) was based on using empirical ground motions and adjusting those motions to site-specific conditions at INL. The approach used the Southwestern United States (SWUS) GMM, which provided complete characterization of median ground motions and their aleatory variability (GeoPentech 2015). The SWUS study utilized all of the available ground-motion prediction equations for extensional tectonic environments and the extensive databases of empirical ground motions compiled in both the U.S. and Europe.

Sensitivity analyses for SSHAC Level 1 PSHA were conducted using reference-rock conditions of the SWUS GMMs. Results were presented in terms of seismic-hazard curves showing the mean total hazard and contributions of multiple sources and individual sources. Disaggregation analysis identified the combination of magnitude and distance pairs that contributed most to the total seismic hazard at MFC, ATR, and NRF, and were presented as histograms calculated at the same AFE as the UHRS. Variance contribution histograms were also produced to show relative contribution to the total epistemic variance in ground motions at a given AFE introduced by each element of the seismic-hazard model logic tree (INL 2016). The SSHAC Level 1 PSHA has SSC and GMC HIDs, along with other electronic files readily available to the SSHAC Level 3 TI teams.

In addition to the SSHAC Level 1 PSHA sensitivity analyses previously conducted, the TI teams will also consider additional hazard sensitivities that can be assessed from SSHAC Level 1 model or modifications that might be made to the model to test for sensitivity. The TI teams will also use their extensive experience and knowledge of hazard to assess the significance of various technical issues.

\subsubsection{Workshop 1}

The objectives of Workshop 1 are to identify the SSC and GMC issues of highest significance to a PSHA at the five sites and to identify and discuss the data and information required to address those issues. Participants at the workshop include the PTI, TI teams, hazard analysts, database manager, resource experts, specialty contractors, sponsor, observers, PM, and PM support (administrative professional and QE). The PPRP, the sponsor, and invited others will attend as observers. Table 5 lists preparation for Workshop 1 (Task 7A) and what will be accomplished during the workshop (Task 7B).

Hazard-sensitivity studies discussed in Section 4.2.5 (Task 6 in Table 5) will be presented at Workshop 1 to assist with identifying important assessment issues in the PSHA that should be addressed with the available data. The sensitivity analyses for Workshop 1 will also be supplemented with discussions of hazard sensitivity at other sites, based on experience, and issues that have generally been shown to be important, which may not have been addressed in the INL SSHAC Level 1 PSHA.

At Workshop 1or 2, the CFPP will present their plans for new data collection. The plans and schedule for data collection may lead to a revision of the SSHAC Level 3 work plan. Following Workshop 1, the work plan would be revised and then disseminated to SSHAC participants (Table 5, Task 8).

The workshop will be held over 5 days. Days 1 and 2 will be centered on SSC issues, and Days 4 and 5 will be centered on GMC issues. Day 3 will be centered on SSC and GMC interface issues. The workshop will include the following:

- Presentations of invited resource experts presenting data, uncertainties, limitations, and caveats in an impartial manner and without advocating a model

- Presentations of existing data, new data collected, and plans data collection (e.g., CFPP)

- Discussions of data needs and how to acquire data 
- Discussions of specific components of the PSHA model and their individual impacts on hazard estimates

- Documentation of SSC and GMC issues, data needs, discussions, decisions, and path forward

- Presentations of the earthquake catalog and tectonic framework

- Discussions of SSC and GMC model-interface issues

- Presentations of SSC and GMC sensitivity analyses

- Documentation of interface issues, discussions, decisions, and path forward.

\subsubsection{Workshop 2}

The objectives of Workshop 2 are to 1) present, discuss, and debate alternative models and methods for addressing key SSC and GMC issues, 2) identify the technical bases for the alternative models and methods and to discuss the associated uncertainties, and 3) provide a basis for the subsequent development of preliminary SSC and GMC models that consider these alternative viewpoints. The workshop will also provide an opportunity to review the progress being made on the database and seismicity catalog activities and to elicit additional input, as needed, regarding these activities. Participants at the workshop include the PTI, TI teams, hazard analysts, database manager, proponent experts, specialty contractors, sponsor, observers, PM, and PM support (administrative professional and QE). The PPRP, the sponsor, and invited others will attend as observers. Table 5 lists preparation for Workshop 2 (Task 10A) and conducting the workshop (Task 10B).

The workshop will be held over 6 days. Days 1, 2, and 3 will be centered on SSC alternatives, and Days 3, 4, and 5 will be centered on GMC alternatives. The workshop will include the following:

- Presentations of invited resource experts presenting data, uncertainties, limitations, and caveats in an impartial manner and without advocating a model

- Presentations of invited proponent experts presenting interpretations, models, and methods (including any members of TI teams who take on this role)

- Presentations regarding interpretations, methods, or models from new data collected for INL SSHAC Level 3 study

- Discussions and debates of alternative viewpoints regarding key SSC and GMC issues

- Identifying technical bases for alternative hypotheses and discussing associated uncertainties, particularly the implications to SSC and GMC models for hazard analysis

- Providing technical bases for subsequent development of preliminary SSC and GMC models that consider alternative viewpoints

- Identifying any other resource or proponent experts that may need to present to the TI teams in a formal working meeting

- Reviews of progress being made on the project database regarding seismicity catalog activities and to elicit additional input, as needed.

\subsubsection{Working Meetings 1 and 2}

Working meetings over a three-day period provide a forum for TI teams to provide the status of work progress, resolve issues, and identify next steps. Working Meetings 1 and 2 will occur during the evaluation process. The PTI, TI teams, two members of the PPRP, and PM (as needed) will attend the meeting. Because the kickoff meeting will be held in January, the field trip to INL and geologic features will be held in conjunction with Working Meeting 1 . The first working meeting will include the following (Table 5, Tasks 9A and 9B): 
- Conduct one-day field trip to INL and geologic features significant to SSC and GMC

- Discussions of work in progress and status of schedule

- Exchanges of views on evaluation process and actions from Workshop 1

- Discussions on elements of the project database with regard to presentations of resource experts at Workshop 1

- Discussions for how to resolve issues and technical challenges

- Identifying resource and proponent experts for Workshop 2.

Working Meeting 2 will include (Table 5, Tasks 11A and 11B):

- Discussions of work in progress and any impacts to schedule

- Exchanges of views on evaluation process and actions from Workshop 2

- Discussions of alternative models and methods based on presentations from proponent experts at Workshop 2

- Discussions of ways to resolve issues and technical challenges

- Presentations by resource or proponent experts, if needed after Workshop 2

- Directing specialty contractors (if needed) to develop amplification functions for site-response.

\subsection{Integration}

The SSHAC participants in the INL Site-wide SSHAC Level 3 study will complete Tasks 12 to 20 (Table 6) to achieve the objective of the SSHAC integration process and to complete the associated steps in the SSHAC work flow shown in Figure 3. The objective will be for the TI teams to build SSC and GMC models by integrating the outcomes of the evaluation process. The models are to reflect both the best estimate of each element of the hazard input as well as the associated uncertainty within the current state of knowledge. The tasks for the integration process include development of preliminary and final SSC and GMC models, hazard calculations and sensitivity analyses, two working meetings, Workshop 3, and the PPRP Briefing meeting. This section presents Table 6 first and, after, a discussion of potential interface issues and discussions of several other tasks for the integration process.

Table 6. Tasks to be performed by SSHAC Level 3 participants under the integration process.

\begin{tabular}{|c|c|c|}
\hline Task & Description of Task & Performers ${ }^{1}$ \\
\hline $12 \mathrm{~A}$ & $\begin{array}{l}\text { Prepare for Working Meeting } 3 \\
\text { - Plan and arrange logistics of the meeting } \\
\text { - Prepare agenda } \\
\text { - Prepare work products to discuss at the meeting } \\
\text { - Invite PPRP participation } \\
\text { - PPRP chair selects two PPRP members to attend for SSC and } \\
\text { GMC }\end{array}$ & $\begin{array}{l}\text { PPRP Chair } \\
\text { PTI } \\
\text { SSC TI Lead } \\
\text { GMC TI Lead } \\
\text { PM } \\
\text { Administrative professional }\end{array}$ \\
\hline $12 \mathrm{~B}$ & $\begin{array}{l}\text { Conduct Three-day Working Meeting } 3 \\
\text { - Transition from evaluation to integration phase } \\
\text { - Discuss development of preliminary SSC and GMC models } \\
\text { - Resolve issues } \\
\text { - PPRP members observe and report back to PPRP chair }\end{array}$ & $\begin{array}{l}\text { PTI } \\
\text { SSC TI team } \\
\text { GMC TI team } \\
2 \text { PPRP members } \\
\text { PM }\end{array}$ \\
\hline
\end{tabular}




\begin{tabular}{|c|c|c|}
\hline Task & Description of Task & Performers ${ }^{1}$ \\
\hline $13 \mathrm{~A}$ & $\begin{array}{l}\text { Develop Preliminary SSC Model } \\
\text { - Construct logic trees to present the CBR of TDI for elements of } \\
\text { the SSC model } \\
\text { - Develop the preliminary SSC model by defining potential } \\
\text { locations and characteristics (e.g., style of faulting, rupture } \\
\text { orientation) of future earthquakes along with earthquake } \\
\text { recurrence rates and models of earthquake magnitudes } \\
\text { - Identify sensitivity analyses using preliminary SSC model }\end{array}$ & $\begin{array}{l}\text { SSC TI team } \\
\text { PTI }\end{array}$ \\
\hline $13 \mathrm{~B}$ & $\begin{array}{l}\text { Develop Preliminary GMC Model } \\
\text { - Construct logic trees to present the CBR of TDI for elements of } \\
\text { the GMC model } \\
\text { - Develop the preliminary GMC model by: 1) defining predictions } \\
\text { for spectral accelerations at the reference-rock horizon in terms of } \\
\text { both medians and the associated aleatory variability; 2) } \\
\text { characterizing epistemic uncertainties in the crustal profiles and } \\
\text { shallow materials used to assess site amplification; and 3) defining } \\
\text { amplification factors for the effect target horizon profiles, which } \\
\text { also include the aleatory variability in site response } \\
\text { - Identify sensitivity analyses using preliminary GMC model }\end{array}$ & $\begin{array}{l}\text { GMC TI team } \\
\text { PTI }\end{array}$ \\
\hline 14 & $\begin{array}{l}\text { Development of Preliminary HID } \\
\text { - Include in the HID, inputs to the preliminary PSHA as defined by } \\
\text { the logic trees for SSC and GMC models that clearly } \\
\text { communicate corresponding branch weights or probability } \\
\text { distributions } \\
\text { - Develop the preliminary SSC HID without commentary or } \\
\text { justification on the model elements (SSC TI Lead) } \\
\text { - Develop the preliminary GMC HID without commentary or } \\
\text { justification on the model elements (GMC TI lead) } \\
\text { Each TI team performs reviews and acceptance of their respective } \\
\text { SSC or GMC HID } \\
\text { - PTI prepares the combined SSC and GMC preliminary HID } \\
\text { PTI transmits the combined SSC and GMC preliminary HID to } \\
\text { the hazard analyst and ensures that it is well understood }\end{array}$ & $\begin{array}{l}\text { SSC TI team } \\
\text { GMC TI team } \\
\text { PTI } \\
\text { Hazard analysts }\end{array}$ \\
\hline 15 & $\begin{array}{l}\text { Conduct Hazard Calculations and Sensitivity Analyses } \\
\text { - Hazard Analysts will use the preliminary HID to set up the input } \\
\text { for the PSHA calculations } \\
\text { - Perform PSHA computations to obtain mean and fractile hazard } \\
\text { curves at the target horizon for a wide range of AFEs, from which } \\
\text { UHRS and the GMRS will be generated } \\
\text { - Perform disaggregation of the hazard at specified frequency }(f) \text { - } \\
\text { AFE combinations } \\
\text { - Perform sensitivity analyses highlighting the influence of } \\
\text { individual logic-tree branches } \\
\text { - Provide all PSHA products to the PTI and TI teams } \\
\text { - Identify sensitivity analyses and results for presentations at } \\
\text { Workshop } 3\end{array}$ & Hazard analysts \\
\hline
\end{tabular}




\begin{tabular}{|c|c|c|}
\hline Task & Description of Task & Performers $^{1}$ \\
\hline $16 \mathrm{~A}$ & $\begin{array}{l}\text { Prepare for Workshop } 3 \\
\text { - Plan and arrange logistics of the workshop } \\
\text { - Request that the sponsor invite regulatory observers } \\
\text { - Prepare the draft and final agendas for the meeting } \\
\text { - Conduct a PPRP review of draft agenda } \\
\text { - Prepare presentations regarding an overview of the project, roles } \\
\text { and responsibilities of all participants attending the workshop, and } \\
\text { technical presentations (Section 4.3.4) }\end{array}$ & $\begin{array}{l}\text { PPRP chair } \\
\text { PTI } \\
\text { SSC TI Lead } \\
\text { GMC TI Lead } \\
\text { PM } \\
\text { Administrative professional } \\
\text { Procurement specialist } \\
\text { Technical editor } \\
\text { Sponsor }\end{array}$ \\
\hline $16 \mathrm{~B}$ & $\begin{array}{l}\text { Conduct Workshop } 3 \text { ( } 5 \text { days): Feedback on Preliminary Models and } \\
\text { Hazard Impact (Section 4.3.4) } \\
\text { - Present preliminary SSC and GMC models to PPRP } \\
\text { - Hazard analyst presents hazard calculations and sensitivity } \\
\text { analyses as specified by the TI teams } \\
\text { - Discussion of the hazard significance of various elements of the } \\
\text { SSC and GMC models } \\
\text { - Receive PPRP feedback regarding the various elements of the } \\
\text { models and the technical justification for all elements } \\
\text { - Document the workshop in a report (including agendas, } \\
\text { participant list, copies of all presentations with reference lists, } \\
\text { daily summaries capturing issues and actions, PPRP consensus } \\
\text { report of activities, and TI team response to PPRP report) } \\
\text { - Add all Workshop } 3 \text { documentation to the project database }\end{array}$ & $\begin{array}{l}\text { PPRP } \\
\text { PTI } \\
\text { SSC TI team } \\
\text { GMC TI team } \\
\text { Hazard analysts } \\
\text { Database manager } \\
\text { Sponsor } \\
\text { Observers } \\
\text { PM } \\
\text { Administrative professional } \\
\text { QE }\end{array}$ \\
\hline $17 \mathrm{~A}$ & $\begin{array}{l}\text { Development of Final SSC Model } \\
\text { - Consider PPRP feedback as appropriate in developing final } \\
\text { models } \\
\text { - Resolve any SSC model-interface issues with the GMC model } \\
\text { - Develop draft final SSC model using the final database and } \\
\text { seismicity catalog } \\
\text { - Fully characterize uncertainties using logic trees (for alternative } \\
\text { conceptual models) and probability distributions (for continuous } \\
\text { parameter distributions) }\end{array}$ & $\begin{array}{l}\text { PTI } \\
\text { SSC TI team }\end{array}$ \\
\hline $17 \mathrm{~B}$ & $\begin{array}{l}\text { Development of Final GMC Model } \\
\text { - Consider PPRP feedback as appropriate in developing final } \\
\text { models } \\
\text { - Resolve any GMC model-interface issues with the SSC model } \\
\text { - Develop draft final GMC model for: 1) predictions for spectral } \\
\text { accelerations at the reference-rock horizon, in terms of both } \\
\text { medians and the associated aleatory variability; and 2) } \\
\text { amplification factors for the effect of the overlying layers, which } \\
\text { includes aleatory variability in site response } \\
\text { - Fully characterize uncertainties using logic trees (for alternative } \\
\text { conceptual models) and probability distributions (for continuous } \\
\text { parameter distributions) } \\
\text { - Apply weights to alternative models and provide the technical } \\
\text { basis for the relative weights }\end{array}$ & $\begin{array}{l}\text { PTI } \\
\text { GMC TI team }\end{array}$ \\
\hline
\end{tabular}




\begin{tabular}{|c|c|c|}
\hline Task & Description of Task & Performers ${ }^{1}$ \\
\hline $18 \mathrm{~A}$ & $\begin{array}{l}\text { Prepare for Working Meeting } 4 \\
\text { - Plan and arrange logistics of the meeting } \\
\text { - Prepare agenda } \\
\text { - Prepare work products to discuss at the meeting } \\
\text { - Prepare QA indoctrination for NQA-1 requirements (specifically } \\
\text { safety software) on final hazard calculations } \\
\text { - Invite PPRP participation } \\
\text { - PPRP chair selects two PPRP members to attend for SSC and } \\
\text { GMC }\end{array}$ & $\begin{array}{l}\text { PPRP chair } \\
\text { PTI } \\
\text { SSC TI lead } \\
\text { GMC TI lead } \\
\text { PM } \\
\text { Administrative professional } \\
\text { QE }\end{array}$ \\
\hline $18 \mathrm{~B}$ & $\begin{array}{l}\text { Conduct Three-day Working Meeting } 4 \\
\text { - Develop final SSC and GMC models } \\
\text { - Resolve model-interface issues } \\
\text { - PPRP members observe and report back to PPRP chair }\end{array}$ & $\begin{array}{l}\text { PTI } \\
\text { SSC TI team } \\
\text { GMC TI team } \\
\text { Hazard analysts } \\
2 \text { PPRP members } \\
\text { PM }\end{array}$ \\
\hline 19 & $\begin{array}{l}\text { Development of Final HID } \\
\text { - Include in the HID, inputs to the final PSHA as defined by the } \\
\text { logic trees for SSC and GMC models that clearly communicate } \\
\text { corresponding branch weights or probability distributions } \\
\text { - Develop the final SSC HID without commentary or justification } \\
\text { on the model elements (SSC TI lead), including associated spatial } \\
\text { information such as seismic source maps } \\
\text { - Develop the final GMC HID without commentary or justification } \\
\text { on the model elements (GMC TI Lead) } \\
\text { - Each TI team performs reviews and acceptance of their respective } \\
\text { final SSC or GMC HID } \\
\text { - PTI prepares a unified SSC and GMC final HID with all } \\
\text { information required to conduct the PSHA calculations } \\
\text { - PTI transmits the unified SSC and GMC final HID to the hazard } \\
\text { analyst who performs an independent review and check } \\
\text { - Perform additional checks if modifications occur to the HID } \\
\text { following initial checks by the Hazard Analyst }\end{array}$ & $\begin{array}{l}\text { PTI } \\
\text { SSC TI team } \\
\text { GMC TI team } \\
\text { Hazard analysts }\end{array}$ \\
\hline $20 \mathrm{~A}$ & $\begin{array}{l}\text { Prepare for PPRP Briefing Meeting } \\
\text { - Plan and arrange logistics of the meeting } \\
\text { - Prepare draft and final agendas for the briefing } \\
\text { - Conduct a PPRP review of draft agenda } \\
\text { - Prepare presentations for the PPRP briefings }\end{array}$ & $\begin{array}{l}\text { PTI } \\
\text { SSC TI team } \\
\text { GMC TI team } \\
\text { Hazard Analysts } \\
\text { PPRP } \\
\text { Administrative Professional } \\
\text { PM }\end{array}$ \\
\hline
\end{tabular}




\begin{tabular}{|c|c|c|}
\hline Task & Description of Task & Performers ${ }^{1}$ \\
\hline $20 \mathrm{~B}$ & $\begin{array}{l}\text { Conduct PPRP Briefing Meeting on Final Models (4 days) } \\
\text { - Present final SSC and GMC models included in the final HID } \\
\text { - Present technical justifications supporting the final SSC and GMC } \\
\text { models } \\
\text { - PPRP questions TI teams regarding SSC and GMC final models } \\
\text { and associated technical justifications } \\
\text { - Document the meeting including which elements of the SSC and } \\
\text { GMC models require particular explanation or justification in the } \\
\text { final documentation } \\
\text { - PPRP provides feedback to PTI and TI teams } \\
\text { - TI teams receive early indications of what should be taken into } \\
\text { account in producing the draft PSHA report }\end{array}$ & $\begin{array}{l}\text { PTI } \\
\text { SSC TI team } \\
\text { GMC TI team } \\
\text { Hazard analysts } \\
\text { PPRP } \\
\text { Administrative professional } \\
\text { PM }\end{array}$ \\
\hline
\end{tabular}

\subsubsection{Model Development and Interface Issues}

The PSHA project consists of building an SSC model to represent potential future earthquakes and a GMC model to estimate distributions of spectral accelerations at the target site as a result of these earthquakes. These models will be combined in PSHA calculations to yield technical products requested by the stakeholders.

SSC model development will involve defining potential locations and characteristics (e.g., style of faulting, rupture orientation) of future earthquakes along with earthquake recurrence rates and earthquake magnitudes. Important characteristics of the SSC model that are important to the GMC model include the types of seismic sources that are included, such as subduction zone sources, crustal seismic source zones, and crustal faults. The three-dimensional geometry of sources within the seismogenic crust is needed, including the expected focal depth distribution as a function of magnitude and style of faulting. The earthquake catalog, which is developed for use by the SSC Team, will be expressed in terms of a unified moment magnitude, which is the magnitude of choice for the GMPEs. The expected styles of faulting for all sources will be assessed, given their importance to the GMC models. Early in the SSC model development process, the expected maximum magnitudes will be estimated for all source types so that the range of applicability of the GMPEs can be established to adequately cover the full range of magnitudes.

GMC model development will involve capturing site-specific ground-motion effects for each site in Table 1. A reference-rock profile will be defined and used to calculate amplification factors. The reference-rock horizon profile will determine the "interface" between the base rock ground motion model capturing the effects of crustal amplification and kappa and the site response calculations used to model the effects of the full profile at each target location on earthquake ground motions. The epistemic uncertainties in the characteristics of the two crustal profiles and in the characterization of the shallow materials used to assess site amplification will be characterized, maintaining any dependencies between the assessments of two aspects of site effects modeling. Assessment of appropriate aleatory variability (sigma) models will likely be based on global studies characterizing the components of aleatory variability. Assessment of sigma will need to take into account the partitioning between epistemic and aleatory components and the degree to which these are represented in modeling the crustal characteristics and near-surface profiles used for site amplification calculations to avoid double counting.

There are numerous interfaces between different elements of the models as well as between the INL SSHAC study and stakeholder (or end-user), as illustrated in Figure 5. The correct identification, management, and resolution of interface issues will be performed by the PTI and will cover the following: 
- Ensuring that the exact requirements of each stakeholder are established in terms of the deliverables needed from the PSHA in terms of definition of the horizontal component of motion, the target oscillator frequencies, the level of structural damping, the target horizon for which the PSHA outputs are required, and method for computing site response for compatibility with down-stream structural analyses (e.g., SSI and FIRS). These definitions then become requirements of the GMC model, and are defined in Sections 2.3 and 2.4 (see Table 1 also).

- Determining the nature of the GMPEs that will be included in the GMC model to then specify requirements for the SSC model. The SSC model will need to provide input values for all independent variables included in the GMC model (other than those related to the site characterization) or at least to provide distributions of features that allow the calculation of the required parameters.

- Defining the final configuration of the SSC model to establish requirements for the GMC model. The spatial extent of the seismic sources determines the largest distance to which the GMC model must be applicable, and similarly, the recurrence models will determine the largest magnitudes for which the GMC model will be applied. The lower bound magnitude of $\mathbf{M} 5$ adopted in the PSHA calculations (Section 2.2.1) determines the lower limit of applicability for the GMPEs. Additionally, the definition of a fault source close to the site within the SSC model may require the GMC model to include nearsource features such as hanging-wall effects (see e.g., Donahue and Abrahamson 2014). Frequent interactions between the SSC and GMC TI leads will occur to ensure that the SSC and GMC models are compatible.

- Resolving interfaces between the rock hazard definition and the relative site amplification factors from the reference rock to the target location profiles. This will be performed by the GMC TI team.

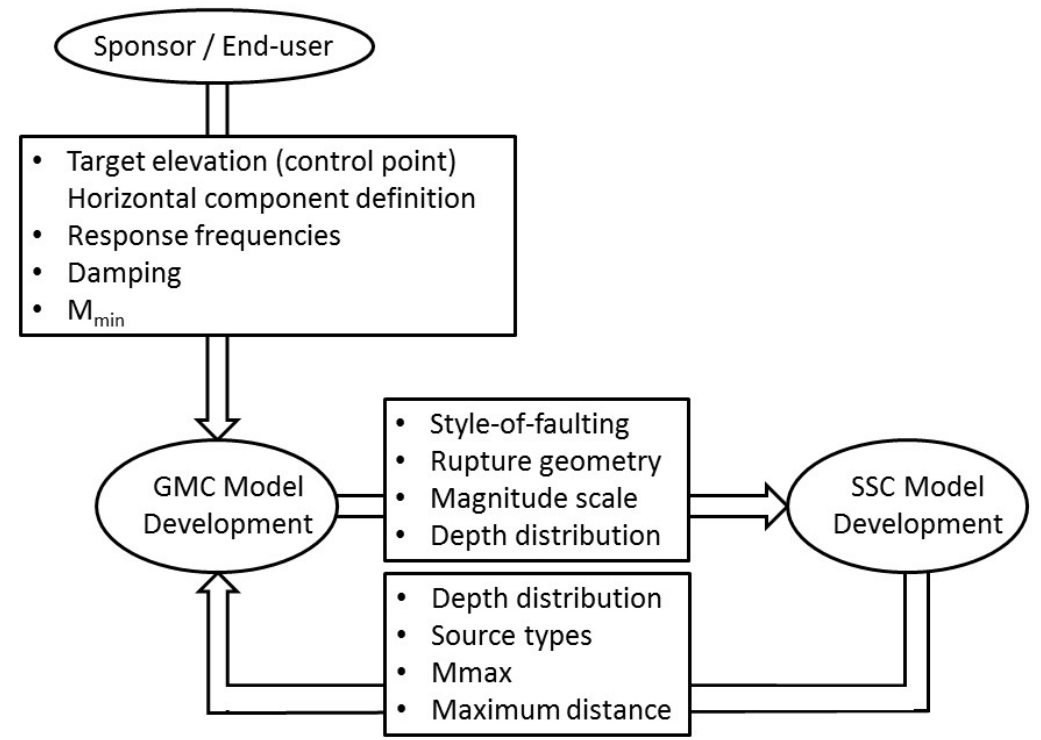

Figure 5. Diagram illustrating key interface issues in a site-specific PSHA (NRC 2017).

\subsubsection{Development of Preliminary Models and HID}

The TI teams develop preliminary SSC and GMC models that are then used to prepare preliminary HIDs for the hazard analysts. Tasks 13A and 13B (Table 6) list the steps involved in constructing logic trees to represent the CBR of TDI for all key elements of the models defining future earthquake occurrence in the region and ground-motion predictions at the site as a result of each earthquake scenario. Preliminary models are developed by the TI teams as the first attempt to capture of the CBR of TDI in terms of alternative models and parameter values. Additional insights are obtained by performing hazard- 
sensitivity calculations using the preliminary models and then receiving feedback from the PPRP in Workshop 3. The TI teams will prepare preliminary HIDs under Task 14 (Table 6), which summarize all inputs required to perform the PSHA calculations without commentary or justification of model elements. The PTI will prepare the combined HID once the TI teams accept and approve the individual HIDs, and then transmit it to the hazard analysts. Each hazard analyst will receive the HIDs for performing hazard calculations and sensitivity analyses consistent with sites listed in Table 1.

\subsubsection{Hazard Calculation and Sensitivity Analysis}

The hazard analysts will perform PSHA calculations to obtain mean and fractile hazard curves at the target horizon for a wide range of AFEs, from which UHRS and the GMRS will be generated (Task 15, Table 6). These calculations provide insights into the consequences of the SSC and GMC models in terms of site-hazard estimates and give the TI teams feedback regarding the influence of specific elements of the models. Such insights will be facilitated through disaggregation of the hazard at specified $f$-AFE combinations and through sensitivity analyses highlighting the influence of individual logic-tree branches. Displays of the results will also be generated comparing the relative influence of each of the model elements.

\subsubsection{Workshop 3}

The objective of Workshop 3 is for the TI teams to present preliminary SSC and GMC models to receive feedback in the form of hazard calculations as well as comments from the PPRP prior to developing final models. Participants at this workshop include the PPRP, PTI, TI teams, hazard analysts, PM, sponsor, and invited observers, (Tasks 16A and 16B, Table 6). The workshop will be held over 5 days. Days 1 and 2 will be centered on SSC, Days 3 and 4 on GMC, and Day 5 on sensitivity analyses, using the preliminary HID, including:

- Presenting preliminary SSC and GMC models

- Presenting justifications and technical basis for all decisions underlying the SSC and GMC models and explaining how they capture the CBR of TDI

- PPRP directly questioning TI teams regarding their presentations of models and technical bases

- Presenting hazard-sensitivity analyses

- PPRP providing feedback to TI teams through discussions of preliminary SSC and GMC models' impacts on hazard results

- PPRP directly questioning TI teams regarding preliminary SSC and GMC models and their impacts to the hazard

- Making daily summaries of key points discussed and path forward.

\subsubsection{Development of Final Hazard Models and HID}

Following Workshop 3 and reception of feedback from the PPRP (Section 4.3.5), the TI teams will construct final SSC and GMC models and prepare the final HIDs. The TI teams will use the final database and completed seismicity catalog. Uncertainties will be fully characterized using logic trees and probability distributions. Tasks 17A and 17B (Table 6) list the steps involved for the SSC and GMC final model developments, respectively. The creation of the final HIDs will follow the steps in Task 19 (Table 6). Once approved by the TI teams, the PTI will then combine the two model summaries into a unified HID. This document will summarize all of the information required to conduct the final PSHA calculations. The HID will then undergo additional review and a check by the hazard analysts prior to a briefing of the PPRP on the final models in final HID (Section 4.3.6). 


\subsubsection{PPRP Briefing Meeting}

The objective of the PPRP Briefing meeting (Tasks 20A and 20B, Table 6) is for the TI teams to present the final SSC and GMC models and respond to questions or recommendations by the PPRP. The meeting is designed to facilitate PPRP's understanding of the final SSC and GMC models prior to running the final hazard and preparing draft report documentation. Participants in this meeting include the PPRP, PTI, TI teams, hazard analysts, and PM. The meeting will be held over 4 days. Days 1 and 2 will be centered on the final SSC model and Days 3 and 4 on the final GMC model. The meeting will include:

- Presentations and explanations of final SSC and GMC models included in the final HID

- Presentations of the technical justifications supporting the final SSC and GMC models

- $\quad$ PPRP direct questioning of the TI teams regarding SSC and GMC final models and associated technical justifications.

\subsubsection{Working Meetings 3 and 4}

Working Meetings 3 and 4 provide the forum for TI teams to provide the status of work progress under the integration process, develop models, resolve model and model-interface issues, and identify next steps. The PPRP chair, PTI, TI leads, PM, and administrative professional will prepare for the meetings (Tasks 12A and 18A, Table 6). The PTI, TI teams, two members of the PPRP, and PM will attend these meetings (Tasks 12B and 18B, Table 6); the hazard analysts will only attend Work Meeting 4 to participate in QA indoctrination.

The objectives of Working Meeting 3 will include transitioning from evaluation to integration and for beginning development of preliminary SSC and GMC models. The meeting will include:

- Discussing work in progress and any impacts to schedule

- Constructing logic trees to represent the CBR of TDI for key elements of the SSC and GMC models

- Discussing or developing aspects of the preliminary SSC model defining potential locations and characteristics (e.g., style of faulting, rupture orientation) of future earthquakes along with earthquake recurrence rates and models of earthquake magnitudes

- Discussing or developing aspects of the preliminary GMC model defining: 1) predictions for spectral accelerations at the reference-rock horizon, in terms of both medians and the associated aleatory variability and 2) amplification factors for the effect of the overlying layers, which also include the aleatory variability in site response.

Working Meeting 4 objectives will include discussions for developing final models and QA indoctrination for participants to perform work under NQA-1 requirements in preparation for the final PSHA calculations. This meeting will include:

- Provide QA indoctrination for NQA-1-applicable work

- Developing final SSC and GMC models

- Resolving model-interface issues.

\subsection{Final Hazard}

In Task 21, the final HID will be used by the hazard analysts to perform the final hazard calculations, following NQA-1 procedures. Final hazard calculations will be conducted by two hazard analysts, consistent with sites listed in Table 1 and working under the direction of the PTI. The final hazard calculations will be performed to produce the technical products required for the study (Section 0). Hazard analysts will conduct final hazard calculations by performing the following steps:

- Use the final HID to set up PSHA computer codes 
- Perform final PSHA computations to obtain the technical products identified in Section 0

- Provide all PSHA products to the PTI and TI teams

- Implement all QA requirements when setting up PSHA inputs, modifying computer codes, performing computations, and producing final hazard products

- Participate in an onsite audit to demonstrate that QA requirements are being implemented during final PSHA calculations.

Calculations that are tied directly to producing the final hazard products will be subject to safety software QA requirements that are specified in the SSHAC Level 3 QA Project Plan (PLN-5753). This includes the software-installation tests, validation, and verification, as well as clear and transparent procedures to check input and output files. BEA will audit the NQA-1 program of the hazard analysts prior to beginning calculations. The development of the final HID and running the final hazard will be done under a qualified supplier's NQA-1 program. Because there are two hazard analysts, additional steps will be taken under the quality requirements prior to running final hazard. Outputs from each of the hazard analysts' codes for a common set of inputs will be used to assess and account for the inevitable differences arising from different approaches to the numerical integrations. Each hazard analyst will follow procedures under the same NQA-1 Quality Program. BEA will audit the program to ensure consistency with NQA-1 requirements.

\subsection{Documentation}

Documentation discussed in this section includes the draft and final PSHA reports and identification of all records for the INL Site-wide SSHAC Level 3 study. The INL SharePoint site, with the web-based portal, will serve as the repository (database) for all documents produced during the study, as well as the technical databases discussed in Section 4.2.2 (Appendix A). Documentation generated during key activities include agendas and presentations for all meetings conducted (kickoff, PPRP Briefing, and working meetings), workshop reports, PPRP reviews following workshops, specialty contractor reports, TI-team white papers, HIDs, draft and final INL Site-wide SSHAC Level 3 reports, and PPRP closure letter. This section first discusses Tasks 22 to 25 in Table 7 for the documentation process of SSHAC and is followed by two sections discussing generation of other documents.

In parallel with the hazard analysts' performing PSHA computations, the PTI and TI teams will prepare the draft INL Site-wide SSHAC Level 3 report with the contents listed under Task 22 in Table 7. The report will be comprehensive and include the technical justifications supporting the PSHA along with the final HID and results. The draft report will then be provided to the PPRP for their review and comment (Task 23) as outlined in Section 6. The PTI and TI teams will address the PPRP's review comments and produce the final INL Site-wide SSHAC Level 3 report (Task 24), which will then be provided back to the PPRP. The PPRP will then document their assessment of the study in the PPRP closure letter. Receipt of the closure letter that documents closure of any technical or process concerns will indicate completion of the INL Site-wide SSHAC Level 3 PSHA study (Task 25). 
Table 7. Tasks to be performed by SSHAC Level 3 participants under the documentation process.

\begin{tabular}{|c|c|c|}
\hline Task & Description of Task & Performers \\
\hline 22 & $\begin{array}{l}\text { Prepare documentation for draft INL Site-wide SSHAC Level } 3 \text { report } \\
\text { Produce documentation for the draft INL Site-wide SSHAC Level } 3 \\
\text { report that is sufficiently complete and detailed such that a third party } \\
\text { can understand and could reproduce the hazard calculations, including: } \\
\text { - Statement of the scope and objectives of the project with an } \\
\text { explanation of project organization and key tasks and activities } \\
\text { undertaken to arrive at the final PSHA results, and the QA } \\
\text { requirements and implementation } \\
\text { - Sections with regional tectonics and the geologic setting together } \\
\text { with evaluation of previous seismic hazard studies } \\
\text { - Separate sections for evaluation phase involving development of the } \\
\text { SSC and GMC databases, including data compilation activities, the } \\
\text { compilation of the earthquake catalog for the region, and site- } \\
\text { response analyses to determine amplification characteristics of the } \\
\text { sites } \\
\text { - Separate sections documenting the final SSC and GMC models, } \\
\text { including decisions made by the TI teams in the integration process } \\
\text { and supporting explanations for development of the final SSC and } \\
\text { GMC models and logic trees, providing full justification for their } \\
\text { technical bases } \\
\text { - A section that presents the PSHA calculations and final results } \\
\text { obtained in terms of hazard curves, UHRS, GMRS, and } \\
\text { disaggregation results as defined under the technical products in } \\
\text { Section 0 } \\
\text { - Comprehensive reference list } \\
\text { - Appendices as needed to include a summary of curricula vivarium } \\
\text { of key project participants, the final HID, the PPRP closure letter, } \\
\text { reports of studies, and indexes to all electronic supplementary files } \\
\text { collection, complete SSC and GMC project database, evaluation } \\
\text { tables and white papers (if applicable), workshop summary reports, } \\
\text { PPRP comments with TI team responses, and all hazard calculation } \\
\text { and result files }\end{array}$ & $\begin{array}{l}\text { PTI } \\
\text { SSC TI team } \\
\text { GMC TI team } \\
\text { Technical editor } \\
\text { GIS specialist } \\
\text { Graphic designer } \\
\text { Database manager } \\
\text { PM } \\
\text { QE }\end{array}$ \\
\hline
\end{tabular}




\begin{tabular}{|c|c|c|}
\hline Task & Description of Task & Performers \\
\hline 23 & $\begin{array}{l}\text { Review of Draft INL Site-wide SSHAC Level } 3 \text { Report by PPRP } \\
\text { - PM transmits the draft INL Site-wide SSHAC Level } 3 \text { report to the } \\
\text { PPRP } \\
\text { - PPRP reviews completeness and clarity of the draft and verifies that } \\
\text { adequate justifications are provided for all technical decisions } \\
\text { underlying the final SSC and GMC models } \\
\text { - PPRP generates comments that pertain directly to the objectives of } \\
\text { the study and contents of the final documentation } \\
\text { - PM and PPRP hold a meeting after individual PPRP members have } \\
\text { completed their reviews } \\
\text { - PPRP chair compiles review comments into a consensus document } \\
\text { from the meeting, generally classifying them into categories to assist } \\
\text { the TI teams, such as editorial comments, questions, suggestions, } \\
\text { concerns, and requirements }\end{array}$ & $\begin{array}{l}\text { PPRP } \\
\text { PM }\end{array}$ \\
\hline 24 & $\begin{array}{l}\text { Prepare Final INL Site-wide SSHAC Level } 3 \text { Report } \\
\text { - PM transmits the PPRP consensus comments on the draft INL Site- } \\
\text { wide SSHAC Level } 3 \text { report to the PTI and TI teams } \\
\text { - SSC and GMC TI team members perform revisions of the draft } \\
\text { report to produce the final INL Site-wide SSHAC Level } 3 \text { report } \\
\text { - SSC and GMC TI team members write responses to PPRP review } \\
\text { comments that explain either how comments were treated to } \\
\text { produce the final INL Site-wide SSHAC Level } 3 \text { report or, where } \\
\text { appropriate, why the final PSHA report was not modified in } \\
\text { response to the comment } \\
\text { - Both PPRP review comments and TI team responses are } \\
\text { documented in the project database } \\
\text { - SSC and GMC TI team members compile all electronic supplements } \\
\text { onto a portable medium such as a DVD }\end{array}$ & $\begin{array}{l}\text { PTI } \\
\text { SSC TI team } \\
\text { GMC TI team } \\
\text { Technical Editor } \\
\text { GIS Specialist } \\
\text { Graphic Designer } \\
\text { Database Manager } \\
\text { PM }\end{array}$ \\
\hline 25 & $\begin{array}{l}\text { Issue PPRP Closure Letter and Final INL Site-wide SSHAC Level } 3 \\
\text { Report } \\
\text { - PM transmits the final INL Site-wide SSHAC Level } 3 \text { report and TI } \\
\text { teams' responses to comments to the PPRP } \\
\text { - PPRP performs reviews of the responses to comments, and that the } \\
\text { final INL Site-wide SSHAC Level } 3 \text { report adequately addresses the } \\
\text { comments and incorporated changes as applicable } \\
\text { - PPRP members provide their concurrence of the final INL Site-wide } \\
\text { SSHAC Level } 3 \text { report and completion of the study to the PPRP } \\
\text { Chair } \\
\text { PPRP Chair writes and transmit a consensus closure letter to the PM } \\
\text { including their consensus that either the project has satisfied all } \\
\text { acceptance criteria of a SSHAC study or the project has failed to } \\
\text { meet the acceptance criteria } \\
\text { - PM and PTI meet with the sponsor to inform them of the PPRP } \\
\text { closure letter and to transmit the final INL Site-wide SSHAC Level } \\
3 \text { report and all project electronic files }\end{array}$ & $\begin{array}{l}\text { PM } \\
\text { PPRP } \\
\text { Sponsor } \\
\text { PTI }\end{array}$ \\
\hline
\end{tabular}




\subsubsection{Workshop Reports and Working Meetings}

Three workshop summary reports will be prepared to provide a complete record of contents covered and outcomes at each workshop. Presenters invited as experts will upload their presentations to a public INL SharePoint site; the database manager will then move these presentations to the INL SharePoint site for access by SSHAC participants (Appendix A). For any data presented at Workshop 1 or 2, the TI teams will request copies after the workshop or make advance arrangements to receive data at the workshop. Individuals external to the SSHAC project will also upload their data to the public INL SharePoint site. The data and any references cited in Workshop 1 or 2 presentations will be put into the project database. A workshop summary report will be prepared and include the following information.

- Final agenda for each day of the workshop.

- Full list of participants and attendees.

- Copies of all presentations in digital format, including the presenter's assigned role, a brief abstract of each presentation, full reference lists, and identification of any transmittals (if data or other information is given separately).

- Daily summaries given by PTI and TI leads that include recordings of the main discussions, decisions, actions, and other significant notations. Summaries are typically captured in an electronic document to be presented to the audience and for TI team contributions.

- PPRP consensus reports covering their observations and recommendations at Workshop 1 and 2 particularly pertaining to other available data, models, or methods that the TI teams should consider and their assessment of responses to direct questioning at Workshop 3.

- TI team's responses to the PPRP report and how concerns or recommendations have been addressed.

All working meetings - including the kickoff meeting and the PPRP Briefing — will have documentation of the contents covered at each meeting. The documentation will be considered as meeting minutes and will not be formally documented into a report but will likely be a collection of documents. Documentation of working meetings will include the following:

- Agenda of topics covered

- List of all attendees

- Copies of presentations (kickoff and PPRP Briefing only)

- Brief summary

- List of actions or other items as determined by the PTI, TI leads, and PM, and including anything that significantly impacts schedule or key tasks and activities in this work plan.

\subsubsection{Specialty Contractor Reports and White Papers}

Specialty contractors and TI team members will perform data evaluations and analyses that will be considered a study that requires documentation. The compilation of an updated earthquake catalog and evaluation of regional earthquake data to assess $\kappa$ are two study examples. Both of these studies may be performed by specialty contractors or by TI team members. The results of these studies can be documented in a standalone report or as a short white paper (which can then be an appendix to the INL Site-wide SSHAC Level 3 report). For either type of documentation, the content will include the following, as applicable to the study performed: purpose and scope; description of data, uncertainties, limitations, and sources; methods used in the evaluation or analyses; results and interpretations with stated uncertainties, caveats, limitations, and assumptions; and full reference list. White papers generated by GMC TI team members will be uploaded to the GMC database on the INL SharePoint site (Appendix A). Electronic copies of data for these studies and all references will be put into the project database. 


\section{SCHEDULE AND DELIVERABLES}

The INL Site-wide SSHAC Level 3 PSHA is scheduled to begin in October 2018 and be completed 33 months later in July 2021. Project set up and preparations for the January 2019 Kickoff meeting will begin in October 2018. The schedule in Table 8 lists all tasks by corresponding number to Table 5, Table 6, and Table 7. Dates of key milestone activities are noted in bold lettering. The deliverables from the INL Site-wide SSHAC Level 3 PSHA include:

- Technical products listed in Section 0

- Final INL Site-wide SSHAC Level 3 report, appendices, and associated electronic files

- INL SharePoint site with all documents and the project database

- QA documentation and associated electronic files.

Table 8. Schedule of tasks for INL Site-wide SSHAC Level 3 PSHA.

\begin{tabular}{|c|c|c|c|}
\hline $\begin{array}{l}\text { Task } \\
\text { No. }\end{array}$ & Task Name & Start Date & End Date \\
\hline 1 & New Data Collection Activities & $1 / 23 / 2019$ & $1 / 2 / 2020$ \\
\hline $2 \mathrm{~A}$ & Prepare for Kickoff Meeting & $11 / 30 / 2018$ & $1 / 15 / 2019$ \\
\hline 2B & Conduct Kickoff Meeting & $1 / 16 / 2019$ & 1/17/2019 \\
\hline $3 \mathrm{~A}$ & Develop and Disseminate the SSC Database & $1 / 21 / 2019$ & $1 / 24 / 2020$ \\
\hline 3B & Develop and Disseminate the GMC Database & $1 / 21 / 2019$ & $1 / 24 / 2020$ \\
\hline 4 & Develop Earthquake Catalog & $1 / 21 / 2019$ & $1 / 24 / 2020$ \\
\hline 5 & Dynamic Site Characterization & $1 / 21 / 2019$ & $8 / 9 / 2020$ \\
\hline 6 & Assessment of Hazard-Significant Issues & $1 / 21 / 2019$ & $4 / 5 / 2019$ \\
\hline $7 \mathrm{~A}$ & Prepare for Workshop 1 & $1 / 21 / 2019$ & $4 / 5 / 2019$ \\
\hline 7B & Conduct Workshop 1: Hazard-significant Issues and Data Needs & 4/8/2019 & 4/12/2019 \\
\hline 8 & Revise Work Plan (if needed) & $4 / 15 / 2019$ & $5 / 7 / 2019$ \\
\hline $9 \mathrm{~A}$ & Prepare for Working Meeting 1 & $4 / 15 / 2019$ & $6 / 7 / 2019$ \\
\hline 9B & Conduct Working Meeting 1 and attend INL field trip & 6/10/2019 & 6/13/2019 \\
\hline $10 \mathrm{~A}$ & Prepare for Workshop 2 & $6 / 17 / 2019$ & $8 / 9 / 2019$ \\
\hline 10B & Conduct Workshop 2: Alternative Models and Interpretations & 8/12/2019 & 8/17/2019 \\
\hline $11 \mathrm{~A}$ & Prepare for Working Meeting 2 & $8 / 19 / 2019$ & $10 / 18 / 2019$ \\
\hline $11 \mathrm{~B}$ & Conduct Working Meeting 2 & $10 / 21 / 2019$ & $10 / 25 / 2019$ \\
\hline $12 \mathrm{~A}$ & Prepare for Working Meeting 3 & $11 / 4 / 2019$ & $1 / 10 / 2020$ \\
\hline $12 \mathrm{~B}$ & Conduct Working Meeting 3 & $1 / 13 / 2020$ & $1 / 17 / 2020$ \\
\hline $13 \mathrm{~A}$ & Develop Preliminary SSC Model & $11 / 4 / 2019$ & $1 / 23 / 2020$ \\
\hline 13B & Develop Preliminary GMC Model & $11 / 4 / 2019$ & $1 / 23 / 2020$ \\
\hline 14 & Development of Preliminary HID & $1 / 24 / 2020$ & $2 / 24 / 2020$ \\
\hline 15 & Conduct Hazard Calculations and Sensitivity Analyses & $2 / 24 / 2020$ & $6 / 5 / 2020$ \\
\hline $16 \mathrm{~A}$ & Prepare for Workshop 3 & $1 / 25 / 2020$ & $6 / 5 / 2020$ \\
\hline 16B & $\begin{array}{l}\text { Conduct Workshop 3: Feedback on Preliminary Models and } \\
\text { Hazard Impact }\end{array}$ & $6 / 8 / 2020$ & $6 / 12 / 2020$ \\
\hline $17 \mathrm{~A}$ & Development of Final SSC Model & $6 / 15 / 2020$ & $9 / 4 / 2020$ \\
\hline
\end{tabular}




\begin{tabular}{|l|l|l|l|}
\hline $\begin{array}{l}\text { Task } \\
\text { No. }\end{array}$ & Task Name & Start Date & End Date \\
\hline 17B & Development of Final GMC Model & $6 / 15 / 2020$ & $9 / 4 / 2020$ \\
\hline 18A & Prepare for Working Meeting 4 & $6 / 15 / 2020$ & $8 / 21 / 2020$ \\
\hline 18B & Conduct Working Meeting 4 & $8 / 24 / 2020$ & $8 / 28 / 2020$ \\
\hline 19 & Development of Final HID & $9 / 7 / 2020$ & $10 / 9 / 2020$ \\
\hline 20A & Prepare for PPRP Briefing Meeting & $9 / 7 / 2020$ & $10 / 19 / 2020$ \\
\hline 20B & Conduct PPRP Briefing Meeting on Final Models & $\mathbf{1 0 / 2 0 / 2 0 2 0}$ & $\mathbf{1 0 / 2 2 / 2 0 2 0}$ \\
\hline 21 & Conduct Final Hazard Calculations & $10 / 26 / 2020$ & $3 / 12 / 2021$ \\
\hline 22 & Prepare Documentation for Draft PSHA Report & $10 / 26 / 2020$ & $3 / 12 / 2021$ \\
\hline 23 & Review of Draft PSHA Report by PPRP & $3 / 15 / 2021$ & $4 / 16 / 2012$ \\
\hline 24 & Prepare Final PSHA Report & $4 / 16 / 2021$ & $6 / 11 / 2012$ \\
\hline $\mathbf{2 5}$ & $\begin{array}{l}\text { Issue PPRP Closure Letter and Final INL Site-wide SSHAC } \\
\text { Level 3 Report }\end{array}$ & $\mathbf{6 / 1 4 / 2 0 2 1}$ & $\mathbf{7 / 9 / 2 0 2 1}$ \\
\hline
\end{tabular}




\section{PPRP REVIEW PROCESS}

The technical and process reviews undertaken by the PPRP are fundamental to the SSHAC Level 3 process. As indicated in Figure 3, the PPRP engages with the INL Site-wide SSHAC Level 3 PSHA on multiple occasions. The engagements provide opportunities to observe the implementation of the SSHAC process and the technical evolution of model development. Participation at the beginning of the study allows the PPRP to raise questions and concerns regarding technical and process issues at early stages so that they can be addressed by the TI teams prior to developing the final SSC and GMC models. The participant roles and responsibilities of the PPRP are discussed in Section 3.4 and listed in Table 3. As discussed in the next three subsections, the PPRP shall complete certain tasks to engage with key assignments and activities of the INL SSHAC study, perform their reviews using review acceptance criteria, and produce documented deliverables. All communications to and from the PPRP chair shall be with the PM.

\subsection{PPRP Tasks and Engagements with INL SSHAC Study}

The PPRP will fulfill their vital oversight role by performing several tasks that engage with the INL Site-wide SSHAC Level 3 study. The engagements and tasks of the PPRP are consistent with NUREG-2213 and are graphically shown in Figure 3. The engagements will occur at specified stages of the study to allow the PPRP to observe the SSHAC process, review technical tasks, and provide feedback as appropriate. PPRP members will attend the kickoff meeting, three workshops, and PPRP Briefing and will review the draft and final INL Site-wide SSHAC Level 3 reports. To observe progress of the TI teams, the PPRP chair will designate one or two members to attend each of the four working meetings. Also, the PPRP chair shall converse with the PM and project sponsor to identify review acceptance criteria, or any other review criteria.

The PPRP will perform the following tasks during their engagements with the INL Site-wide SSHAC Level 3 study.

- Attend the kickoff meeting and perform the following:

- Adopt and formalize the PPRP review acceptance criteria, and communicate them to the PM and TI teams (Section 6.2)

- Review the scope, purpose, objectives, and schedule in the INL Site-wide SSHAC Level 3 work plan and composition of the SSHAC participants performing work

- Review the framework for the database and approach for development

- Provide early verbal and written feedback to the PM and PTI of any potential issues

- Hold separate breakout sessions to complete PPRP tasks.

- Review agendas and participant lists for Workshops 1 and 2, closely review the list of invited proponent experts for Workshop 2, and provide feedback as appropriate

- Attend the INL field trip to be held during the first working meeting

- Attend Workshops 1 and 2 and perform the following:

- Observe the TI teams' approach to identifying data, models, and methods that exist in the technical community

- Provide verbal feedback at the end of each day to the PM and PTI

- Participate in daily closed debriefing meetings with the PM, PTI, and the TI leads

- Hold separate breakout sessions to complete PPRP tasks

- Document PPRP review comments and transmit them to the PM.

- Attend Workshop 3 and perform the following: 
- Actively engage with TI teams by questioning their assessments and technical justifications

- Directly question TI teams about preliminary SSC and GMC models with regard to capturing the CBR of TDI

- Provide verbal feedback at the end of each day to the PM and PTI

- Participate in daily closed debriefing meetings with the PM, PTI, and the TI leads

- Hold separate breakout sessions to complete PPRP tasks

- Document PPRP review comments and transmit them to the PM.

- One or more representatives of the PPRP attend each formal working meeting to review implementation of the SSHAC evaluation and integration processes and report their findings to the other panel members

- Attend the PPRP Briefing meeting and perform the following:

$\circ \quad$ Review the final HID with final SSC and GMC models

- Review technical justifications supporting final models

- Identify any technical issues that must be resolved

- Provide verbal and documented feedback to the PTI and PM

- Hold separate breakout sessions to complete PPRP tasks.

- Review the draft and final INL Site-wide SSHAC Level 3 reports

- Provide documented comments to the PM for the TI teams

- Review the final report and TI teams' responses to review comments on the draft report

- Issue the PPRP closure letter following completion and acceptance of final project report.

\subsection{Review Acceptance Criteria}

Through the engagements listed in Section 6.1, the PPRP is afforded ample opportunity to monitor SSHAC processes and perform reviews of the technical bases supporting the final SSC and GMC models and resulting hazard estimates. The PPRP shall use criteria to perform their reviews and to determine acceptance of the INL Site-wide SSHAC Level 3 study, final PSHA report, and final hazard products.

At the kickoff meeting, the PPRP will develop review acceptance criteria. The PPRP will communicate these criteria to the PM, PTI, and TI teams. The criteria used by the PPRP shall be consistent with NUREG-2213 requirements (listed below). Other criteria can be determined by the PPRP or provided by the project sponsor at a later date. At a minimum, the PPRP shall use the following review criteria from NUREG-2213:

- All relevant data, models, and methods have been identified and documented

- All elements of the model have been defined in sufficient detail

- Model elements and expressions of uncertainty (e.g., logic-tree branches and associated weights) have been sufficiently and technically justified

- The choice of the SSHAC Level has been explained

- The essential steps of the SSHAC process have been followed (i.e., checklist has been successfully completed) and documented

- The evaluation process has been sufficiently justified, including documented evidence that the data, models, and methods of the larger technical community have been considered

- The integration process has been sufficiently documented such that the CBR of the TDI are well justified. 
As part of the QA requirements, the PPRP shall use the Participatory Peer Review Checklist to monitor and document that their tasks and reviews have been completed. Attachment A to the checklist includes the review criteria developed by the PPRP (Appendix B). Tracking of checklist activities will be through use of the "Add Checklist Item" form on the INL SharePoint site (Appendix A). The checklist covers:

- Identifying and adopting formalized PPRP review acceptance criteria

- Reviewing sections of INL Site-wide SSHAC Level 3 work plan

- Reviewing the framework for the database and approach for development

- Providing review comments for each workshop

- Reviewing final HID and final SSC and GMC models

- Reviewing the final project database

- Reviewing and providing written comments on the draft PSHA report

- Reviewing the final PSHA report

- Transmittal of the PPRP closure letter to the PM.

Ultimately, the PPRP must collectively agree to positive responses to the majority of their criteria to determine the acceptance of a successful study. This assessment shall be documented in the PPRP closure letter, which shall be completed after the review of the final INL Site-wide SSHAC Level 3 report. The closure letter shall include the following:

- Review acceptance criteria used by the PPRP

- Assessments of the study against the review acceptance criteria

- Overall assessment of whether the INL Site-wide SSHAC Level 3 PSHA successfully captured and sufficiently documented the CBR of TDI

- Determination of PPRP concurrence of the products for intended purposes and uses

- Completed Participatory Peer Review Checklist as an attachment.

\subsection{PPRP Documentation and Deliverables}

The PPRP will provide documentation to the PM. Documentation shall be in the format of a letter report addressed to the PM. The following lists documentation identified as deliverables from the PPRP to the PM:

- List of review acceptance criteria for the PPRP to perform their reviews

- Comments and feedback identified on the Participatory Peer Review Checklist for workshops, database review, and PPRP Briefing

- Review comments on the draft and final PSHA report as specified on Participatory Peer Review Checklist

- Completed and signed Participatory Peer Review Checklist

- PPRP Closure Letter. 


\section{REFERENCES}

10 CFR Part 52, Licenses, Certifications, and Approvals for Nuclear Power Plants.

10 CFR Part 52 Subpart C, Combined Licensing Application.

ANSI, 2008. Probabilistic Seismic Hazard Analysis. American National Standards Institute, American Nuclear Society. ANSI/ANS-2.29-2008, p. 33.

ASCE, 2005. Seismic design criteria for structures, systems, and components in nuclear facilities. American Society of Civil Engineers. ASCE/SEI 43-05, p. 81.

ASME NQA-1 2008/2009 Addendum, Quality Assurance Requirements for Nuclear Facilities Applications.

Bommer, J.J. and Crowley, H., 2017. The purpose and definition of the minimum magnitude limit in PSHA calculations, Seismological Research Letters, v. 88, p. 1-10.

DOE, 2012a. Facility Safety. U.S. Department of Energy DOE O 420.1C.

DOE, 2012b. Natural Phenomena Hazards Analysis and Design Criteria for DOE Facilities. U.S. Department of Energy DOE-STD-1020-12, 90.

DOE, 2016. Natural Phenomena Hazards Analysis and Design Criteria for DOE Facilities. U.S. Department of Energy DOE-STD-1020-16, 59.

Donahue, J.L., and Abrahamson, N.A., 2014. Simulation-based hanging wall effects. Earthquake Spectra, v. 30 , p. $1,269-1,284$.

GeoPentech, 2015, Southwestern United States Ground Motion Characterization SSHAC Level 3 Technical Report, Rev. 2, March.

INL, 2016. SSHAC Level 1 Probabilistic Seismic Hazard Analysis for the Idaho National Laboratory. Battelle Energy Alliance External Report INL/EXT-15-36682, Revision 2, doi: 10.2172/1367865.

NRC, 1997. SSHAC — Senior Seismic Hazard Analysis Committee. U.S. Nuclear Regulatory Commission NUREG/CR-6372, p. 280.

NRC, 2001, Technical basis for revision of regulatory guidance on design ground motions: Hazard and risk-consistent ground motion spectra guidelines, U.S. Nuclear Regulatory Commission, NUREG/CR-6728.

NRC, 2007a. Regulatory Guide 1.206: Combined License Applications for Nuclear Power Plants. U.S. Nuclear Regulatory Commission, June.

NRC, 2007b. Regulatory Guide 1.208: A performance-based approach to define the site-specific earthquake ground motions. U.S. Nuclear Regulatory Commission, March.

NRC, 2012. Practical Implementation Guidelines for SSHAC Level 3 and 4 Hazard Studies. U.S. Nuclear Regulatory Commission NUREG-2117, Rev. 1, p. 235.

NRC, 2018. Updated Implementation Guidelines for SSHAC Hazard Studies. U.S. Nuclear Regulatory Commission NUREG-2213, October. 
Appendix A

SharePoint Data Management and Usage 


\section{Appendix A}

\section{SharePoint Data Management and Usage}

\section{A-1 Introduction}

This appendix contains a description of the INL SSHAC Level 3 (SSHACL3) (https://sshacl3.inl.gov) SharePoint web portal site, and instructions on how to use and populate the SSHACL3 project database. The SSHACL3 project database will house all project files and the SSC and GMC databases and peer reviews of the PPRP, which support the final SSC and GMC models of the PSHA. This appendix describes the SharePoint structure, permissions, utilization procedures, SSHACL3 project database content, and workflow forms used to upload and track files. The appendix identifies the initial Sharepoint site structure and will be updated as needed to support the work of SSHAC participants. This appendix shall be used in place of a procedure for data management and the use of the SharePoint site.

The SharePoint site, https://sshac13@inl.gov (or SSHACL3), is a managed and secured site, which is accessible only to those working on the INL SSHAC Level 3 project and others designated as visitors. The SSHACL3 SharePoint site provides a single location and structure to house professional literature, scientific data, Geographic Information Systems (GIS) files, maps, graphics, information, and documents for SSHACL3 participants to perform their work. It also provides documentation of TI team evaluations of data and information as to their relevance to INL PSHA. TI teams and PPRP members will have access to a common set of data, maps, and graphics as they perform their work. All incoming data, professional literature, and workshop presentations to the SSHACL3 project database will use data entry forms that request metadata and then populate the entries into the correct SSHACL3 SharePoint libraries.

\section{A-2 SharePoint Structure and Permissions}

The SSHACL3 SharePoint site is structured and has permissions to allow all users access to open subsites, but only allows SSHAC participants access to their respective subsites where they perform work. The SharePoint site allows all users granted permission to access the site to enter the "Home" page, which allows access to four open subsites: Seismic Reference Library, Open Database Library, Products subsite, and Workshop subsite. Two subsites have permissions dependent the role of the SSHAC participant; they include the PPRP subsite and TI Team subsite.

Three user groups have been created for visitors, PPRP members, and the TI Team. Visitors are defined as the project sponsor (DOE), stakeholders (e.g., Carbon Free Power Project), observers (NRC and DNFSB), and other INL staff as approved by the project manager. Visitors can access four open subsites: Seismic Reference Library, Open Database Library, Products subsite, and Workshop subsite. The PPRP members can access the four open subsites and PPRP subsite. Both TI teams along with INL project team can access the four open subsites and the TI Team subsite (Figure A-1). Note that PPRP members cannot access the TI team subsites, and TI team members cannot access the PPRP subsites. Permissions have been set up to maintain independence of work performed by the TI teams from the reviews performed by PPRP members. Permissions of three groups allow access as follows:

- Visitor Group can read and download files only in open subsites

- TI-Team Group has contributor access to open subsites and the TI Team subsite which allows them to upload, download, edit files, edit lists, use workflow forms, create folders, and delete folders

- PPRP Member Group has contributor access to open subsites and the PPRP subsite which allows them to upload, download, edit files, edit lists, use workflow forms, create folders, and delete folders 
- Owner Group has full control to access, create, and manage all subsites and the SSHACL3 SharePoint site; this group reserved for the Project Manager, Database Manager, Quality Engineer, and INL SharePoint Developer.

\section{A-3 Development of Project Database}

In order to provide accessible and efficient collection, compilation and dissemination for all SSHAC L3 working files, the SSHACL3 dedicated SharePoint site was created. A distinction is made between the project database, which houses all project files, versus the SSC and GMC databases which support models used in the PSHA. Project database files can be uploaded by SSHAC participants without the use of forms and are primarily managed by the database manager, project manager, PTI, and TI leads. These files will be documents generated by the project to facilitate work, or may be products produced by TI teams for review by the PPRP.

Compiling data for evaluation by the SSC and GMC TI teams is a critical step and is easily managed by the SSHACL3 SharePoint site. A wide range of data and information with various file formats are needed for the project. All incoming data and information files will be uploaded through the use of workflow forms. The workflow forms allow incoming data and information to be identified by including requested metadata, and then to be placed in the correct library repository. All data and information compiled for evaluation by the TI teams will be uploaded to the SSHACL3 SharePoint site into one of two open access libraries.

1. Seismic Reference Library houses all unrestricted, openly accessible publications, reports, professional literature, and other documents formatted as a portable document file (pdf).

2. Open Database Library houses all unrestricted, openly accessible data and information in a variety of formats (e.g., GIS shape files, ascii files, zip files, etc.). Data and information compiled in this library are considered "raw" and unprocessed (such as GIS data) by SSHAC participants.

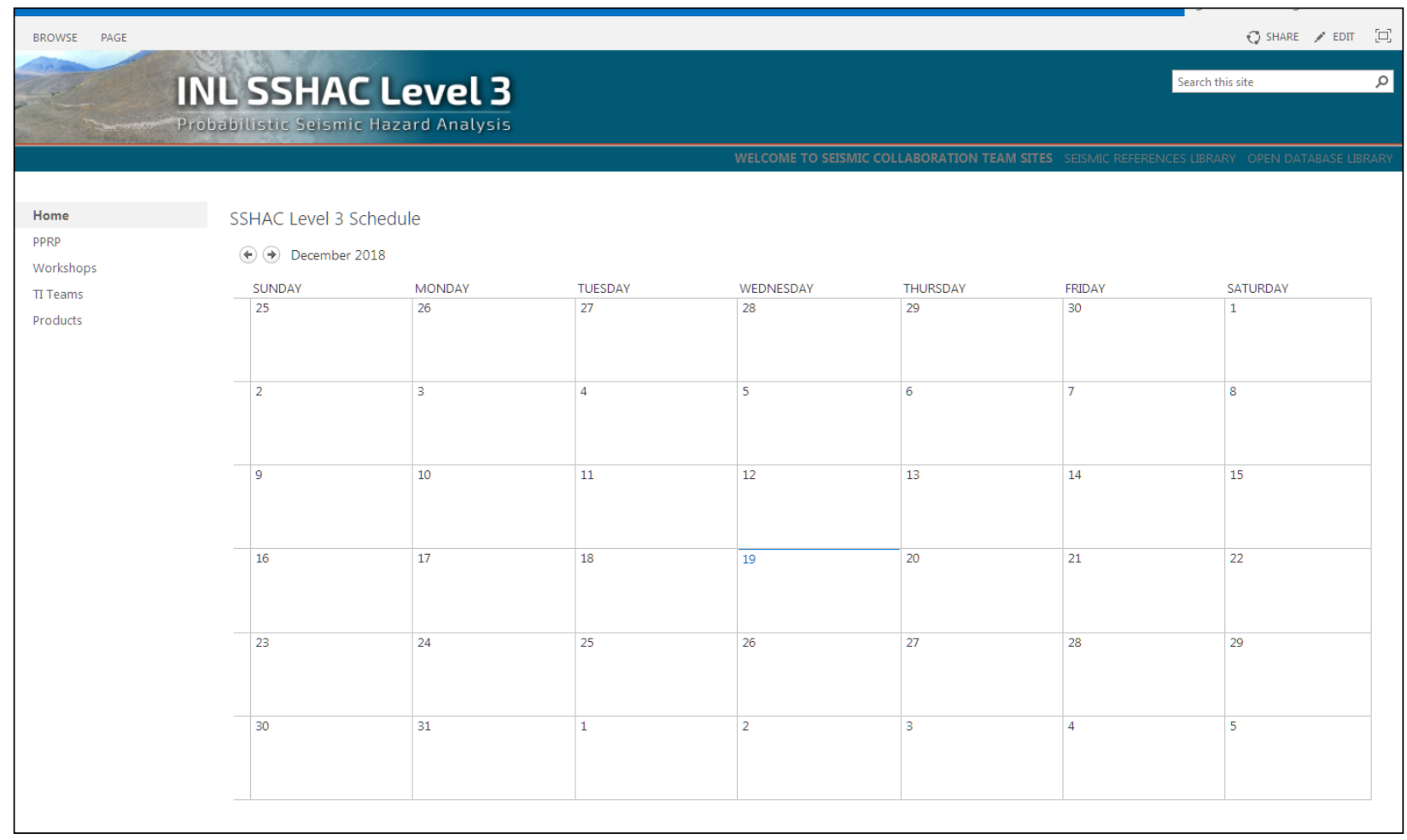

Figure A-1. Screen shot of the Home page of SSHAC Level 3 SharePoint site. 
TI team members, all other SSHAC participants, and the database manager are required to use the workflow forms, which are available on each library page in the upper right corner. The following describes each entry form and how it will be used.

- Add a New Reference is located on the Seismic Reference Library subsite of the SSHACL3 SharePoint site. The form allows a publicly available or published article to be uploaded to the Seismic Reference Library. The form requires selection of the electronic article for upload, full citation of the article (in a common format), and, if applicable, determination of whether (via yes or no) the SSC or GMC TI team (or both) has evaluated the article for its relevance. Tracking of the evaluation by SSC or GMC will be performed by designated TI Team members and Database Manager. The designations demonstrate to the PPRP that recommended articles have been evaluated by the TI Teams.

- Upload Data File is located on the Open Database Library subsite of the SSHACL3 SharePoint site. The form allows a publicly available and unrestricted data (accessible by everyone) file to be uploaded to the Open Database Library. The form requires selection of the electronic data file, title of data, description of data, file header definitions, source of data, and, if applicable, determination of whether (via yes or no) the SSC or GMC TI team (or both) has evaluated the data for their relevance. The designations demonstrate to the PPRP that recommended data have been evaluated by the TI Teams.

To manage the numerous citations that will be needed for the final INL Site-wide SSHAC Level 3 report, the entry form for adding references requires the use of a common citation format. The INL SSHAC Level 3 project shall use citation format of the Geology, which is a journal published by Geological Society of America (GSA). Figure A-2 shows Geology citation examples, and a file of these examples will be available on the Seismic Reference Library page.

At workshops, resource and proponent experts will use a separate SharePoint site (https://SSHACL3public.inl.gov) or another process (such as email to database manager) to provide their presentations or data and information to the project. Instructions will be provided to experts for how to submit their presentations for the workshops. The database manager will then move the presentation files to the Workshop subsite on the SSHACL3 SharePoint site. This public site will also be used to allow onetime anonymous access for uploads of data or other information. Data files will be uploaded using the Upload Data form. The form requires selection of the electronic file, name of contributor, title of file, contact information, and file contents description. An INL anonymous site will temporarily house these files. The Database Manager will move the files to the SSHACL3 SharePoint site under the appropriate location such as uploading the file into the Open Database Library.

\section{A-4 Dissemination of Data and Information to TI Teams and PPRP}

The Seismic Reference Library and Open Database Library are two subsites that are open access to TI team members and PPRP members. TI team members will look in the two libraries for data and information to perform their evaluations. References not found in the Seismic Reference Library can be requested from the Database Manager. The Database Manager can work with the INL Library to obtain electronic copies of published articles, university theses and dissertations, and other hard to find library documents. The database manager can alert TI team members when new articles or a requested article has been uploaded to the Seismic Reference Library. TI team members can also upload articles and alert other team members. The database manager can obtain copies of references from the lists provided by workshop participants.

Raw data and information for the Open Database Library can be obtained by the database manager and TI team members alerted when they are uploaded to the library. Most data and information will be obtained from individuals identified by TI team members. Other sources include subcontractors 


\section{Reference Examples}

References should include enough information so that another person will be able to find the material.

Abstract

LeMasurier, W.E., and Landis, C.A., 1991, Plume related uplift measured by fault displacement of the West Antarctic erosion surface, Marie Byrd Land [abs.]: Eos (Transactions, American Geophysical Union), v. 72, p 501

McKinnon, W.B., and Schenk, P.M., 2000, Chaos on Io: A model for formation of mountain blocks by crustal heating: Houston, Texas, Lunar and Planetary Institute, Lunar and Planetary Science XXXI, CD-ROM, abstract 2079.

Sammis, C.G., 1993, Relating fault stability to fault zone structure: Geological Society of America Abstracts with Programs, v. 25, no. 6, Book p. A115-A116.

Burchfiel, B.C., Chen Zhiliang, Hodges, K V Liu Yuping, Royden, L.H Deng Changrong, and Xu Jiene, 1992, The South Tibetan detachment system, Himalayan orogen: Geological Society of America Special Paper 269,41 p. [Chinese names may be spelled out, family name first, followed by given name.]

Coffin, M.F., Frey, F.A., Wallace, P.J., et al., 2000, Proceedings of the Ocean Drilling Program, Initial reports, Volume 183: College Station, Texas, Ocean Drilling Program, CD-ROM. [Include names of co-chief scientists.]

France-Lanord, C., Derry, L., and Michard, A., 1993, Evolution of the Himalay since Miocene time: Isotopic and sedimentologic evidence from the Bengal Fan, in Treloar, P.J., and Searle, M., eds., Himalayan tectonics: Geological Society [London] Special Publication 74, p. 603-621.

Vogt, P., and Tucholke, B., editors, 1986, The western North Atlantic region: Boulder, Colorado, Geological Society of America, Geology of North America, v. M, 696 p., 11 pl.

Computer Program

Lahr, J.C., 1999, HYPOELLIPSE: A computer program for determining local earthquake hypocentral parameters, magnitude, and first-motion pattern: U.S. Geological Survey Open-File Report 99-23, 93 p.

Database

Schweitzer, P.N., 1993, Modern average global sea-surface temperature: U.S Geological Survey Digital Data Series DDS-10.

Journal

Brown, M., $1993 P-T-t$ evolution of orogenic belts and the causes of regional metamorphism: Geological Society [London] Journal, v. 150, p. $227-241$.

Doglioni, C., 1994, Foredeeps versus subduction zones: Geology, v. 22, p. $271-274$.

Walter, L.M., Bischof, S.A., Patterson, W.P., and Lyons, T.L., 1993 , Dissolution and recrystallization in modern shelf carbonates: Royal Society of London Philosophical Transactions, ser. A, v. 344, p. 27-36.

Comment, Discussion, Reply

Silberling, N.J., Jewell, P.W, and Nichols, K.M., 2001, Earliest Carboniferous cooling step triggered by the Antler orogeny?: Comment: Geology, v. 29 , p. 92

Saltzman, M.R., 2001, Earliest Carboniferous cooling step triggered by the Antler orogeny?: Reply: Geology, v. 29, p. 93

Guidebook

Barton, C.C., and Hsieh, P.A., 1989, Physical and hydrologic-flow properties of fractures, in International Geological Congress, 28th, Field Trip Guidebook T385: Washington, D.C., American Geophysical Union, $36 \mathrm{p}$.

Blackstone, D.L., Jr., 1990, Rocky Mountain foreland exemplified by the Owl Creek Mountains, Wyoming, in Specht, R., ed., Wyoming sedimentation and tectonics: Wyoming Geological Association, 41st Annual Field Conference, Guidebook, p. 151-166

In Press

Dott, R.H., Jr., 2001, Wisconsin roots of the modem revolution in structural geology: Geological Society of America Bulletin, v. 113 (in press).
Map

Abrams, G.A., 1993, Complete Bouguer gravity anomaly map of the State of Colorado: U.S. Geological Survey Miscellaneous Field Studies Map MF-2236, scale $1.500000,1$ sheet.

Emst, W.G., 1993 Geology of the Pacheco Pass quadrangle, centra California Coast Ranges: Geological Society of America Map and Chart Series MCH078, scale 1:24 000, 1 sheet, 12 p. text

Open-File Report

Wilson, A.B., 2001, Compilation of various geologic time scales: U.S. Geological Survey Open-File Report 01-0052: http://greenwood.cr.usgs.gov/pub/open-file-reports/ofr-01-0052/ (July 2001)

National Earthquake Information Center, 1992, Earthquake data report, August 1992: U.S. Geological Survey Open-File Report 92-0608-A $458 \mathrm{p}$.

Paper in a Government or University Serial Publication

Hay, R.L., 1963, Stratigraphy and zeolitic diagenesis of the John Day Formation of Oregon: University of California Publications in Geological Sciences, v. 42, p. 199-262.

Yager, R.M., 1993, Estimation of hydraulic conductivity of a riverbed and aquifer system on the Susquehanna River in Broome County, New York: U.S. Geological Survey Water-Supply Paper 2387, 49 p.

Paper in a Multiauthor Volume

Carpenter, F.M., 1992, Superclass Hexapoda, in Kaesler, R. L., ed, Treatise on invertebrate paleontology, Part R, Arthropoda 4, Volume 3: Boulder, Colorado, Geological Society of America (and University of Kansas Press), $277 \mathrm{p}$.

Kane, J.S., and Neuzil, S.G., 1993, Geochemical and analytical implications of extensive sulfur retention in ash from Indonesian peats, in Cobb, J.C., and Cecil, C.B., eds., Modem and ancient coal-forming environments: Geological Society of America Special Paper 286, p. 97-106.

Sawyer, D.S., Buffler, R.T., and Pilger, R.H., 1991, The crust under the Gulf of Mexico basin, in Salvador, A., ed., The Gulf of Mexico Basin: Boulder, Colorado, Geological Society of America, Geology of North America, v. J p. 53-72.

Taylor, J.C.M., 1990, Upper Permian-Zechstein, in Glennie, K.W., ed, Introduction to the petroleum geology of the North Sea (third edition): Oxford, UK, Blackwell, p. 153-190.

Proceedings from a Symposium or Conference

[Include year of conference if it differs from publication year.

Baar, C., 1972, Creep measured in deep potash mines vs. theoretical predictions, in Proceedings, Canadian Rock Mechanics Symposium, 7th, Edmonton: Ottawa, Canada Department of Energy, Mines and Resources, p. 23-77.

MacLeod, N.S., Walker, G.W., and McKee, E.H., 1976, Geothermal significance of eastward increase in age of rhyolitic domes in Oregon, in Proceedings, Second United Nations Symposium on the Development and Use of Geothermal Resources, San Francisco, May 1975, Volume 1: Washington, D.C., U.S. Government Printing Office (Lawrence Berkeley Laboratory, University of California), p. 465-474. Thesis

Wopat, M.A., 1990, Quaternary alkaline volcanism and tectonics in the Mexican Volcanic Belt near Tequila, Jalisco, southwestern Mexico [Ph.D. thesis]: Berkeley, University of California, $277 \mathrm{p}$.

\section{Web Site}

[Month and year in parentheses at end denote date author accessed site.]

MARGINS, 1999, The Seismogeric Zone Experiment (SEIZE): Science plan: http://www.soesthawaii.edu/margins/SEIZE sci plan.html (July 2001).

Johnson, A.B., 2001, Raw data for relay stations AB1-AB15 in the Mojave desert: http://www.seismo.berkeley.edu/mojave (December 2001)

Figure A-2. Examples of citation format from journal Geology to be used in the SSHACL3 Seismic Reference Library. 
performing work at INL for other projects such as CFPP. Individuals not working on the SSHAC project shall use the public access (https://SSHACL3public.inl.gov) SharePoint site to upload files. The database manager will move these files to the Open Database and can then alert TI Team members that new data are available to them.

\section{A-5 Development of the SSC and GMC Databases}

Two evaluation forms were created to develop the SSC and GMC databases and track evaluations performed by each TI team. The SSC TI Team will use the SSC Evaluation Form to evaluate data and then populate the SSC database as to their topic and relevance to the SSC model. The GMC TI Team will use the GMC Evaluation Form to upload short reports (or white papers) that document their evaluation and relevance to the GMC model. As part of tracking, the TI leads will indicate that data have been verified through the various approaches for qualifying data. Qualifying data is considered to be a part of the objective evaluation of data, models, and methods typically performed by TI team members and then peer reviewed by the PPRP during their engagements with SSHAC workflow processes.

To document these evaluations on the SSHACL3 SharePoint site, the following two forms shall be used by TI team members as applicable to SSC and GMC.

- SSC Evaluation Form allows an SSC TI team member to document the evaluation of data, models, and methods as to their relevance to the SSC model. The form requires selection of the topic from categories specified by the TI team, relevance from categories specified by the TI team as to how used, selection of the file from drop-down menu of references from the Seismic Reference Library or data from the Open Database Library, automatic population of the citation (if from Seismic Reference Library) or description of data (if from Open Database Library), summary of the evaluation, and verification of evaluation by the SSC TI lead (via yes or no). The SSC Formation Form button can be found on the upper right corner of the SSC Database page or on the SSC Team page.

- GMC Evaluation Form allows a GMC TI team member to document evaluation of data, models, and methods as to their relevance to the GMC model. The GMC TI team plans to compose their evaluations in short reports or white papers. The form requires title of the white paper, selection of the white paper file for upload, topic of the paper, GMC team author or authors, short summary of the white paper, selection of relevance from topic categories specified by the TI team, and verification of evaluation by the GMC TI lead (via yes or no). The GMC Formation Form button can be found on the upper right corner of the GMC Database page or on the GMC Team page.

\section{A-6 PPRP Checklist on SharePoint}

PPRP members have access to the PPRP subsite to manage files and perform work. The PPRP Checklist page was set up to track completion of PPRP activities. The activities are identified on the Participatory Peer Review Checklist. The checklist has the list of activities to document completion of periodic reviews and engagements with SSHAC workflow processes and TI teams. The PPRP Checklist subsite has an Add Checklist Item Form via a button at the top of the page to allow the PPRP chair to upload activities from the checklist, item number per the checklist, add initials to confirm completion, add the date of completion, and upload a file with review comments (if applicable). A list of the completed activities on the PPRP Checklist page will provide a way for the quality engineer and project manager to track progress of reviews and engagements by the PPRP.

\section{A-7 Utility of SharePoint Site and Subsite Pages}

The following sections discuss accessing the SharePoint site and provide definitions of the subsite pages and their uses. The subsites begin with the open access pages and then discuss the PPRP and TI team subsites individually. The last section discusses the GIS pages and use of an interactive map for TI team members. 


\section{A-7.1 Accessing the SSHACL3 SharePoint Site}

The following steps are used to access the SSHACL3 SharePoint site and navigate to the home page. Open a web browser using Chrome or Safari (preferred), or Firefox. Type in the URL: https://SSHACL3.inl.gov which will take the user to the INL SharePoint login portal. External (or nonINL) users will select Collaboration Portal Account Sign In page and then enter their login name and password. Once successfully logged in, the user will be on the SSHACL3 home page Welcome to Seismic Collaboration Team Sites page, which provides the INL SSHAC Level 3 project banner, a highlevel project calendar. In the banner at the top of the page (above the calendar) two links are provided to the Seismic Reference Library and Open Database Library (Figure A-1). Along with the Library links, on the top banner, the user can find a fill in (type) Search the Site tool which searches for site pages and content. On the left side bar is a list of subsites that the user has access to. If you do not have access to a subsite, then it is not displayed.

\section{A-7.2 Seismic Reference Library (Open access to all)}

As discussed in Section A-3, the Seismic Reference Library houses a listing of pdfs for unrestricted, openly accessible published articles, reports, university theses and dissertations, and other professional literature. The page displays a list showing: name of the pdf in the format of the authors name and year published (e.g., Abrahamson-Silva_1997 for Abrahamson and Silva, 1997); yes or no indications if SSC or GMC evaluations have been performed; full citation using Geology format (Figure A-2), who uploaded the file, and date of upload. Add a New Reference button to upload new articles is located at the top of the page and requests the information to populate the list (see Section A-3). The default for either SSC or GMC evaluations is "No". The list will be edited by a TI Team member or Database Manager at a later date to indicate the article was evaluated (Yes is selected).

\section{A-7.3 Open Database Library (Open access to all)}

The Open Database Library houses raw and unprocessed (by SSHAC participants), unrestricted and openly accessible data and information in a variety of formats (e.g., GIS files, ascii files, zip files, etc.). All incoming data shall reside in the Open Database Library. The page displays a list showing name of data file with its extension, yes or no indications if SSC or GMC evaluations have been performed, source of the file, description of the data or information, and header definitions for contents in the file. The Upload Data File button to upload incoming data is located at the top of the page and requests the information to populate the list (see Section A-3). The list will be edited by a TI Team member or database manager at a later date to indicate the article was evaluated (Yes is selected).

\section{A-7.4 Workshop Subsite (Open access to all)}

The Workshop subsite houses presentations from the three workshops and other documents generated at the workshops. Separate pages for each workshop (Workshop 1, Workshop 2, and Workshop 3) will have folders for the workshop documents and lists of files with the presentations. Presentation files will be uploaded by the database manager and other SSHAC participants as applicable. Invited presenters to the workshops will provide their presentations to the separate SSHACL3 public site or email them to the database manager. The database manager will move the presentation files from the public site to the appropriate workshop page. PPRP comments from the workshops will also be housed on the respective workshop page.

\section{A-7.5 Products Subsite (Open access to all)}

The Products subsite houses final document files that are available to the sponsor, stakeholders, and regulatory observers. These documents will include workshop reports and the final report that has been reviewed and released for external access outside of INL. 


\section{A-7.6 PPRP Subsite (Accessed by PPRP Members)}

The PPRP subsite will house a project calendar with the 25 tasks (Table 8), PPRP working files, and the PPRP Checklist page. The PPRP subsite for working files will be set up as the chair and members determine to perform their work. All documents identified on the Participatory Peer Review Checklist will be uploaded using the Add Checklist Item Form, which also documents the activity, initials of the PPRP chair, and completion date of the activity. On the PPRP Checklist page, the listing shows: item number of the checklist, activity, PPRP chair initials, and date activity was completed.

\section{A-7.8 TI Team Subsite (Accessed by TI Team and INL Project Team)}

The TI team subsite has a full project calendar of tasks from Table 8 and several subsites to manage and index documents generated by the TI teams and INL project team. Table A-1 lists the subsite names, purpose, and who has the lead for managing the content. Although leads are identified, the database manager will assist with managing files on all TI Team subsites. TI Team members will contribute to their respective team pages and databases. The SSC and GMC database pages are discussed in more detail since they support the final models for the PSHA.

As discussed in Section A-5, the SSC and GMC database pages house the evaluations performed by each of the TI teams and identify the sources of data from either the Seismic Reference or Open Database libraries. The SSC Evaluation Form and GMC Evaluation Form are each used to upload information regarding the evaluations and to track verification of data that are used in the evaluations. The SSC Database page shows a list of evaluations performed by the SSC TI team. The list includes: SSC topic, relevance to SSC, file name, full citation or data description, summary of evaluation, and verification by SSC TI lead (Yes or No). The information is uploaded using the SSC Evaluation Form button at the top of the SSC database page or SSC TI Team page (see Section A-5). The GMC Database page shows the list of white papers documenting the evaluations performed by GMC TI team members. The list includes: title of the white paper, topic of paper, authors, summary of the evaluation, and verification by the GMC TI lead (Yes or No). The information is uploaded using the "GMC Evaluation Form" button at the top of the GMC database page or GMC TI Team page (see Section A-5).

Table A-1. List of the TI Team subsite names, purpose, and lead for managing page contents

\begin{tabular}{|l|l|c|}
\hline Subsite or Page Name & \multicolumn{1}{|c|}{ Purpose of Subsite } & Content Manager Lead(s) \\
\hline SSC Team & $\begin{array}{l}\text { Retain working meeting minutes of the } \\
\text { SSC TI team and exchange working } \\
\text { files as designated by the SSC TI lead. }\end{array}$ & SSC TI Team Lead \\
\hline SSC Database & Maintain the list of SSC evaluations. & SSC TI Team Members \\
\hline GMC Team & $\begin{array}{l}\text { Retain working meeting minutes of the } \\
\text { GMC TI team and exchange working } \\
\text { files as designated by the SSC TI lead. }\end{array}$ & GMC TI Team Lead \\
\hline GMC Database & Maintain the list of GMC evaluations. & GMC TI Team Members \\
\hline HID & $\begin{array}{l}\text { Retain and make accessible GIS files } \\
\text { and maps that have been developed by } \\
\text { INL GIS Database Experts, which will } \\
\text { be used by the TI teams. }\end{array}$ & Database Manager \\
\hline Hazard Analysts & $\begin{array}{l}\text { Retain and make the preliminary and } \\
\text { final HIDs accessible to PTI, TI Team } \\
\text { members and Hazard Analysts. }\end{array}$ & $\begin{array}{l}\text { Retain and allow exchange of files } \\
\text { between the two Hazard Analysts, and } \\
\text { provide files for the Quality Engineer } \\
\text { for periodic audits of the final hazard } \\
\text { calculations. }\end{array}$ \\
\hline
\end{tabular}




\begin{tabular}{|c|c|c|}
\hline Subsite or Page Name & Purpose of Subsite & Content Manager Lead(s) \\
\hline $\begin{array}{l}\text { INL PSHA and } \\
\text { Other Project Docs }\end{array}$ & $\begin{array}{l}\text { Resource of INL files and regulatory } \\
\text { documents. INL files contained on this } \\
\text { subsite have not been reviewed for } \\
\text { external release (such as previous INL } \\
\text { PSHAs and geotechnical studies for } \\
\text { facility foundations). Also, the resource } \\
\text { for SSHAC Level } 1 \text { files (e.g., HID and } \\
\text { amp functions), and links to other } \\
\text { SSHAC Level } 3 \text { studies. }\end{array}$ & Database Manager \\
\hline Study Report & $\begin{array}{l}\text { Retain edited versions of reports and } \\
\text { provide file exchange for TI team } \\
\text { members to develop sections of } \\
\text { preliminary and final INL Site-wide } \\
\text { SSHAC Level } 3 \text { reports for the Tech } \\
\text { Editor. }\end{array}$ & Project Manager and Tech Editor \\
\hline Kickoff Meeting & $\begin{array}{l}\text { Retain presentations at the Kick-off } \\
\text { meeting, and agendas, PPRP comments, } \\
\text { meeting summaries, and list of } \\
\text { attendees. }\end{array}$ & Project Manager and PTI \\
\hline PPRP Briefing Meeting & $\begin{array}{l}\text { Retain presentations at the PPRP } \\
\text { Briefing meeting, and agendas, PPRP } \\
\text { comments, meeting summaries, and list } \\
\text { of attendees. }\end{array}$ & Project Manager and PTI \\
\hline Quality Assurance & $\begin{array}{l}\text { Retain Quality Assurance Project Plan } \\
\text { (QAPP), INL SSHAC Level } 3 \text { Work } \\
\text { Plan, administrative procedures, and } \\
\text { other project files associated with } \\
\text { quality assurance. }\end{array}$ & Quality Engineer \\
\hline
\end{tabular}

\section{A-8 GIS Specific Data Collections and Considerations}

The GIS subsite under TI Team subsite houses GIS files that have been processed by INL GIS data experts for TI Team members to use when performing their work. These files include flat files, graphics, maps, and file geodatabases that contain vector, raster, and tabular geospatial data. The GIS data repository will be maintained using the Environmental Systems Research Institute (ESRI) ArcGIS software compatible with SharePoint sites.

All GIS files to be processed by the INL GIS Database Experts will be uploaded to the Open Database Library, unless they are not to be released externally. INL houses GIS files that have not been reviewed for release, but will be if used by the TI Teams.

The GIS subsite is organized with GIS data and information for the user to use an interactive map on the SharePoint. Figure A-4 shows an example of the GIS subsite with the interactive map, list of GIS datasets and collection of folders with incoming GIS data uploads and the Official GIS Datasets that have been reviewed and processed by INL GIS database experts.

\section{A-8.2 GIS File Organization and Formats}

The file geodatabase will be organized using a file geodatabase where feature datasets will be used to house data by theme. Additionally, a unique and clarifying naming convention will be adopted:

SSHACL3INLFeatureTypeAuthorDateRev\#.<file suffix > 
where Feature Type will identify the type of data represented (e.g., SEIS for seismic; IMAG for satellite or aerial imagery; ELEV for elevation, etc.), Author Date will identify who contributed the data and the date, Rev\# will be the revision number. FGDC compliant and complete metadata will accompany all data.

GIS data is usually complex data types. A single themed layer may include multiple file types in order to be used in GIS applications and requires additional considerations to meet utilization requirements. A GIS subsite has been created to manage the unique requirements and accessibility. Whereas an upload of GIS data may include more than one file, we encourage participants to upload GIS data in compiled and compressed formats such as:

- Zip (*.zip or *.inl as upload workaround) This is good format for shapefiles. Inclusion of the projection $(*$.prj) is required and layer symbology $(* . l y r)$ file would be helpful;

- Geodatabases (*.gdb);

- ArcGIS Map Packages (*.mpk). These will include files such feature classes, geodatabase, layer symbology files $(*$.lyr) and map documents $(* . m x d)$.

Other accepted GIS specific file formats include the following:

- Shapefiles (*.shp). These have multiple files associated with them and should be compressed (*.zip);

- Kml or KMZ. These are common Google Maps and Google Earth formats;

- $\quad$ Imagery (typically *.TIFF + *.tfw). Other imagery file formats that include a world file can be submitted. Various imagery types have specific associated world file formats;

- EXCEL Spreadsheets (*.xls) This is not GIS file format per se, but spreadsheets with latitude and longitude coordinate $(\mathrm{X}, \mathrm{Y})$ can be utilize in a GIS;

- ArcInfo Coverages (*. e00). Coverages must be in an .e00 compressed format for upload;

- $\quad$ AutoCAD (*.dwg); this format must include a world file.

GIS data will comprise current INL datasets, existing SSHAC-L1 data, and contributions from the TI Team. Any data that are posted to the SharePoint page will go through a review which will assess completeness of the data, accompanying documentation or metadata including source attribution, a defined coordinate system, scale, and topological integrity. Data will be reprojected into the standards listed above as necessary. Appropriate transformations will be considered when reprojection occurs in order to preserve shape, area, distance, or direction. Then, this validated GIS data will be posted on the GIS SharePoint page of the SSHAC Level 3 study.

Uploaded data will be housed in its original format, in a location on the SharePoint site where it can be accessed by the GIS database expert and disseminated as needed. Two separate folders will exist within the SharePoint site for the GIS subsite, one folder will serve solely as an upload repository for data, and the other for downloading GIS data that has gone through validation. These folders will be restricted to TI Teams, where the upload folder will only provide permissions to allow users to add data, and the download folder will only provide permissions for users to retrieve data. This will allow control of the flow of data as well as only permit downloading of validated data. 


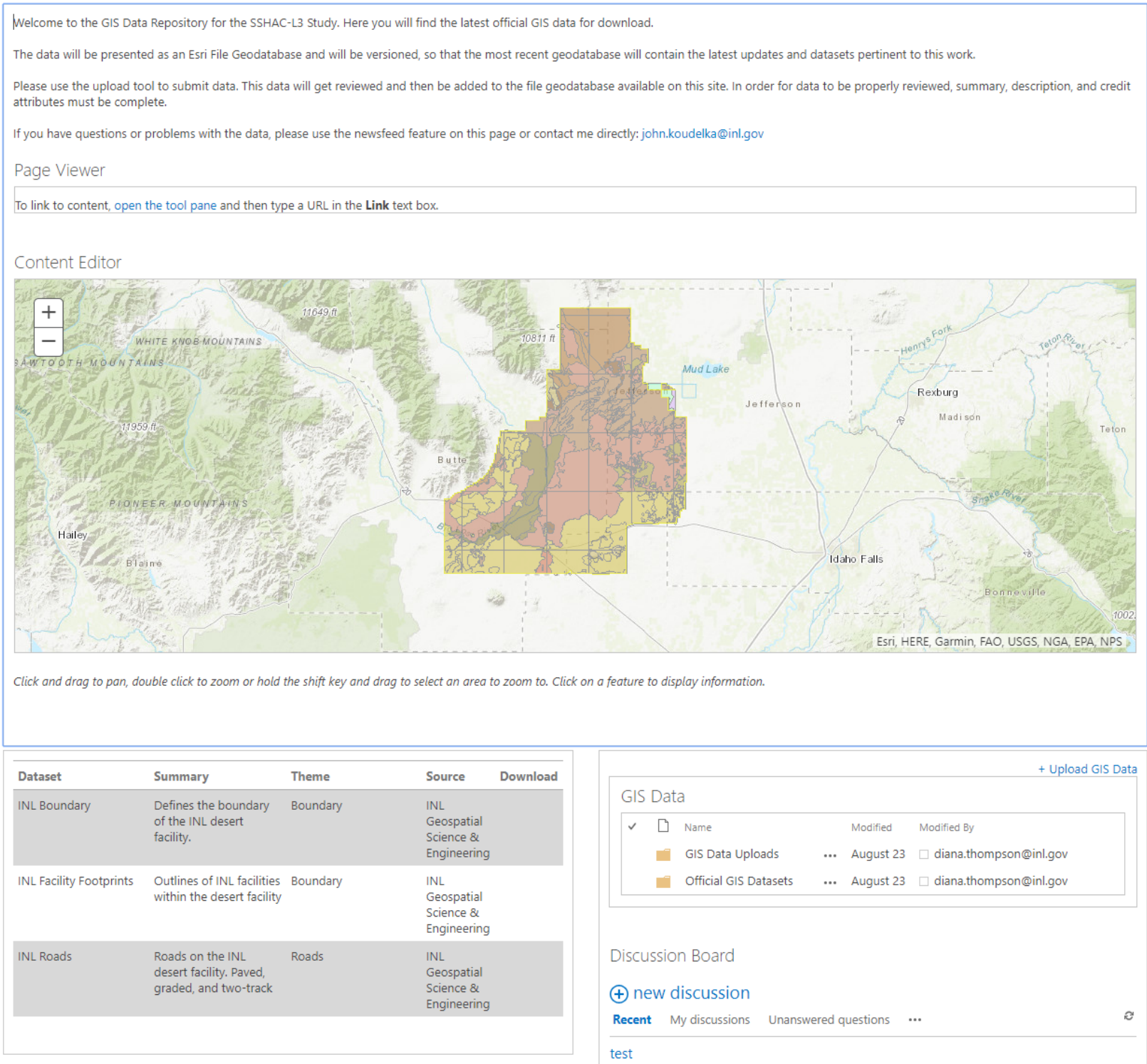

Figure A-3. A preliminary mockup of the GIS subsite page provides user guidance, a listing of compiled spatial data in GIS database, an interactive map, and access to the spatial data.

\section{A-8.2 Datum for SSHAC Level 3 project GIS files}

The GIS database will use the Idaho East State Plane coordinate system, WKID 2241, based on the 1983 North American Geographic Coordinate System. The INL desert site straddles the dividing line between the Central and East State Plane zones, and the projection reference points are a similar distance away from the boundary, so it will have similar accuracy whether it is in the Central or East zone. Because the INL Geospatial Science \& Engineering (GeoSE) organization is responsible for the INL desert facility, as well as the in-town facilities that reside fully in the Eastern zone, Idaho East State Plane became the standard coordinate system for the INL GIS.

The North American Vertical Datum of 1988 (NAVD 88), established in 1991 from leveling observations in Canada, the United States, and Mexico, calculates the location of the geoid from modeled local gravity. The Idaho Department of Water Resources and the USGS use this datum for well head heights in the area. This is the best-available vertical datum for Idaho, until NAPGD 2022 is published. 


\section{A-8.3 GIS Data Management Procedures}

An Esri file geodatabase will be used to house and organize validated GIS data for the INL SSHACL3 project. Feature datasets will be created to organize the data into categories or themes. The initial database design will contain general themes; topography, geology, hydrology, and can easily be expanded as the TI Teams and workshops require.

Data that will be made available in the mapping inset of the SharePoint GIS subsite will be a duplicate of the validated database and will be updated when a new version of the database is available. Table A-2 lists the tasks involved with creating the file geodatabase and who will perform the task.

Table A-2. List of tasks for creating GIS data and participant for performing the task.

\begin{tabular}{|c|c|c|}
\hline Task & Description of Task & Participants \\
\hline Data Review & $\begin{array}{l}\text { Review uploaded data and ensure the following is } \\
\text { completed for each dataset: } \\
\text { - } \quad \text { Metadata (summary, description, type, source, } \\
\text { scale, creation date, point of contact) } \\
\text { - } \quad \text { Proper coordinate system } \\
\text { - } \quad \text { Completeness of data (no empty fields) } \\
\text { - } \quad \text { Topological integrity (closed polygons, shapes fit } \\
\quad \text { within a reasonable domain, etc.) }\end{array}$ & GIS Database Expert \\
\hline Data Acceptance & $\begin{array}{l}\text { Add data to the file geodatabase into appropriate feature } \\
\text { dataset and name the dataset appropriately: } \\
\text { - } \quad \text { Feature type (vector, raster, seismic, etc.) } \\
\text { - } \quad \text { Author } \\
\text { - } \\
\text { - }\end{array}$ & GIS Database Expert \\
\hline $\begin{array}{c}\text { Maintain GIS } \\
\text { SharePoint Subsite }\end{array}$ & $\begin{array}{l}\text { - } \quad \text { Add latest file geodatabase to the downloads folder } \\
\text { - Update data table with new information when a } \\
\text { new dataset is added. } \\
\text { - } \quad \text { Move uploaded data to repository }\end{array}$ & GIS Database Expert \\
\hline $\begin{array}{l}\text { Provide GIS } \\
\text { Support for } \\
\text { Workshops }\end{array}$ & $\begin{array}{ll}\text { - } & \text { Set up GIS Data upload repository for workshops } \\
\text { - } & \text { Set up GIS validated file geodatabase for download } \\
\text { - } & \text { Prepare GIS datasets for rapid dissemination (i.e.: } \\
& \text { flash drive) } \\
\text { - } & \text { Provide platform for rapid visualization for GIS } \\
\text { datasets during workshop. }\end{array}$ & $\begin{array}{l}\text { GIS Database Expert, } \\
\text { Database Manager }\end{array}$ \\
\hline $\begin{array}{l}\text { Develop GIS } \\
\text { Figures for } \\
\text { Reports }\end{array}$ & $\begin{array}{l}\text { - Develop format for maps } \\
\text { - } \quad \text { Develop color scheme for maps } \\
\text { - } \quad \text { Produce maps for reports adhering to the format } \\
\text { and color scheme outlined above }\end{array}$ & $\begin{array}{l}\text { GIS Database Expert, } \\
\text { Database Manager, } \\
\text { Graphics Artist }\end{array}$ \\
\hline
\end{tabular}




\begin{tabular}{|c|c|c|}
\hline Task & Description of Task & Participants \\
\hline $\begin{array}{c}\text { Generate GIS } \\
\text { datasets from } \\
\text { documents }\end{array}$ & 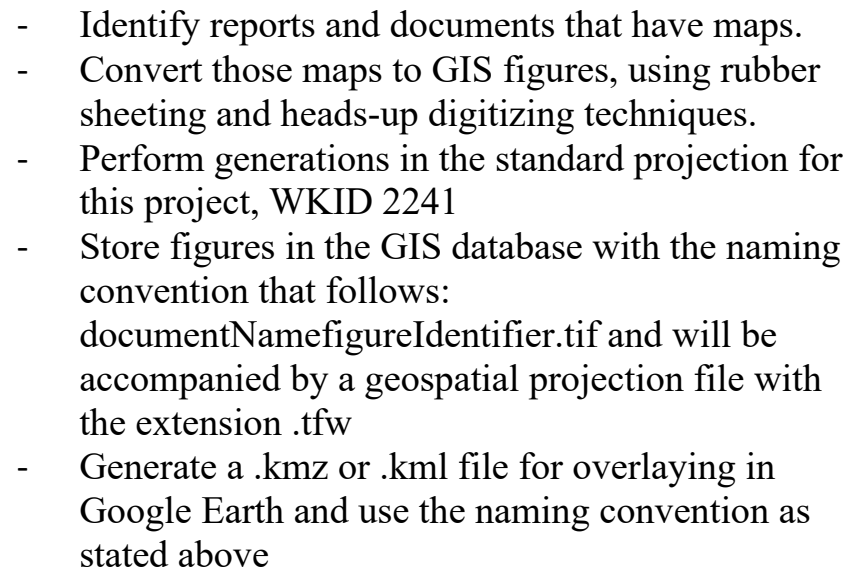 & $\begin{array}{c}\text { GIS Database Expert, } \\
\text { Database Manager }\end{array}$ \\
\hline $\begin{array}{l}\text { Develop } \\
\text { Interactive Map of } \\
\text { SSHACL3 GIS } \\
\text { Data }\end{array}$ & $\begin{array}{l}\text { - Utilize existing configurable web map viewer } \\
\text { (Open Source } \\
\text { - } \begin{array}{l}\text { Identify spatial layers to make available in } \\
\text { interactive map, }\end{array} \\
\text { - } \\
\text { Publish map documents to be used in map } \\
\text { Make interactive available to participant to assist } \\
\text { with dissemination of project spatial data }\end{array}$ & $\begin{array}{l}\text { GIS Database Expert, } \\
\text { Database Manager }\end{array}$ \\
\hline
\end{tabular}


Appendix B

\section{Supplemental Information for PPRP}




\section{Appendix B}

\section{Supplemental Information for PPRP}

Appendix B contains a copy of the PPRP Checklist and its associated attachment. 


\begin{tabular}{|c|c|c|c|}
\hline \multicolumn{4}{|c|}{ Participatory Peer Review Checklist for INL Site-wide SSHAC Level 3 PSHA } \\
\hline $\begin{array}{l}\text { Participatory Peer Review Panel Chair: } \\
\text { Marty McCann }\end{array}$ & \multicolumn{3}{|c|}{$\begin{array}{l}\text { INL Project Manager: } \\
\text { Samuel Dixon }\end{array}$} \\
\hline \multirow{2}{*}{\multicolumn{2}{|c|}{ Participatory Peer Review Panel (PPRP) Activity }} & \multicolumn{2}{|c|}{$\begin{array}{c}\text { PPRP Chair } \\
\text { Acknowledgment }\end{array}$} \\
\hline & & Initials & Date \\
\hline \multicolumn{2}{|c|}{$\begin{array}{l}\text { 1. PPRP Chair conversed with the Project Sponsor and Project Manager to } \\
\text { identify review acceptance criteria. }\end{array}$} & & \\
\hline \multicolumn{2}{|c|}{$\begin{array}{l}\text { 2. Adopted and formalized PPRP review acceptance criteria, and } \\
\text { communicated them to Project Manager and TI Teams (Attachment A). }\end{array}$} & & \\
\hline \multicolumn{2}{|c|}{$\begin{array}{l}\text { 3. Reviewed scope, purpose, objectives, and schedule in the INL Site-wide } \\
\text { SSHAC Level } 3 \text { Work Plan and composition of SSHAC participants } \\
\text { performing the work; provided written comments to Project Manager. }\end{array}$} & & \\
\hline \multicolumn{2}{|c|}{$\begin{array}{l}\text { 4. Reviewed framework for the database and approach for development; } \\
\text { provided feedback to the Project Manager. }\end{array}$} & & \\
\hline \multicolumn{2}{|c|}{$\begin{array}{l}\text { 5. Workshop } 1-\text { PPRP observed the TI Teams approach to identifying data } \\
\text { that exist in the technical community. }\end{array}$} & & \\
\hline \multicolumn{2}{|c|}{$\begin{array}{l}\text { a. Workshop } 1 \text { review comments have been received, consolidated, } \\
\text { and transmitted to the Project Manager in the format of a letter. }\end{array}$} & & \\
\hline \multicolumn{2}{|c|}{$\begin{array}{l}\text { b. Responses to comments on Workshop } 1 \text { have been received from } \\
\text { the Project Manager in the format of a letter. }\end{array}$} & & \\
\hline \multicolumn{2}{|c|}{$\begin{array}{l}\text { 6. Workshop } 2 \text { - PPRP observed the TI Teams approach to identifying } \\
\text { models and methods that exist in the technical community. }\end{array}$} & & \\
\hline \multicolumn{2}{|c|}{$\begin{array}{l}\text { a. Workshop } 2 \text { review comments have been received, consolidated, } \\
\text { and transmitted to the Project Manager in the format of a letter. }\end{array}$} & & \\
\hline \multicolumn{2}{|c|}{$\begin{array}{l}\text { b. Responses to comments on Workshop } 2 \text { have been received from } \\
\text { the Project Manager in the format of a letter. }\end{array}$} & & \\
\hline \multicolumn{2}{|c|}{$\begin{array}{l}\text { 7. Workshop } 3 \text { - PPRP actively engaged with TI Teams by questioning their } \\
\text { Evaluation and Integration assessments, technical justifications, and } \\
\text { preliminary SSC and GMC models with regard to capturing CBR of TDI. }\end{array}$} & & \\
\hline \multicolumn{2}{|c|}{$\begin{array}{l}\text { a. Workshop } 3 \text { review comments have been received, consolidated, } \\
\text { and transmitted to the Project Manager in the format of a letter. }\end{array}$} & & \\
\hline \multicolumn{2}{|c|}{$\begin{array}{l}\text { b. Responses to comments on Workshop } 3 \text { have been received from } \\
\text { the Project Manager in the format of a letter. }\end{array}$} & & \\
\hline \multicolumn{2}{|c|}{$\begin{array}{l}\text { 8. Reviewed the final HID and final SSC and GMC models at the PPRP } \\
\text { Briefing meeting; written feedback was provided to the Project Manager. }\end{array}$} & & \\
\hline \multicolumn{2}{|c|}{$\begin{array}{l}\text { 9. The draft INL Site-wide SSHAC Level } 3 \text { report has been reviewed by the } \\
\text { PPRP and review comments have been received from all PPRP members. }\end{array}$} & & \\
\hline
\end{tabular}




\begin{tabular}{|c|c|c|c|}
\hline \multicolumn{4}{|c|}{ Attachment A - PPRP Acceptance Criteria } \\
\hline \multirow{2}{*}{$\begin{array}{l}\text { SSHAC } \\
\text { Essential Steps } \\
\text { and Attributes }\end{array}$} & \multirow[b]{2}{*}{ Specific Acceptance Criteria } & \multicolumn{2}{|c|}{ Assessment } \\
\hline & & Yes & No \\
\hline \multirow{7}{*}{ Project Plan } & $\begin{array}{l}\text { a. A Project Plan was prepared that describes the elements of } \\
\text { the SSHAC Level } 3 \text { project and how the tasks in the project } \\
\text { would be implemented. }\end{array}$ & & \\
\hline & $\begin{array}{l}\text { b. The Project Plan described the roles and responsibilities of } \\
\text { the Project participants. }\end{array}$ & & \\
\hline & $\begin{array}{l}\text { c. The Project Plan described project interfaces and how they } \\
\text { would be controlled: } \\
\text { 1. SSC Team - GMC Team } \\
\text { 2. PTI - Users of Project products } \\
\text { 3. PTI - non-Project participants providing new data or } \\
\text { analyses } \\
\text { 4. PTI and Project Manager - Project sponsor(s) } \\
\text { 5. PPRP - Project Manager } \\
\text { 6. PTI - Hazard Calculation Team }\end{array}$ & & \\
\hline & $\begin{array}{l}\text { d. The Project Plan provided a schedule with logical } \\
\text { connections between tasks and reasonable times for tasks to } \\
\text { be performed. }\end{array}$ & & \\
\hline & $\begin{array}{l}\text { e. The Project Plan described how the review by the PPRP of } \\
\text { the SSHAC Level } 3 \text { process would be facilitated. }\end{array}$ & & \\
\hline & $\begin{array}{l}\text { f. The Project Plan makes reference to the quality assurance } \\
\text { requirements for the project. }\end{array}$ & & \\
\hline & $\begin{array}{l}\text { g. The Project Plan implemented the guidance of NUREG- } \\
2213 \text {. }\end{array}$ & & \\
\hline \multirow{2}{*}{$\begin{array}{l}\text { Selection of } \\
\text { Project Participants }\end{array}$} & $\begin{array}{l}\text { a. Resource experts engaged to participate in workshops and } \\
\text { working meetings covered an appropriate range of relevant } \\
\text { data, models and methods. }\end{array}$ & & \\
\hline & $\begin{array}{l}\text { b. Proponent experts engaged to participate in workshops and } \\
\text { working meetings covered an appropriate range of relevant } \\
\text { alternative methods and models. }\end{array}$ & & \\
\hline \multirow{3}{*}{$\begin{array}{l}\text { Training and } \\
\text { Cognitive Bias }\end{array}$} & $\begin{array}{l}\text { a. Project participants were provided training regarding their } \\
\text { roles and responsibilities within a SSHAC process. }\end{array}$ & & \\
\hline & $\begin{array}{l}\text { b. TI Team members were provided training on types and } \\
\text { sources of cognitive bias. }\end{array}$ & & \\
\hline & $\begin{array}{l}\text { c. The implications of cognitive bias with respect to achieving } \\
\text { the goal of the SSHAC process were discussed by the PTI } \\
\text { with the TI Teams. }\end{array}$ & & \\
\hline
\end{tabular}




\begin{tabular}{|c|c|c|c|}
\hline \multicolumn{4}{|c|}{ Attachment A - PPRP Acceptance Criteria } \\
\hline SSHAC & \multirow[b]{2}{*}{ Specific Acceptance Criteria } & \multicolumn{2}{|c|}{ Assessment } \\
\hline and Attributes & & Yes & No \\
\hline \multirow{2}{*}{$\begin{array}{l}\text { Training and } \\
\text { Cognitive Bias } \\
\text { (continued) }\end{array}$} & $\begin{array}{l}\text { d. Means to avoid bias impacting the evaluation and integration } \\
\text { process were discussed with the TI Teams. }\end{array}$ & & \\
\hline & $\begin{array}{l}\text { e. The TI Teams exhibited awareness of cognitive biases during } \\
\text { the compilation, evaluation, and integration process. }\end{array}$ & & \\
\hline $\begin{array}{c}\text { Data Compilation } \\
\text { and } \\
\text { Characterization }\end{array}$ & $\begin{array}{l}\text { a. Relevant SSC and GMC datasets were identified and } \\
\text { compiled into a common database: } \\
\text { 1. The project database was easily accessible to Project } \\
\text { participants, including the PPRP. } \\
\text { 2. Local and global experts were engaged to identify } \\
\text { potentially relevant data and to minimize the potential } \\
\text { for exclusion of potentially relevant data. } \\
\text { 3. Project participants were made aware of updates to the } \\
\text { database in a timely manner. } \\
\text { 4. Available data were sufficiently summarized and } \\
\text { presented to support the SSHAC evaluation and } \\
\text { integration steps. } \\
\text { 5. Uncertainties or possible bias in original measurements } \\
\text { were identified. } \\
\text { 6. Interpretations and/or evaluations included in the } \\
\text { processing of datasets were identified. } \\
\text { 7. Data quality issues were identified. }\end{array}$ & & \\
\hline \multirow[t]{2}{*}{ Evaluation Process } & $\begin{array}{l}\text { a. Workshop } 1 \text { facilitated the discussion and understanding of } \\
\text { available data/models/methods, gaps/needs, and hazard- } \\
\text { significant issues } \\
\text { 1. The objectives and scope of Workshop 1 were } \\
\text { adequately defined. } \\
\text { 2. TI Team members actively engaged in discussions with } \\
\text { resource experts to understand how available data were } \\
\text { obtained (e.g., recorded), and what interpretations may } \\
\text { have been required to support data processing. } \\
\text { 3. TI Team members were actively engaged in discussions } \\
\text { to identify and understand hazard significant issues. } \\
\text { 4. Appropriate information and feedback on hazard } \\
\text { significant issues and sensitivities were provided to the } \\
\text { GMC and SSC TI Teams to support their evaluation } \\
\text { responsibilities. }\end{array}$ & & \\
\hline & $\begin{array}{l}\text { b. The process to identify and compile potentially applicable } \\
\text { data, models, and methods was adequate and documented. }\end{array}$ & & \\
\hline
\end{tabular}




\begin{tabular}{|c|c|c|c|}
\hline \multicolumn{4}{|c|}{ Attachment A - PPRP Acceptance Criteria } \\
\hline SSHAC & \multirow[b]{2}{*}{ Specific Acceptance Criteria } & \multicolumn{2}{|c|}{ Assessment } \\
\hline $\begin{array}{l}\text { Essential Steps } \\
\text { and Attributes }\end{array}$ & & Yes & No \\
\hline \multirow[t]{3}{*}{$\begin{array}{l}\text { Evaluation Process } \\
\quad \text { (continued) }\end{array}$} & $\begin{array}{l}\text { c. Workshop } 2 \text { facilitated the discussion and understanding of } \\
\text { relevant alternative models and methods: } \\
\text { 1. The range of potentially applicable models and methods } \\
\text { was presented by proponent and resource experts. } \\
\text { 2. Proponent and resource experts advocated for their } \\
\text { models and methods and responded to questions } \\
\text { factually. When a model was presented by someone } \\
\text { who did not develop the model (e.g., TI team member), } \\
\text { it was described from a proponent perspective. } \\
\text { 3. TI Team members actively interacted with and } \\
\text { challenged proponent and resource experts to gain } \\
\text { understanding of the technical bases, strengths, } \\
\text { uncertainties, and limitations of alternative models and } \\
\text { methods. }\end{array}$ & & \\
\hline & $\begin{array}{l}\text { d. During TI Team Working Meetings - the TI Team members } \\
\text { objectively evaluated data, models, and methods. }\end{array}$ & & \\
\hline & $\begin{array}{l}\text { e. Throughout the evaluation process, the TI Team Leads } \\
\text { ensured participation by all team members. }\end{array}$ & & \\
\hline \multirow{3}{*}{ Integration Process } & $\begin{array}{l}\text { a. The TI Teams integrated their evaluations of data, models, } \\
\text { and methods to develop the PSHA inputs representing the } \\
\text { center, body, and range of technically defensible } \\
\text { interpretations: } \\
\text { 1. The integration process involved all Team members } \\
\text { according to their expertise and experience. } \\
\text { 2. Assessments during the integration process had sound } \\
\text { technical bases, including the exclusion of any data, } \\
\text { models and method. }\end{array}$ & & \\
\hline & $\begin{array}{l}\text { b. Workshop } 3 \text { facilitated presentation and discussion of } \\
\text { preliminary SSC and GMC models: } \\
\text { 1. TI Team members presented elements of the } \\
\text { preliminary models and their technical bases that were } \\
\text { clear and sufficiently detailed to allow PPRP } \\
\text { questioning and feedback. } \\
\text { 2. Hazard implications of the models were clearly } \\
\text { presented in sufficient detail to allow discussion and } \\
\text { understanding by the TI Teams. }\end{array}$ & & \\
\hline & $\begin{array}{l}\text { c. The TI Teams appropriately considered feedback from both } \\
\text { the PPRP comments as well as hazard sensitivity analyses in } \\
\text { developing final SSC and GMC input models. }\end{array}$ & & \\
\hline
\end{tabular}




\begin{tabular}{|c|c|c|c|}
\hline \multicolumn{4}{|c|}{ Attachment A - PPRP Acceptance Criteria } \\
\hline \multirow{2}{*}{$\begin{array}{l}\text { SSHAC } \\
\text { Essential Steps } \\
\text { and Attributes }\end{array}$} & \multirow[b]{2}{*}{ Specific Acceptance Criteria } & \multicolumn{2}{|c|}{ Assessment } \\
\hline & & Yes & No \\
\hline \multirow{2}{*}{$\begin{array}{l}\text { Integration Process } \\
\quad \text { (continued) }\end{array}$} & $\begin{array}{l}\text { d. Final PSHA model inputs represent the center, body, and } \\
\text { range of technically defensible interpretations and have } \\
\text { sound technical bases. }\end{array}$ & & \\
\hline & $\begin{array}{l}\text { e. The PPRP Briefing adequately presented the final SSC and } \\
\text { GMC models to allow the PPRP to understand and identify } \\
\text { elements where the technical bases need to be justified and } \\
\text { explained in the project report }\end{array}$ & & \\
\hline \multirow{4}{*}{$\begin{array}{c}\text { Hazard } \\
\text { Calculations }\end{array}$} & $\begin{array}{l}\text { a. Hazard calculations based on preliminary input models } \\
\text { demonstrated the impact of alternative models and } \\
\text { parameters to provide useful feedback to the TI Teams. } \\
\text { 1. The range of hazard products produced using the } \\
\text { preliminary input models was based on discussions } \\
\text { between the TI Teams and the Hazard Calculation Team }\end{array}$ & & \\
\hline & $\begin{array}{l}\text { b. Final hazard calculations were based on the final input } \\
\text { models as documented in the Hazard Input Documents. }\end{array}$ & & \\
\hline & $\begin{array}{l}\text { c. Propagation of uncertainties into PSHA results and products } \\
\text { was appropriate. }\end{array}$ & & \\
\hline & $\begin{array}{l}\text { d. Trimming of logic tree branches, if needed to achieve } \\
\text { computational efficiency, was justified through the use of } \\
\text { sensitivity studies or other demonstrations. }\end{array}$ & & \\
\hline \multirow[b]{3}{*}{ Documentation } & a. The Project Plan was appropriately documented. & & \\
\hline & $\begin{array}{l}\text { b. The data compiled as part of the Project was appropriately } \\
\text { documented, including original data measurements, } \\
\text { uncertainties, data processing, and potential sources of bias. }\end{array}$ & & \\
\hline & $\begin{array}{l}\text { c. The evaluation process was documented in an appropriate } \\
\text { manner, including: } \\
\text { 1. Workshop } 1 \text { participants, proceedings and summaries } \\
\text { 2. Workshop } 2 \text { participants, proceedings and summaries } \\
\text { 3. The evaluation of potentially applicable data, models, } \\
\text { and methods. }\end{array}$ & & \\
\hline
\end{tabular}




\begin{tabular}{|c|c|c|c|}
\hline \multicolumn{4}{|c|}{ Attachment A - PPRP Acceptance Criteria } \\
\hline SSHAC & \multirow[b]{2}{*}{ Specific Acceptance Criteria } & \multicolumn{2}{|c|}{ Assessment } \\
\hline and Attributes & & Yes & No \\
\hline \multirow[t]{3}{*}{$\begin{array}{l}\text { Documentation } \\
\text { (continued) }\end{array}$} & $\begin{array}{l}\text { d. The integration process was documented in an appropriate } \\
\text { manner: } \\
\text { 1. SSC and GMC input models were documented in } \\
\text { sufficient detail. } \\
\text { 2. The technical bases for the elements of the input models } \\
\text { were reasonable and well documented, including, the } \\
\text { basis for excluding certain interpretations. } \\
\text { 3. If new models or methods were developed to supplement } \\
\text { existing models and methods in order to represent the } \\
\text { CBR of TDI, then the limitations of the existing models } \\
\text { or methods were documented. } \\
\text { 4. The conclusion that the SSC, GMC and site response } \\
\text { models represent the center, body, and range of } \\
\text { technically defensible interpretations was clearly and } \\
\text { sufficiently supported. } \\
\text { 5. Preliminary and final PSHA and site response analysis } \\
\text { input models were documented in Hazard Input } \\
\text { Document(s) that provided complete information needed } \\
\text { for the calculations to be implemented and, if necessary, } \\
\text { reproduced. } \\
\text { 6. Workshop } 3 \text { participants, proceedings, and summaries. } \\
\text { 7. PPRP Briefing participants, proceedings, and } \\
\text { summaries. }\end{array}$ & & \\
\hline & e. The project database is included in the final project report. & & \\
\hline & $\begin{array}{l}\text { f. The Final Project Report described the process and results of } \\
\text { the Project, including the data compilation process, the } \\
\text { evaluation process, the integration process, final models } \\
\text { (including models of aleatory uncertainty), and hazard and } \\
\text { site response results. }\end{array}$ & & \\
\hline
\end{tabular}

